\title{
CHARACTERIZATION OF AIRFLOWS NEAR THE EXIT OF HVAC REGISTERS USING LASER DOPPLER VELOCIMETRY (LDV)
}

Narinder K. Tutu, C. R. Krishna, John W. Andrews, and Thomas A. Butcher

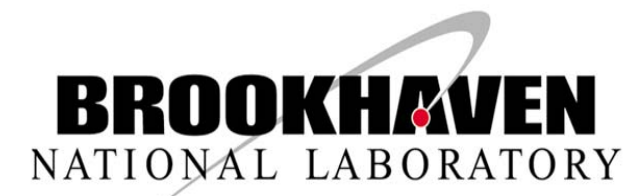

Energy Resources Division

Energy Science and Technology Department

Brookhaven National Laboratory

Brookhaven Science Associates

Upton, New York 11973-5000 


\section{DISCLAIMER}

This report was prepared as an account of work sponsored by an agency of the United States Government. Neither the United States Government nor any agency thereof, nor any of their employees, nor any of their contractors, subcontractors, or their employees makes any warranty, express or implied, or assumes any legal liability or responsibility for the accuracy, completeness, or usefulness of any information, apparatus, product, or process disclosed, or represents that its use would not infringe privately owned rights. Reference herein to any specific commercial product, process, or service by trade name, trademark, manufacturer, or otherwise, does not necessarily constitute or imply its endorsement, recommendation, or favoring by the United States Government or any agency, contractor or subcontractor thereof. The views and opinions of authors expressed herein do not necessarily state or reflect those of the United States Government or any agency, contractor, or subcontractor thereof. 


\begin{abstract}
A facility to characterize the airflow at the exit of HVAC registers was designed and fabricated. The objective of this work is to obtain velocity and turbulence data at the exit of registers, which can then be used as an input boundary condition in a modern Computational Fluid Dynamics (CFD) code to predict the velocity and temperature distribution in an enclosure, and also the register performance parameters such as throw. During the course of this work, two commonly used registers were tested. Both registers were 8"x4" sidewall registers. Laser Doppler Velocimetry was used to measure the axial and vertical components of the velocity vector at various locations across the face of the registers. For the two cases of registers studied here, the results suggest that the velocity field at the very exit of each of these registers scales with the flow rate through the registers. This means that, in the mode of operation in which the supply fan (of an HVAC system) has a "High" and "Low" setting, similar velocity scaling would result for the type of registers tested here.
\end{abstract}




\section{ACKNOWLEDGEMENT}

The authors would like to thank Dave Elling for excellent cooperation and for efficient fabrication and assembly of the facility. The Office of Building Technologies in the Department of Energy is acknowledged for financial support of the work reported here. 


\section{TABLE OF CONTENTS}

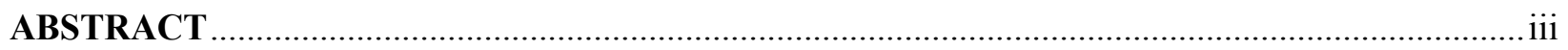

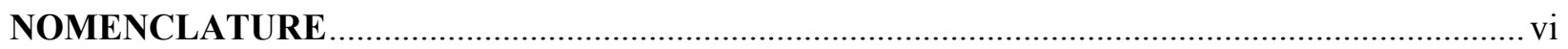

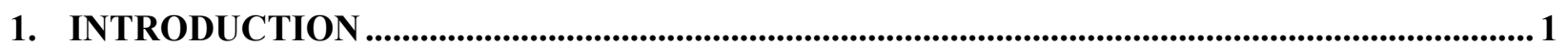

2. EXPERIMENTAL SET UP AND MEASUREMENT TECHNIQUE........................................

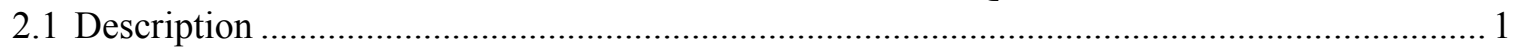

2.2 Velocity Profiles at the Exit of the Flow Conditioning System ........................................... 4

3. VELOCITY MEASUREMENTS AT THE EXIT OF THE LIMA REGISTER .........................5

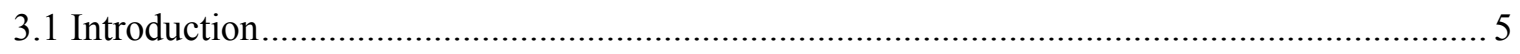

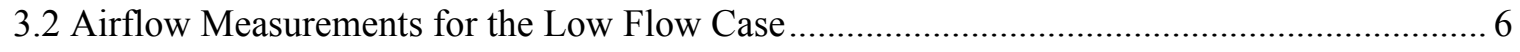

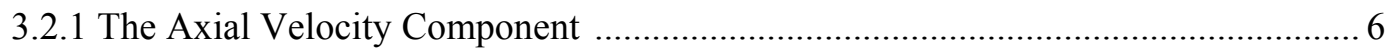

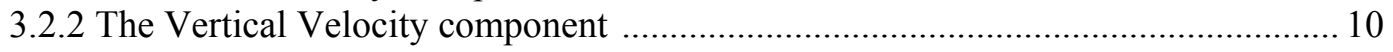

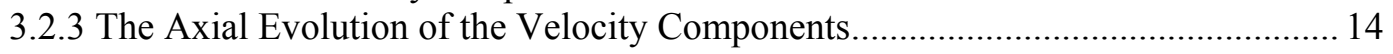

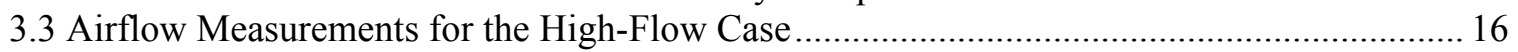

3.3.1 The Axial and Vertical Velocity Components........................................................ 16

3.3.2 The Scaling of Velocity Components with Flow Rate for the Lima Register ......... 16

4. VELOCITY MEASUREMENTS AT THE EXIT OF THE HART \& COOLEY REGISTER .. 22

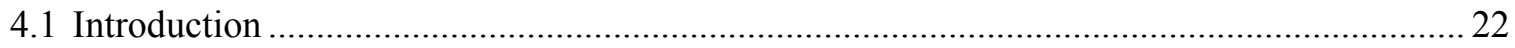

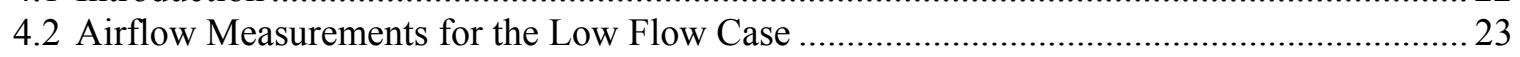

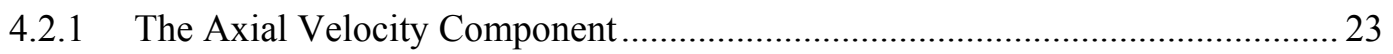

4.2.2 The Vertical Velocity Component ..................................................................... 27

4.2.3 The Axial Evolution of the Velocity Components for the Hart \& Cooley Register................................................................ 29

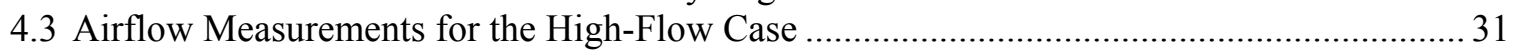

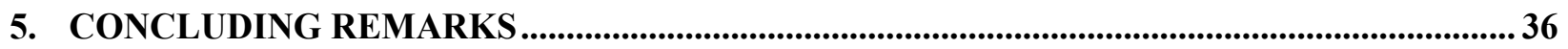




\section{NOMENCLATURE}

$<>\quad$ Denotes averaging operator

$\mathrm{U} \quad$ Instantaneous velocity component in the axial (X) direction.

W Instantaneous velocity component in the vertical $(Z)$ direction.

$<\mathrm{U}>\quad$ Mean velocity component in the axial direction

$<\mathrm{W}>$ Mean velocity component in the vertical direction

$\mathrm{u}^{\prime} \quad$ root mean square $(\mathrm{rms})$ fluctuation in the axial velocity component $=\sqrt{\left\langle(U-\langle U\rangle)^{2}\right\rangle}$

w' rms fluctuation in the vertical velocity component

$\mathrm{X} \quad$ Axial distance from the register exit. (See Figure 1)

Y Lateral distance from the center of the register. (See Figure 1)

$\mathrm{Z} \quad$ Vertical distance form the register center. (See Figure 5)

$\mathrm{r} \quad$ The radial distance from the physical centerline. 


\section{INTRODUCTION}

Air distribution systems are used to supply conditioned air to a physical enclosure whose environment needs to be regulated within certain limits. The physical enclosure may be an office space, a room in a house, or an industrial space; and the limits may relate to air temperature, velocity, and turbulence level. Depending upon the season and application, the conditioned supply air may be warmer or cooler than the average temperature in the conditioned space. A key element of the air distribution system is the air supply outlet, which is called a register. Its design determines the manner in which the supply air is distributed within the enclosure (to be simply referred to as a room hereafter), and the resultant mixing of the ambient room air with the supply air. In order to determine the ability of a given register design to produce an acceptable performance, detailed velocity and temperature measurements downstream of the register exit in the entire room must be performed. However, such a task is time intensive and very costly. A more practical approach is to perform detailed velocity field measurements at the very exit of the register, and then use these measurements as the boundary condition for a modern Computational Fluid Dynamics (CFD) code to predict the velocity and temperature distribution within the room. The CFD predictions can then be used to determine the register performance parameters, for example, the "throw" as a function of flow rate. Some very limited velocity and temperature measurements at selected downstream locations in the room can be performed to test the validity of CFD predictions. Nevertheless, the detailed near-field velocity measurements at the very exit of the register are sufficient to characterize ${ }^{1}$ the fluid dynamic performance of the register design.

During this investigation the near-field velocity measurements at the exit of two different commercially available registers were performed. One was a "Hart \& Cooley" (Model A611MS) register and the other was a "Lima" (Series 10V) register. These registers were chosen in consultation with IBACOS, which is a member of DOE's Building America program.

A Laser Doppler Velocimeter (LDV) was used to measure two components of the velocity vector at the exit of the register at various locations across the face of the register. Details of the experimental facility and instrumentation are presented in the next section. The measurements for the Lima register are presented in Section 3 and the measurements for the Hart \& Cooley register are discussed in Section 4. Finally, concluding remarks are presented in Section 5.

\section{EXPERIMENTAL SET UP AND MEASUREMENT TECHNIQUE}

\subsection{Description}

In order to ensure a well-characterized flow without any anomalies into the register, a flow conditioning system was designed and constructed. Although the duct systems used in most American homes and small businesses would not have standardized flow characteristics, it is nevertheless important to ensure that the airflow entering into the register-boot combination is relatively uniform and symmetric. Otherwise, any unanticipated or interesting observations will always be suspected as having been probably caused by the idiosyncrasies of the flow delivery system. Furthermore, this flow regime must be known (measured) prior to testing of the registers. A schematic of the flow conditioning system and the experimental apparatus is shown in Figure 1. Photographs of the test facility are shown in Figure 2. A variable speed 10-inch diameter duct blaster was used as a source for the air delivery. As shown in Figure 1, it delivers air to the flow conditioning system, which consists of a "diffuser" followed sequentially by a 4-feet long and 18-inch diameter settling chamber, a contraction, and a 5-feet long 7inch diameter duct. The "settling chamber" has a six-inch deep "flow straightener" (denoted by EC in Figure 1), which consists of 6-inch deep and 1-inch square openings with a screen on either end. The

\footnotetext{
${ }^{1}$ As discussed later, the velocity field at the exit of the register is influenced by the design of the "boot" - the transition piece between the register and the supply duct. Thus, for practical applications the boot and the register should be considered as an integrated system.
} 


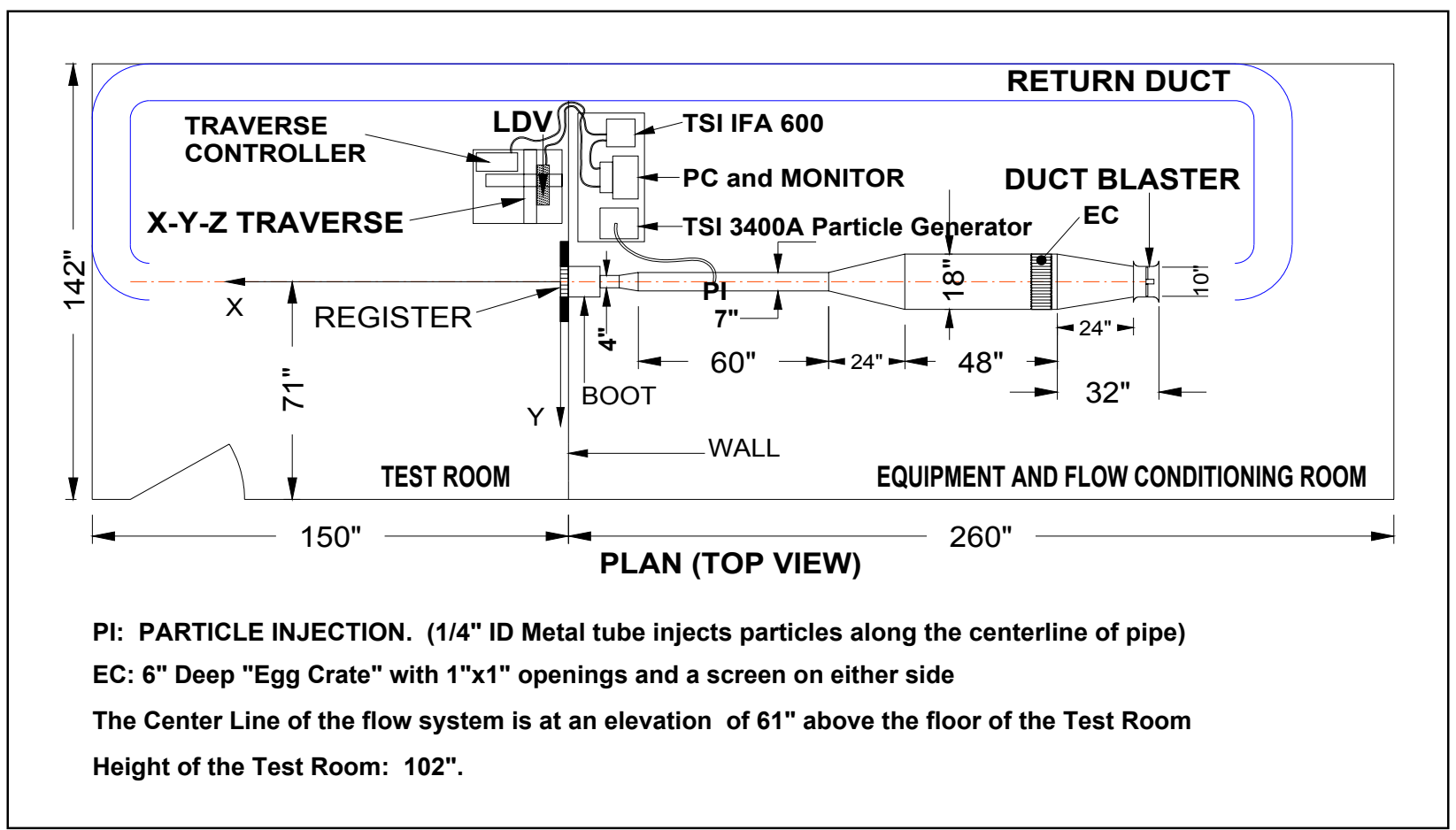

Figure 1. A schematic of the experimental facility for the study of velocity profiles at the exit of HVAC registers. $X$ and $Y$ are the axial and lateral coordinates respectively. Model number of the $X-Y-Z$ traverse controller is: Velmex VP 9000 Motor Control Unit.
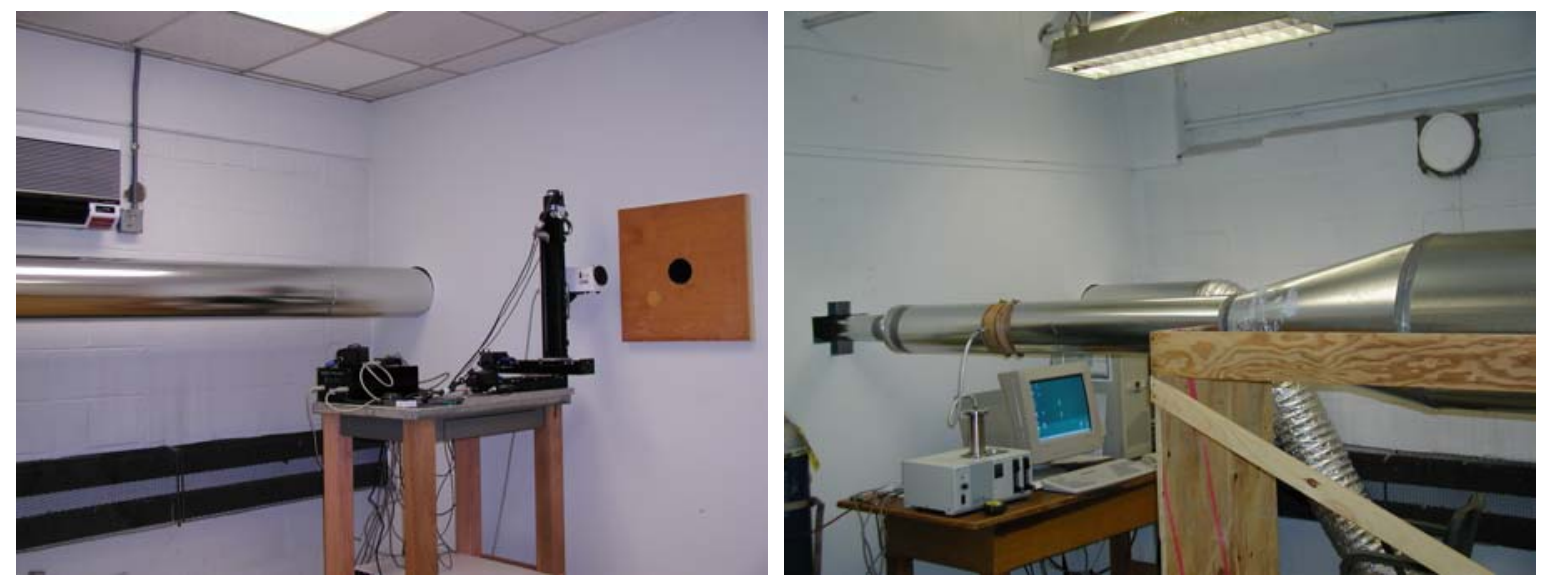

Figure 2. Photographs of the experimental facility. The left photograph is the "Test Room" showing the air outlet prior to installation of the boot and register, the LDV probe mounted on the X-Y-Z traverse, the traverse controller, and a part of the return air duct. The photograph on the right shows a partial view of the "Equipment and Flow Conditioning Room." 
purpose of the flow straightener is to remove any swirling components of velocity from the airflow, and also to dampen any flow nonuniformities.

Since the laser Doppler technique uses the scattered light from particles in the flow to measure the flow velocities, particles need to be injected into the flow. A "TSI Model 3400A fluidized bed particle generator" was used for this purpose to inject titanium dioxide particles in the air stream. The particles were injected along the centerline of the 7 -inch diameter duct via a $1 / 4$-inch internal diameter tube. The particle injection location is shown in Figures 1 and 2. The nominal mean diameter of these particles is 3 microns. The LDV system consists of the following components:

(a) TSI Laservec Model LDP 100, and

(b) TSI Model IFA 600 Digital Burst Processor.

The LDP 100 contains a single diode laser, optics (beam splitter, Bragg cell, lenses), and a detector. The laser has a wavelength of $685 \mathrm{~nm}$ and a power of $50 \mathrm{~mW}$. The IFA 600 contains the electronics to process the signals from the LDP 100. It is controlled from a desktop personal computer (PC) via TSI supplied software, and the processed data is transferred to the PC. A 350-mm focal length lens is connected to the front end of the LDP 100. It outputs two laser beams that intersect at a distance of $350-\mathrm{mm}$. The beams are $50 \mathrm{~mm}$ apart at the lens. To enable the measurement of the direction of the velocity component, the frequency of one of the beams is shifted by $40 \mathrm{MHz}$ by the Bragg cell in its path. The lens also serves the function of collecting the scattered radiation from the region of intersection, and focusing it on to a detector. The region of intersection of these two beams is therefore the measurement volume, i.e., the location at which the instantaneous velocity is measured. For the specific lens used here, this measurement volume is an elongated ellipsoid 3.8-mm in length with minor axes of 0.3 and $0.1 \mathrm{~mm}$. For all the measurements performed here, the $3.8-\mathrm{mm}$ long major axis was always aligned parallel to the lateral Y coordinate direction. Each time a particle crosses the measurement volume, the LDP 100 generates a signal and the IFA 600 processes the signal. If the signal satisfies certain requirements (for example, signal to noise ratio), the instantaneous velocity is transferred to the PC. As can be seen from the above description, the velocity data from a given location thus consists of a series of instantaneous values: $U_{1}, U_{2}, U_{3} \ldots U_{N}$, which are recorded at discrete times $t_{1}, t_{2}, t_{3} \ldots t_{N}$. These data can then be used to calculate such items as mean velocity and the root mean square velocity fluctuation.

The TSI LDP 100 probe was mounted on a motor-controlled 3-axis "BiSlide" traversing mechanism from Velmex Inc. The traverse has a total travel of $245-\mathrm{mm}$ in each of the two horizontal directions, and a travel of $375-\mathrm{mm}$ in the vertical direction. The position of the LDV probe is indicated on the front panel display of the Velmex VP 9000 controller with a resolution of $0.005-\mathrm{mm}$. This position is also transferred to the PC and recorded along with the velocity data. By installing a 90-degree bracket on the vertical traversing axis of the traversing mechanism, the LDP 100 can be rotated by 90 degrees, which effectively rotates the imaginary plane formed by the two laser beams leaving the LDP 100 . Since the LDV measures the component of velocity along the plane of the laser beams and normal to a line that bisects the angle between the two beams, two orthogonal velocity components could be measured by rotating the LDP 100 by 90 degrees. During these experiments the axial (U) and the vertical (W) velocity components were measured. Although all the three velocity components are needed for the complete characterization of the velocity field, only two components of the velocity vector were measured. However, the chosen register designs were such that the velocity vectors at the exit of these registers have only two dominant velocity components. Excluding the outer edges of the flow, the mean value of the third velocity component (which was not measured) is expected to be very much smaller than the axial component. Therefore, and also because of time constraints, the third velocity component was not measured. 


\subsection{Velocity Profiles at the Exit of the Flow Conditioning System}

The registers to be tested were 8 " $x 4$ " in cross-section. These are typically screwed on to an 8 " $\mathrm{x} 4$ " boot. The boot, in turn, is connected to the air delivery system via a 4" diameter duct. As shown in Figure 1, a short length of 4" diameter sheet metal duct was connected to the end of the flow conditioning system. The flow conditioning system was then moved till the end of this duct was flush with the location where the register would be located during the tests. A photograph of this case is shown in Figure 3. The LDV instrumentation was then set up to measure velocity profiles at the exit of this duct.

Measurements of the axial velocity component along four different diameters, and at a distance of 20-mm from the duct exit, were performed. Both the mean and the turbulence level in the axial velocity were computed. These are plotted in Figure 4. As can be seen, the velocity profile is reasonably uniform and symmetric. Furthermore, the turbulence level is low. These measurements show no anomalies, and demonstrate that the flow conditioning system is working as designed. The nominal flow rate during these measurements was $82 \mathrm{cfm}$. This flow rate is in-between the two flow rate settings of $66 \mathrm{cfm}$ and 126 $\mathrm{cfm}$ at which the measurements with the registers were made.

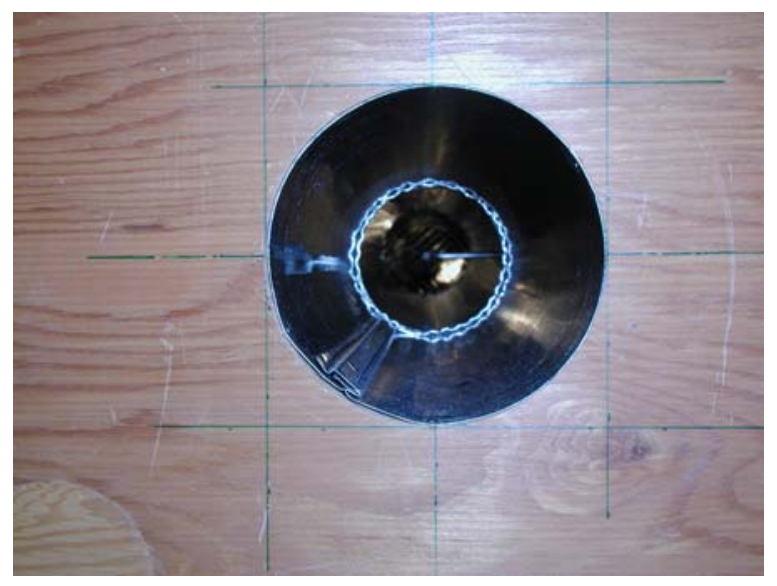

Figure 3. A photograph of the air outlet prior to installation of the boot and the register 


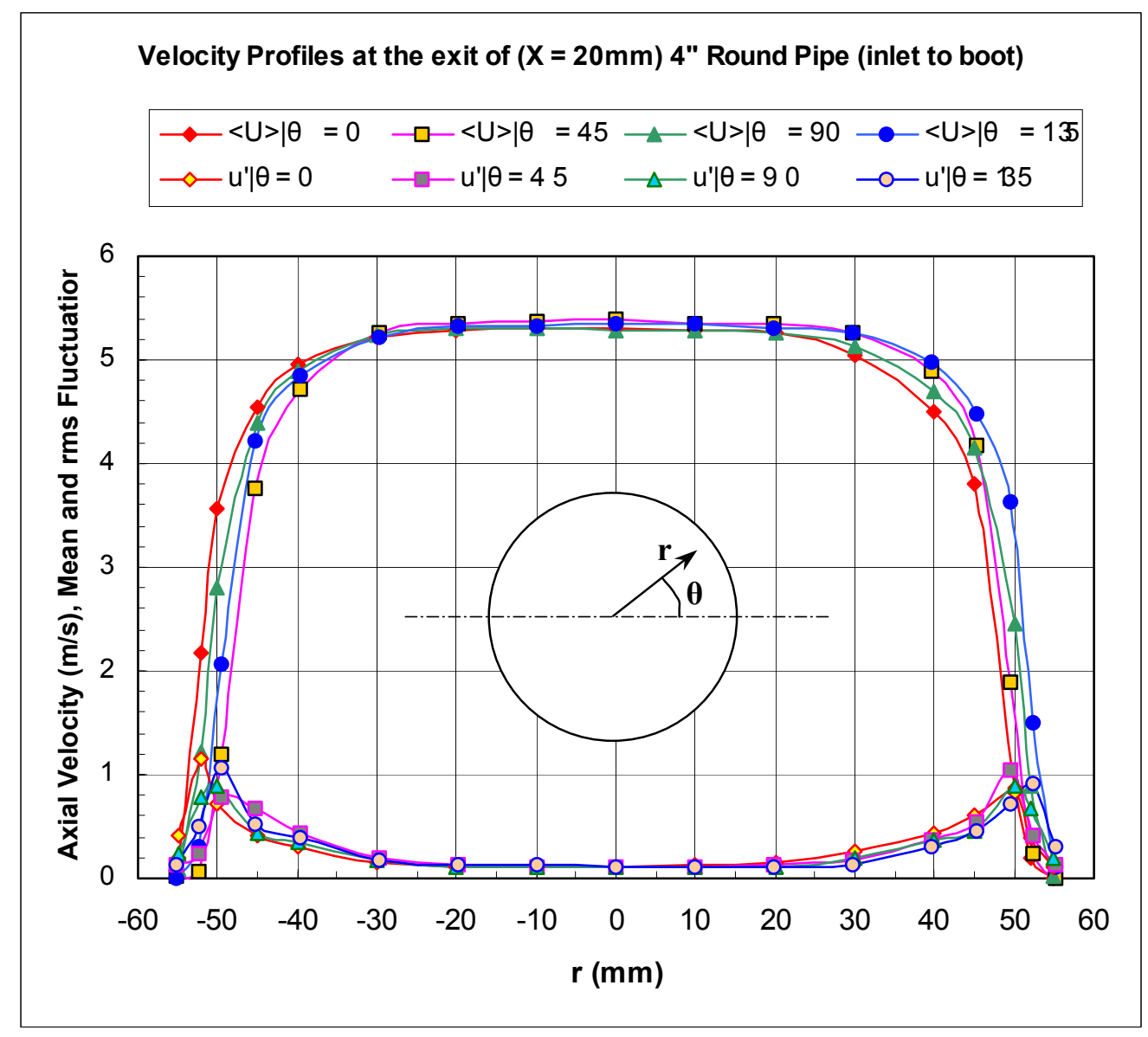

Figure 4. Mean axial velocity $(<U>)$ and rms fluctuation in axial velocity ( $\left.u^{\prime}\right)$ measurements $20-m m$ downstream of the 4 " diameter duct.

\section{VELOCITY MEASUREMENTS AT THE EXIT OF THE LIMA REGISTER}

\subsection{Introduction}

Following the velocity measurements at the exit of the 4" diameter duct, an 8"x4" rectangular boot, shown in Figure 5, was installed at the end of this duct. The boot is 10 inches deep. As shown in Figure 5 , the 8" $x 4$ " Lima register was then screwed on to the boot. This register is designed for flow rates from $65 \mathrm{cfm}$ to $125 \mathrm{cfm}$. Therefore, velocity measurements were performed for two flow rates: (a) the "low flow" case, and (b) the "high flow" case. This was also true for the Hart \& Cooley register, which is discussed in Section 4. For the "low flow" setting on the duct blaster speed control, the flow rate varied form $65 \mathrm{cfm}$ to $67.5 \mathrm{cfm}^{2}$ during the experiments. The nominal value of the airflow rate at this setting was $66 \mathrm{cfm}$. For the "high flow" case the flow rate varied from $124.8 \mathrm{cfm}$ to $126.5 \mathrm{cfm}$. The nominal value of the airflow rate at this setting was $126 \mathrm{cfm}$.

Velocity measurements were performed at three downstream locations (the $\mathrm{X}$ coordinate) for the Lima register: $X=5 \mathrm{~mm}, X=10 \mathrm{~mm}$, and $X=100 \mathrm{~mm}$. For each of these locations, measurements were

\footnotetext{
${ }^{2}$ The manufacturer provides an orifice-type of flow restricting ring that is installed at the inlet of the duct blaster for this purpose. The flow rate was measured by measuring the pressure difference across this flow-restricting ring. The calibration data provided by the duct blaster manufacturer was used for the flow rate measurement.
} 
performed at various points across the face of the register. This register has two flow dampers (visible as two vertical lines behind the flow deflecting vanes in Figure 5) whose length is along the $\mathrm{Z}$ direction. For these experiments, the dampers were set in the fully open position.

\subsection{Airflow Measurements for the Low Flow Case}

\subsubsection{The Axial Velocity Component}

Axial velocity measurements at $X=5 \mathrm{~mm}$ and $\mathrm{Y}=0$ as a function of the vertical coordinate $\mathrm{Z}$ are presented in Figure 6. The periodic variations in the mean velocity are clearly due to the deflecting vanes/blades of the register. These blades are fixed for the Lima register. The top set of blades point upwards and the bottom set of blades point downwards. We also note that the flow is reasonably symmetric about $\mathrm{Z}=0$. Another point to note is that peak value of each cycle is not the same, but starts to drop off sharply after $Z= \pm 50 \mathrm{~mm}$ even though more blades exist at either end. Thus the airflow drops off more rapidly with $\mathrm{Z}$ than would be expected from the register design itself. However, it is observed that this distance of $100 \mathrm{~mm}$ (corresponding to $Z= \pm 50 \mathrm{~mm}$ ) is nearly the same as the diameter of the circular opening $(101.6 \mathrm{~mm})$ at the inlet of the boot. Thus the sharp drop off in velocity beyond $Z= \pm 50 \mathrm{~mm}$ is,
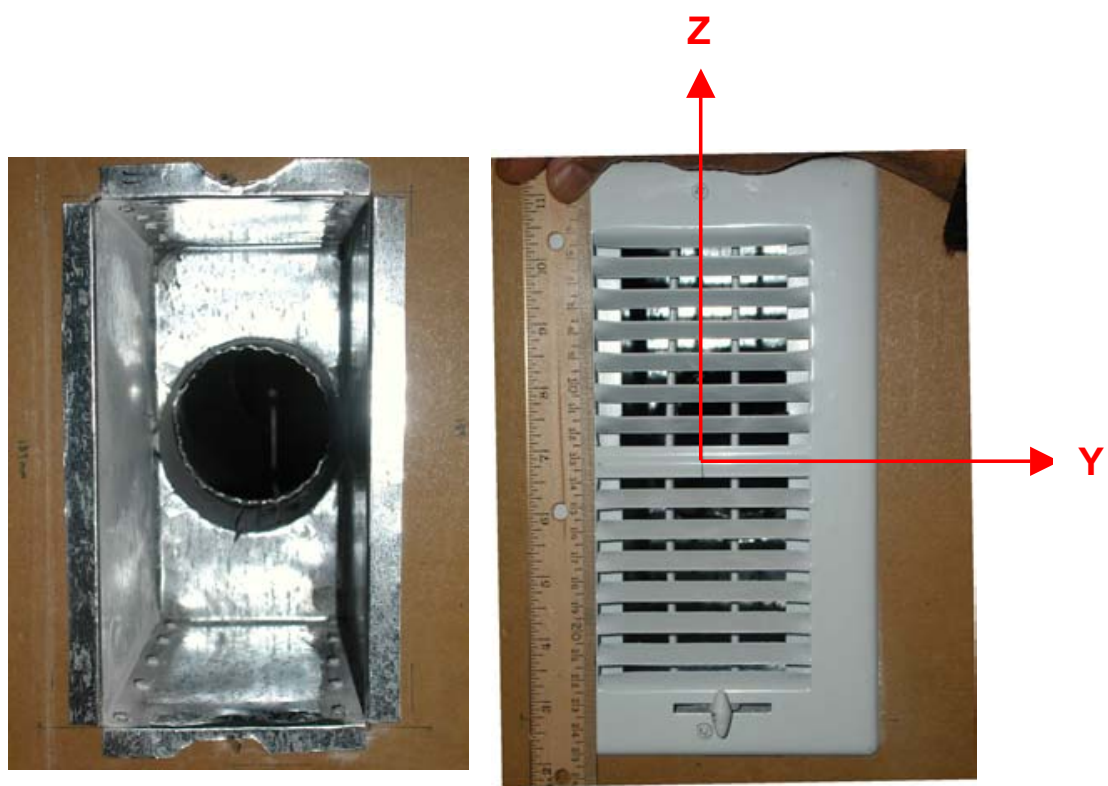

Figure 5. Photographs of the rectangular boot (left) and the installed Lima register (right). As indicated, the longer dimension of the boot is aligned with the vertical $Z$ direction. as one might expect, related to the simple boot design that is a sudden expansion. A gentle (and longer) smooth expansion from the 4-inch diameter circular duct to the larger 8" $\mathrm{x} 4$ "rectangular cross section should result in a more uniform flow. As one would expect from the central blade, which is normal to the axial flow direction, the mean axial velocity behind it near $Z=0$ is very small and negative, indicating reverse flow. While the peak mean axial velocity is about $4 \mathrm{~m} / \mathrm{s}$, the peak turbulent fluctuation (rms value) in the axial velocity is about $1 \mathrm{~m} / \mathrm{s}$.

Axial mean velocity profiles from $Y=-50 \mathrm{~mm}$ to $\mathrm{Y}=50 \mathrm{~mm}$ are summarized in Figure 7 and 8 . The velocity profiles are approximately symmetric about $\mathrm{Z}=0$ and $\mathrm{Y}=0$. The measured turbulent fluctuations in the axial velocity component are summarized in Figures 9 and 10. 


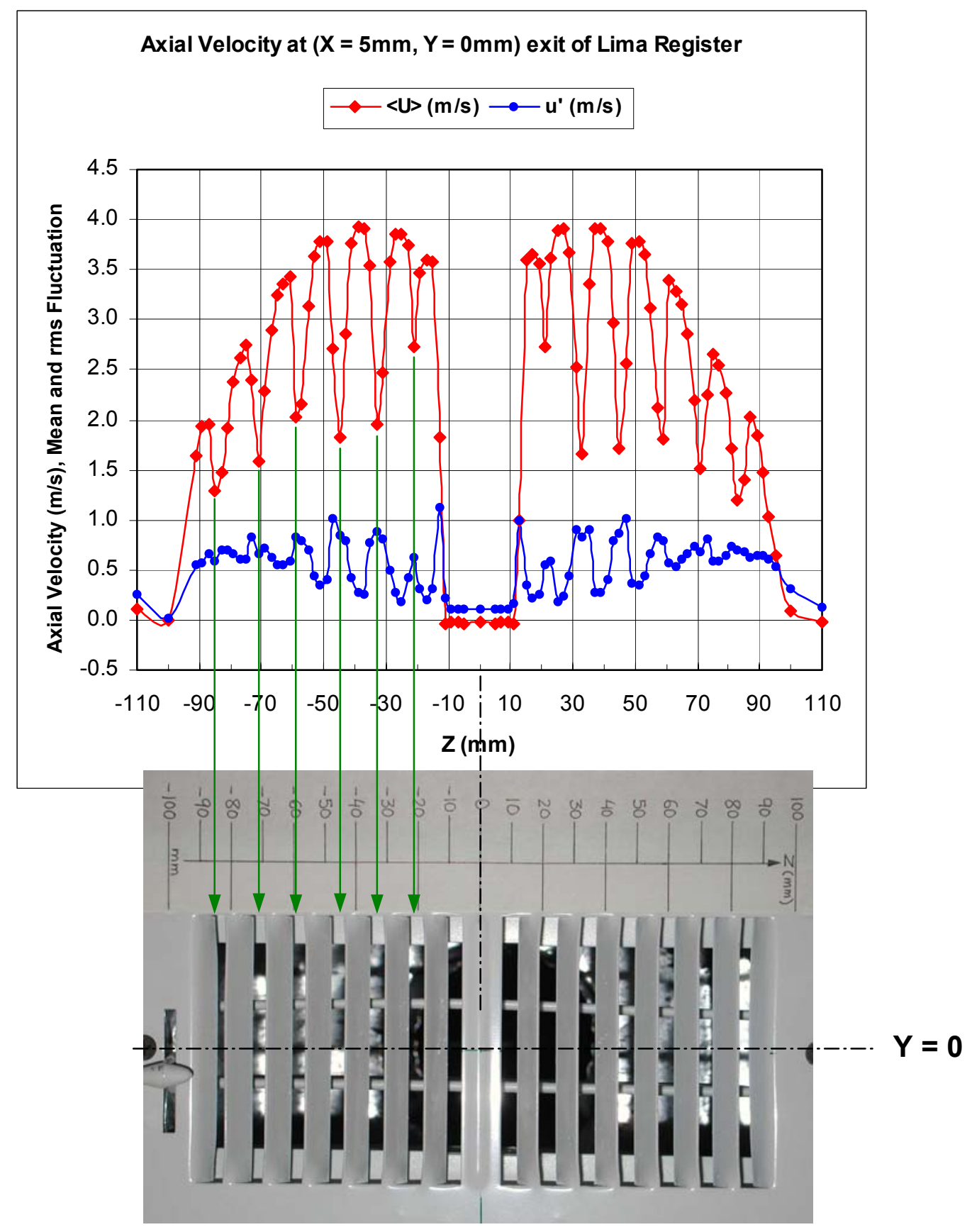

Figure 6. Measured mean and rms fluctuation of the axial velocity component at the exit of the Lima register. Nominal flow rate: $66 \mathrm{cfm}$. A superimposed photograph of the register shows the correlation between the velocity variations and the deflecting vanes of the register. Measurements at $5 \mathrm{~mm}$ downstream of the register exit and $Y=0 \mathrm{~mm}$. Note that $Z$ is positive in the vertically upward direction 


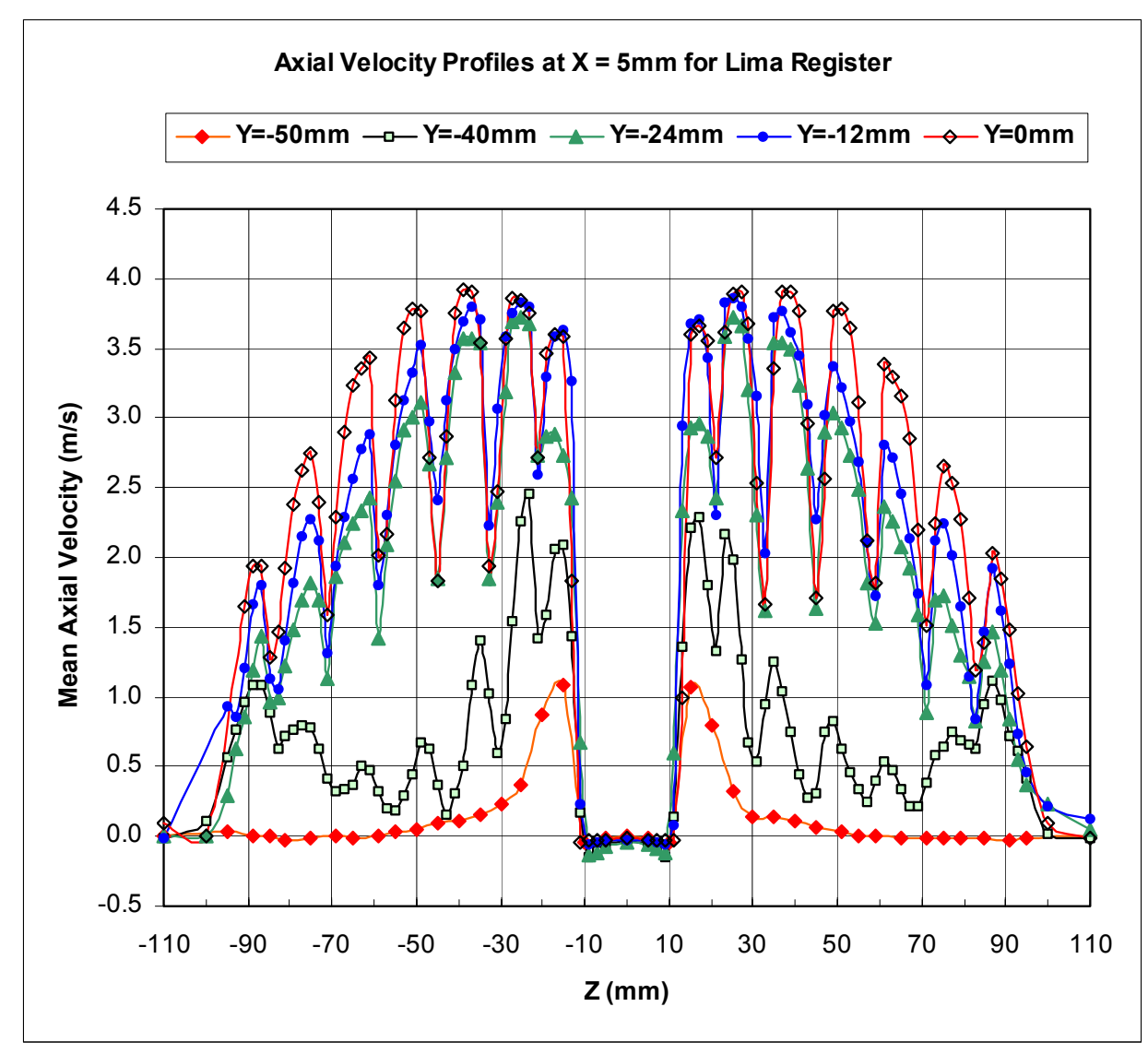

Figure 7. Measured mean axial velocity component $(<U>)$ profiles at the exit of the Lima register. Measurements from $Y=0$ to $Y=-50 \mathrm{~mm}$ at $5 \mathrm{~mm}$ downstream of the register exit. Nominal flow rate: $66 \mathrm{cfm}$.

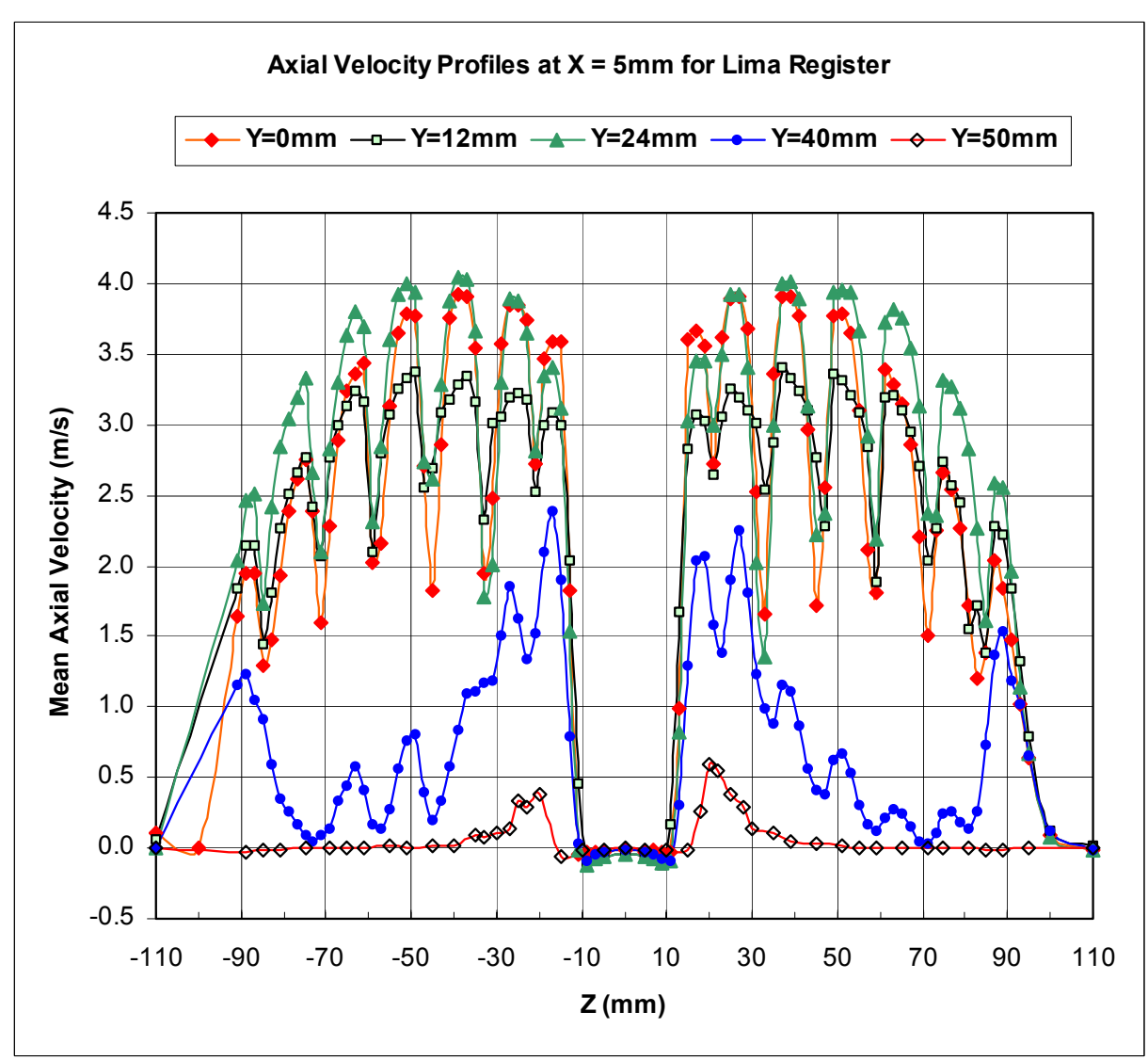

Figure 8. Measured mean axial velocity component $(\langle U\rangle)$ profiles at the exit of the Lima register. Measurements from $Y=0$ to $Y=50 \mathrm{~mm}$ at $5 \mathrm{~mm}$ downstream of the reaister exit. Nominal flow rate: $66 \mathrm{cfm}$. 


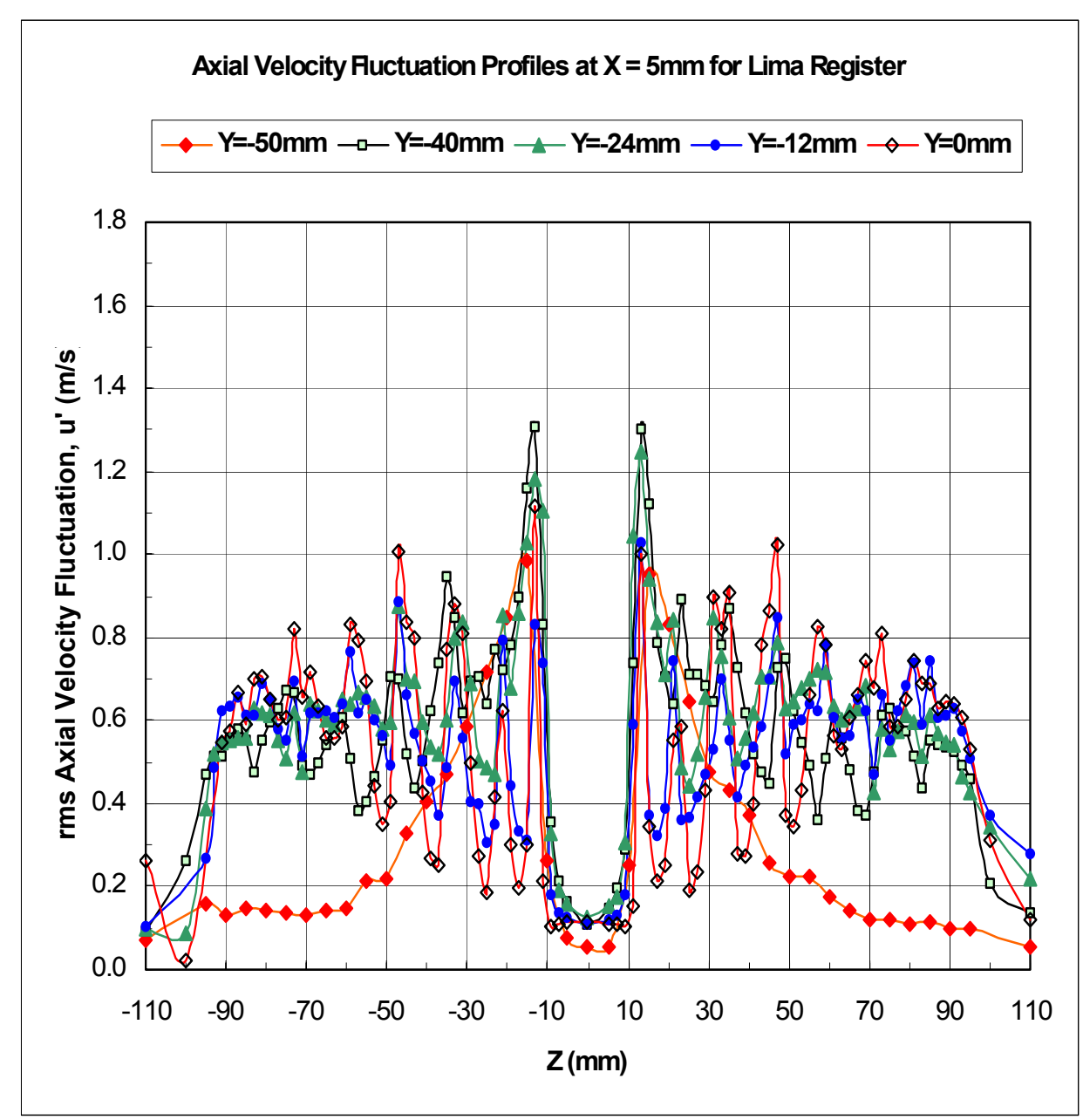

Figure 9. Measured turbulence level in the axial velocity component at the exit of the Lima register. Measurements from $Y=0$ to $Y=-50 \mathrm{~mm}$ at $5 \mathrm{~mm}$ downstream of the register exit. Nominal flow rate: $66 \mathrm{cfm}$

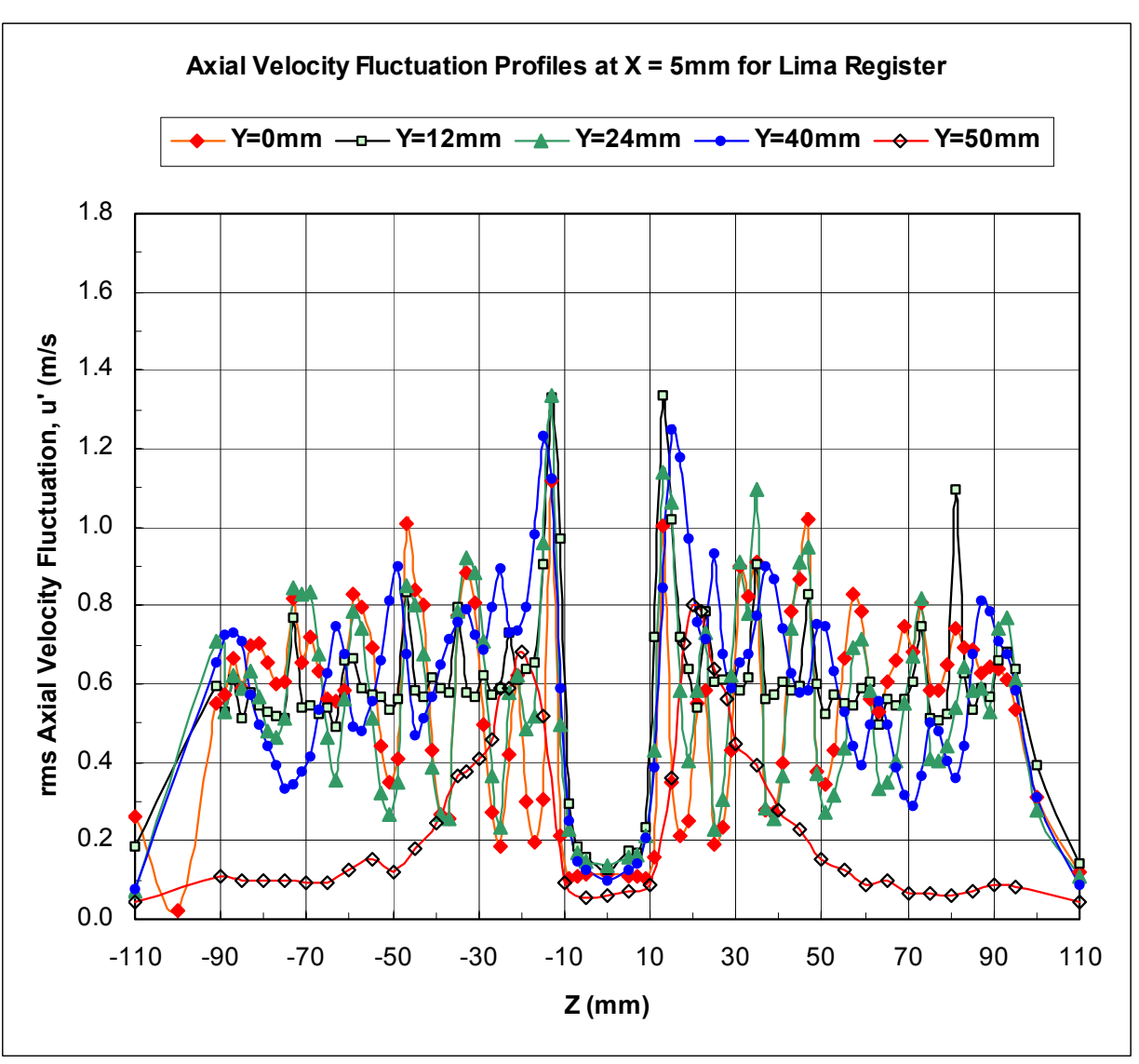

Figure 10. Measured turbulence level in the axial velocity component at the exit of the Lima register. Measurements from $Y=0$ to $Y=50 \mathrm{~mm}$ at $5 \mathrm{~mm}$ downstream of the register exit. Nominal flow rate: $66 \mathrm{cfm}$. 


\subsubsection{The Vertical Velocity component}

After completing the axial velocity measurements, the LDV probe was rotated by 90 degrees and bolted on to the traversing mechanism via a right-angle bracket to allow the measurement of the vertical velocity component, W. During realignment of the laser beams it was found that the traversing mechanism could not be moved back to the axial position of $X=5 \mathrm{~mm}$ at which the axial velocity component measurements were made. This was due to the fact that the LDV probe would physically hit the wall at approximately X $=8 \mathrm{~mm}$. Therefore, the vertical velocity component measurements were performed at $\mathrm{X}=10 \mathrm{~mm}$. Time constraints did not allow another complete set of axial velocity measurements to be made at $\mathrm{X}=10 \mathrm{~mm}$. However, one additional axial velocity profile measurement was made at $\mathrm{X}=10 \mathrm{~mm}$ and $\mathrm{Y}=0 \mathrm{~mm}$.

The vertical velocity component measurements at $\mathrm{Y}=0 \mathrm{~mm}$ are shown in Figure 11. As can be seen from this figure, the flow is moving upwards (positive $<\mathrm{W}>$ ) in the top region and downwards in the bottom region. This is, as one would expect from orientation of the blade angles in the register. Similar to the axial component, the vertical velocity component also exhibits periodic variations corresponding to the blades. This can be seen more clearly from Figure 12 , which shows the measurements of the axial and vertical velocity components at the same location $(\mathrm{X}=10 \mathrm{~mm}, \mathrm{Y}=$ $0 \mathrm{~mm})$. The correlation between the two components is strong. From these measurements the angle of the mean velocity vector in the $Z-X$ Z-Velocity Component at $(X=10 \mathrm{~mm}, Y=0 \mathrm{~mm})$ for Lima Register

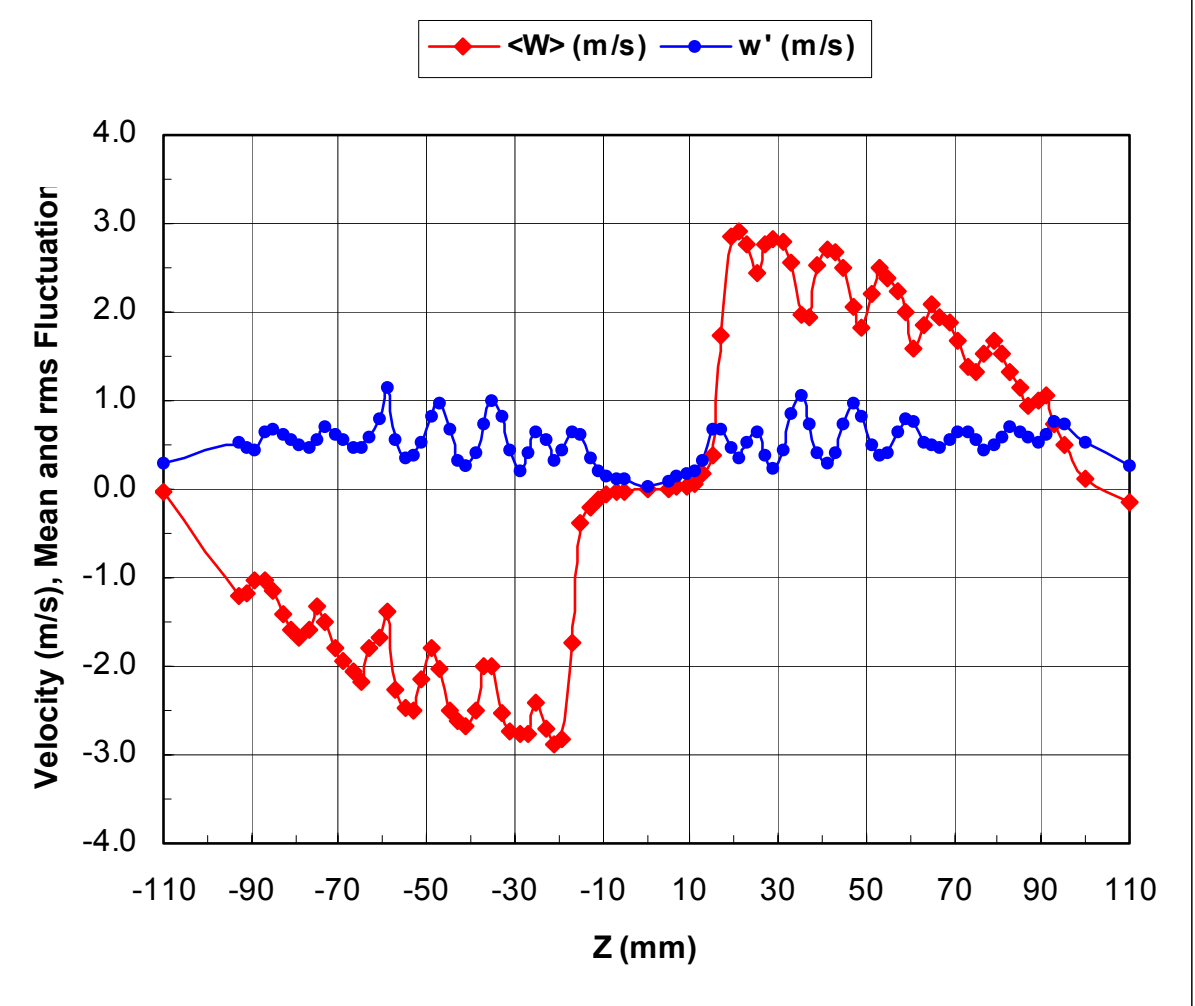

Figure 11. Measured mean and rms fluctuation of the vertical velocity component at the exit of the Lima register. Measurements at $10 \mathrm{~mm}$ downstream of the register exit and $\mathrm{Y}=0 \mathrm{~mm}$. Nominal flow rate: $66 \mathrm{cfm}$ plane to the $\mathrm{X}$-axis was calculated. This angle, $\theta=\tan ^{-1}(<\mathrm{W}>/<\mathrm{U}>)$, is plotted in Figure 13. As can be seen, the vector angle is fairly constant, about +37 degrees across the upper half of the register, and -36 degrees across the lower half of the register.

The mean vertical velocity component profiles from $\mathrm{Y}=-50 \mathrm{~mm}$ to $\mathrm{Y}=50 \mathrm{~mm}$ are summarized in Figures 14 and 15 . The profiles of the magnitude of the velocity component are approximately symmetric about $\mathrm{Z}=0$ and $\mathrm{Y}=0$. The measured turbulent fluctuations in the vertical velocity component are summarized in Figures 16 and 17. 


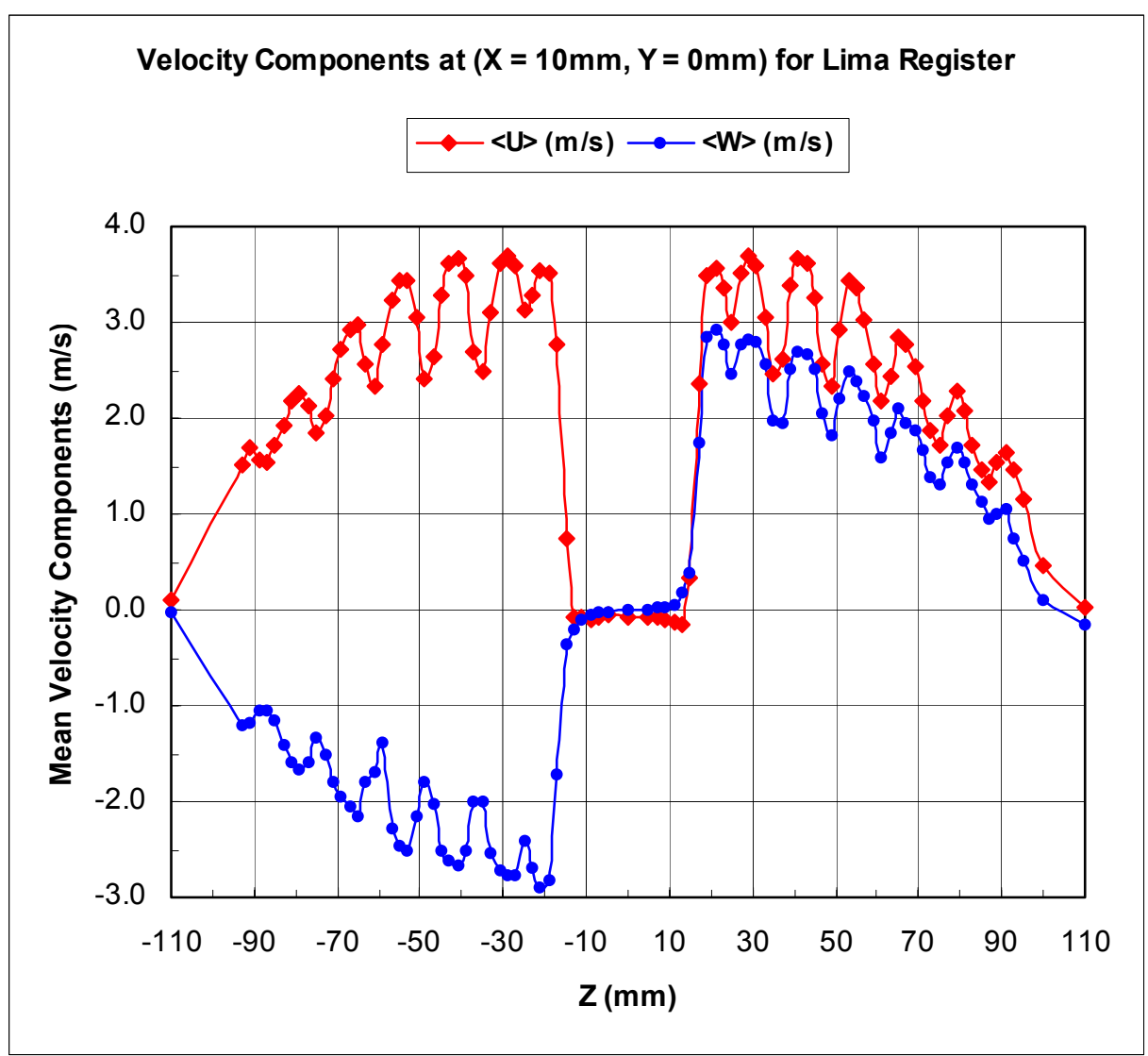

Figure 12. Measured mean axial and vertical velocity components at the exit of the Lima register. Measurements at $10 \mathrm{~mm}$ downstream of the register exit and $Y=0 \mathrm{~mm}$. Nominal flow rate: $66 \mathrm{cfm}$

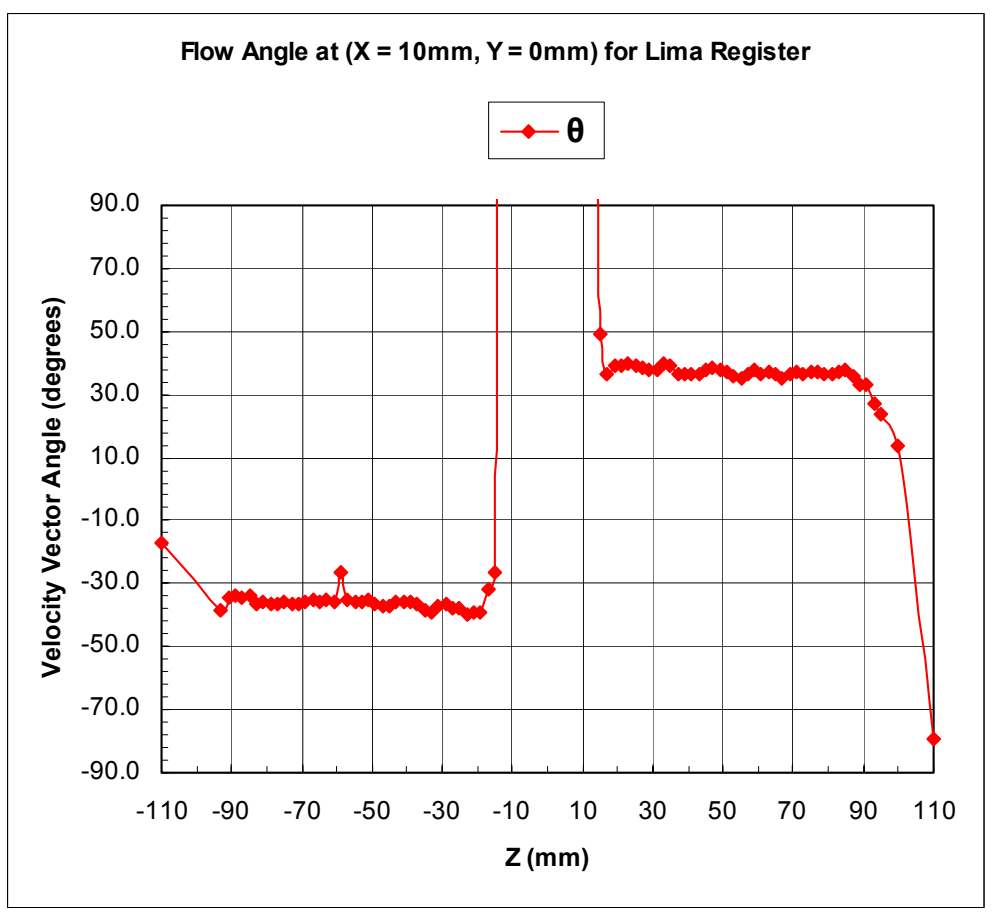

Figure 13. Velocity vector angle to the horizontal in the Z-X plane at $10 \mathrm{~mm}$ downstream of the register exit and $Y=0 \mathrm{~mm}$. Nominal flow rate: $66 \mathrm{cfm}$.

(Average angle: $+37,-36$ degrees) 


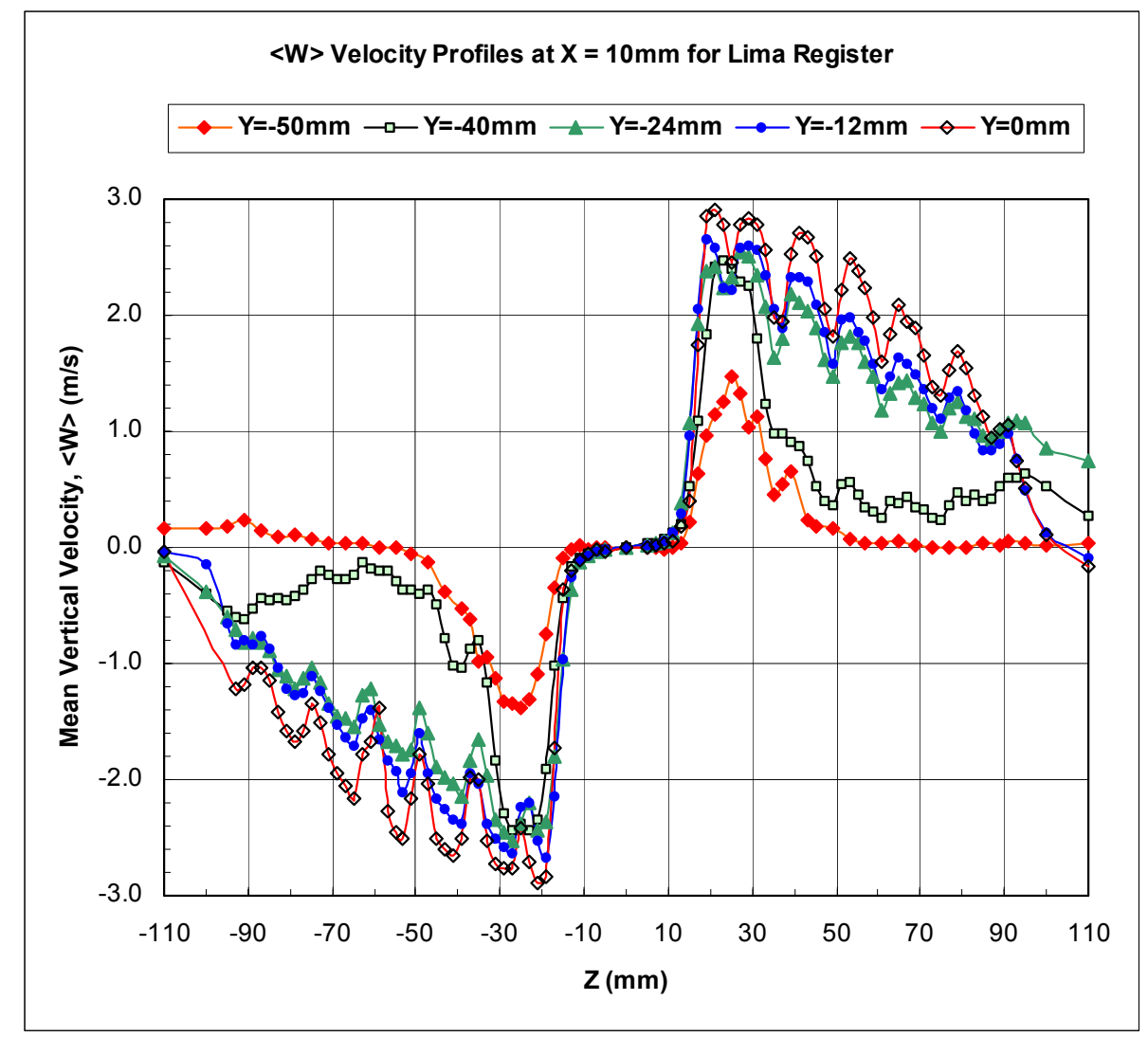

Figure 14. Measured mean vertical velocity component profiles at the exit of the Lima register. Measurements from $Y=0$ to $Y=-50 \mathrm{~mm}$ at $10 \mathrm{~mm}$ downstream of the register exit. Nominal flow rate: $66 \mathrm{cfm}$

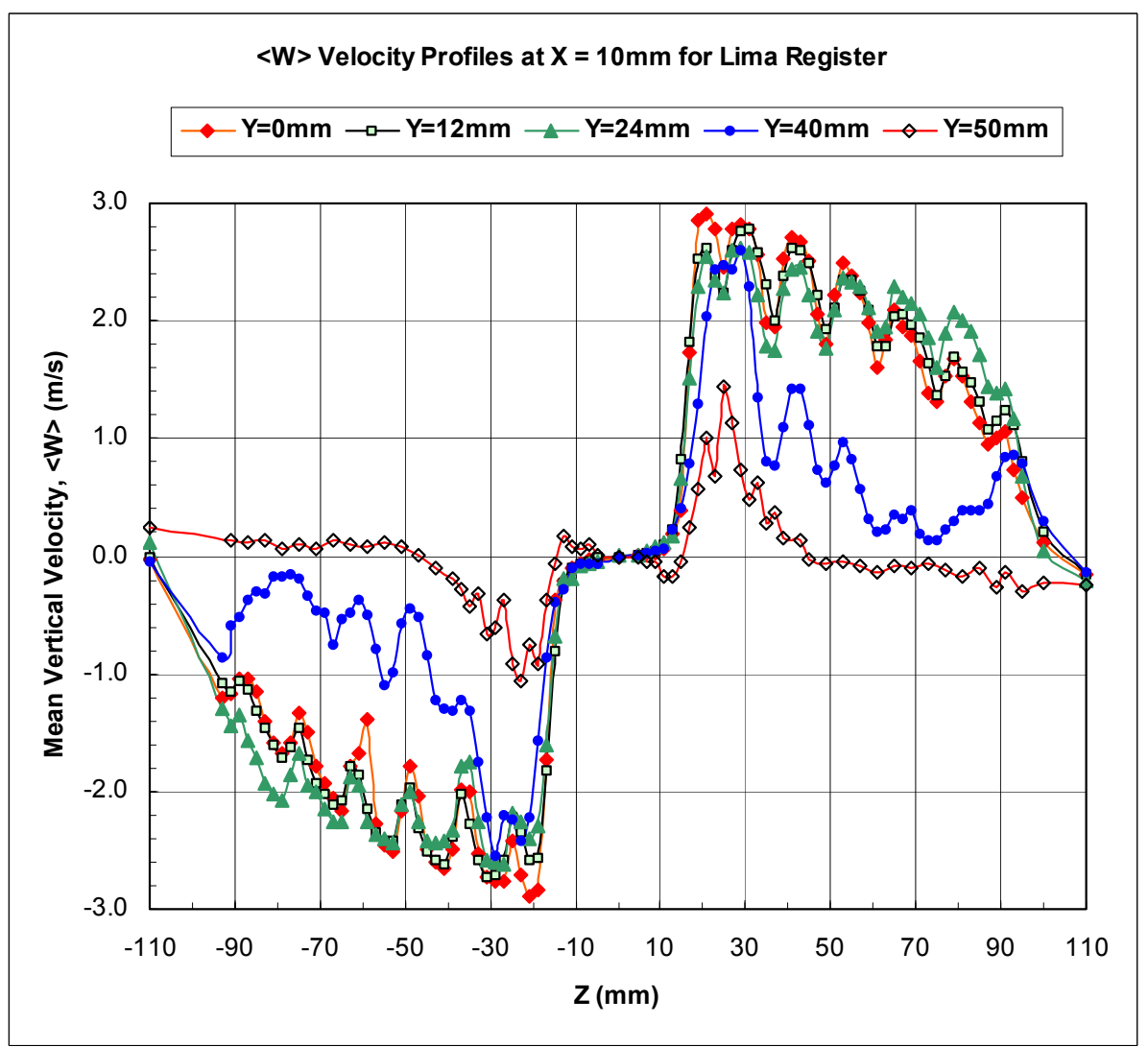

Figure 15. Measured mean vertical velocity component profiles at the exit of the Lima register. Measurements from $Y=0$ to $Y=50 \mathrm{~mm}$ at $10 \mathrm{~mm}$ downstream of the register exit. Nominal flow rate: $66 \mathrm{cfm}$ 


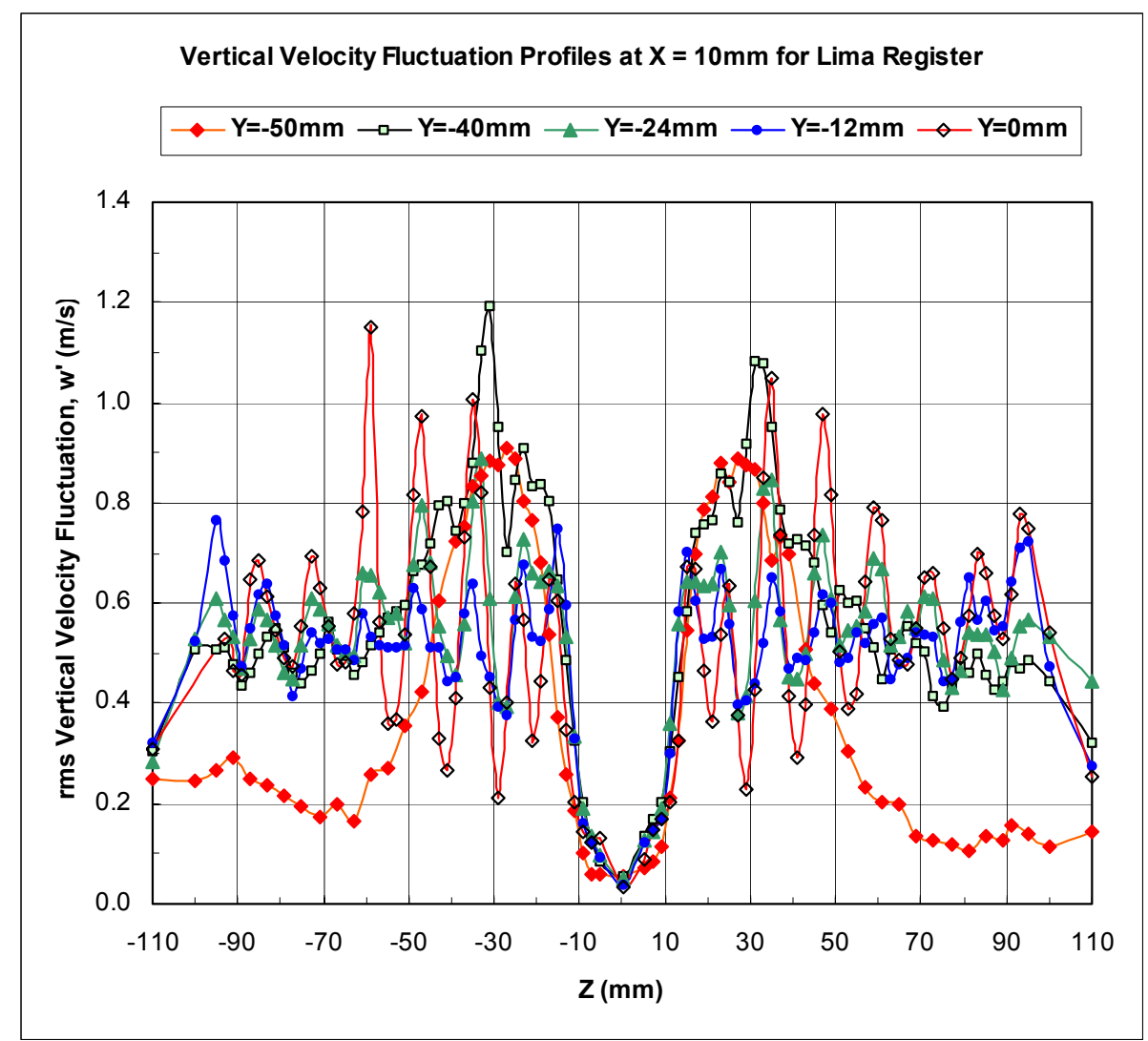

Figure 16. Measured turbulence level in the vertical velocity component at the exit of the Lima register. Measurements from $Y=0$ to $Y=-50 \mathrm{~mm}$ at $10 \mathrm{~mm}$ downstream of the register exit. Nominal flow rate: $66 \mathrm{cfm}$

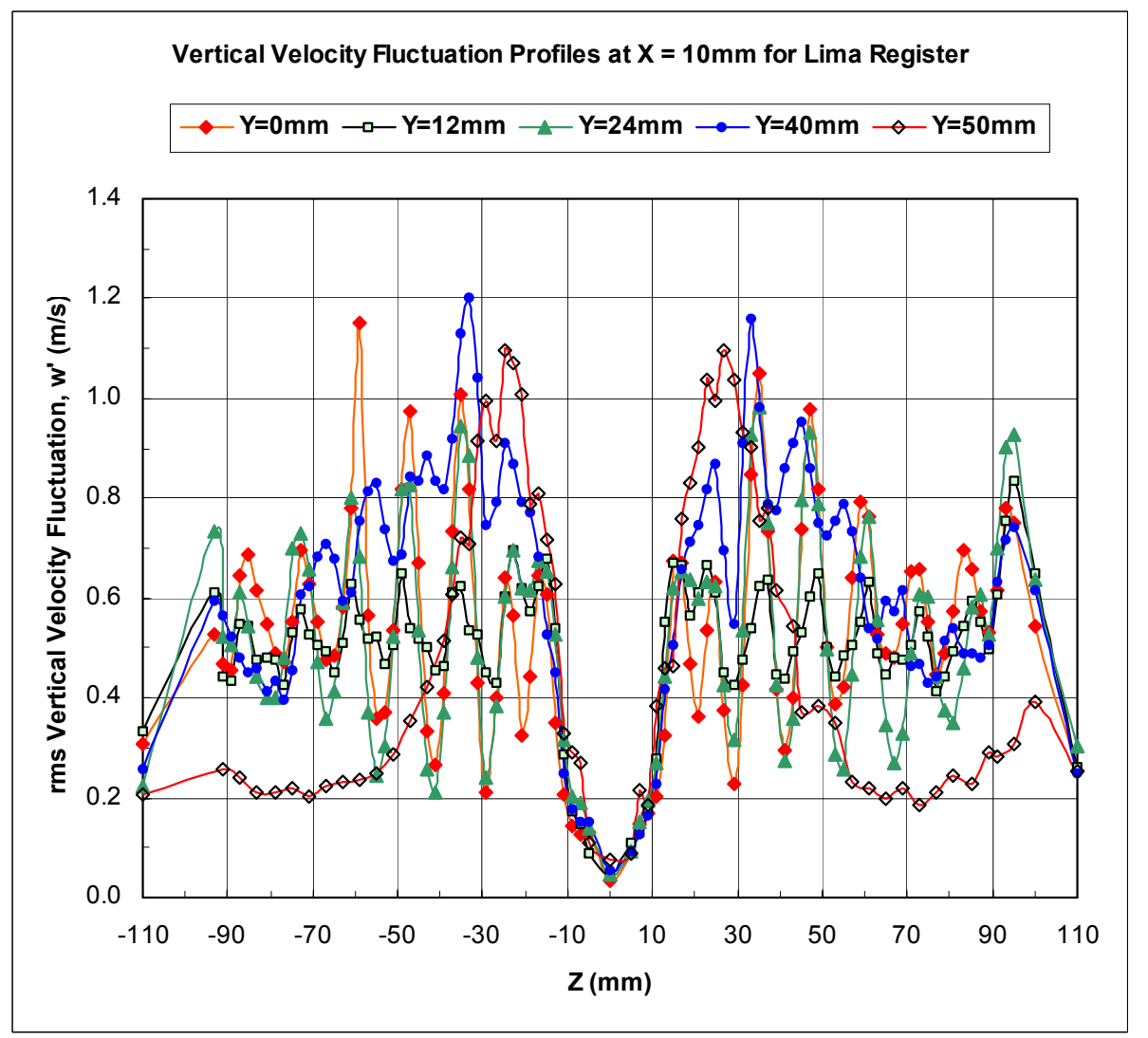

Figure 17. Measured turbulence level in the vertical velocity component at the exit of the Lima register. Measurements from $Y=0$ to $Y=50 \mathrm{~mm}$ at $10 \mathrm{~mm}$ downstream of the register exit. Nominal flow rate: $66 \mathrm{cfm}$ 


\subsubsection{The Axial Evolution of the Velocity Components}

The axial and vertical velocity components were also measured at a downstream distance of $100 \mathrm{~mm}$. The evolution of the axial velocity component with the downstream distance is shown in Figures 18 and 19.

As can be see from these figures, the periodic variations in the magnitude of the velocity due the deflecting blades have completely vanished at $X=100 \mathrm{~mm}$. Furthermore, these plots suggest that this register is very effective in splitting the incoming airflow into two diverging jets - as the register designers presumably intended.

The measurements of the vertical velocity component at $\mathrm{X}=100 \mathrm{~mm}$ are presented in Figure 20. These measurements, together with

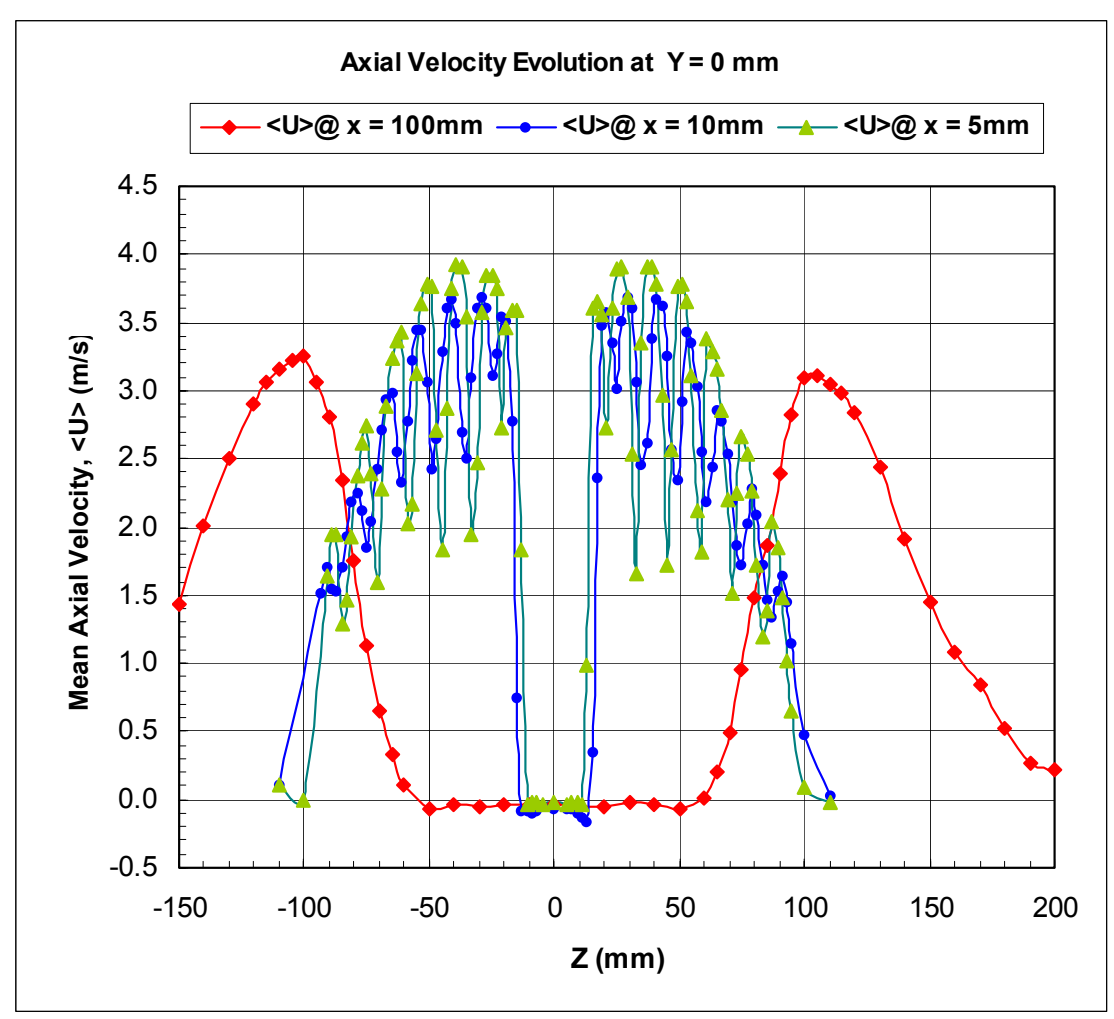

Figure 18. The evolution of the mean axial velocity component profiles with the downstream distance, $X$ for the Lima register. Measurements at $Y=0$. Nominal flow rate: $66 \mathrm{cfm}$. the measurements of the axial velocity component, were used to generate a plot of airflow velocity vectors as projected on to the $\mathrm{X}-\mathrm{Z}$ plane. The velocity vectors on the $X-Z$ plane passing through $Y=0$ are shown in Figure 21 . The velocity vectors are to scale, and have been plotted for the two axial locations of $X=10 \mathrm{~mm}$ and $X=100 \mathrm{~mm}$. As can be seen, in the neighborhood of $Z=0$ there is a large region (of recirculating flow) with small velocities towards the register. 


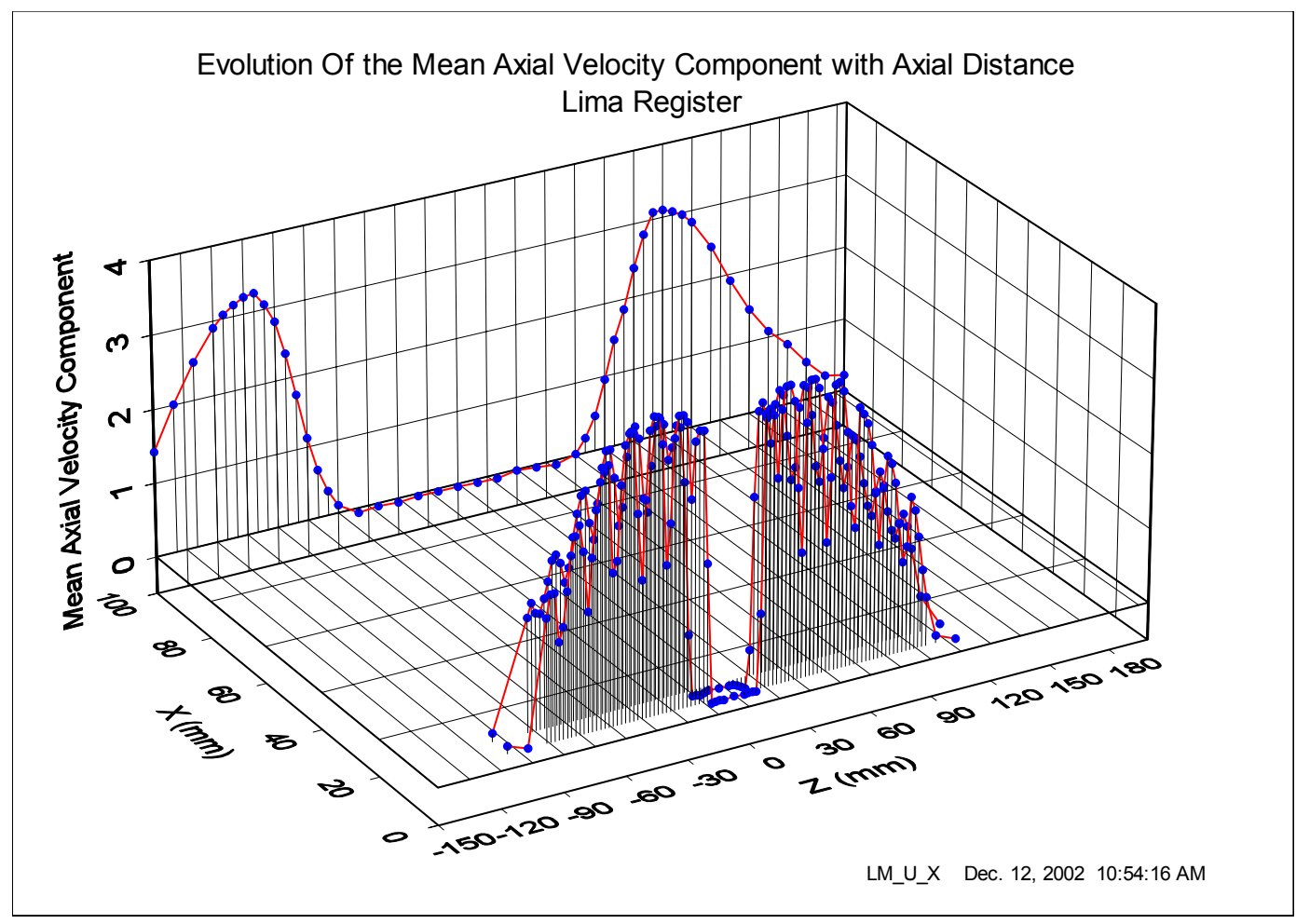

Figure 19. The evolution of the mean axial velocity component profiles with the downstream distance, $X$ for the Lima register. Measurements at $Y=0$. Nominal flow rate: $66 \mathrm{cfm}$.

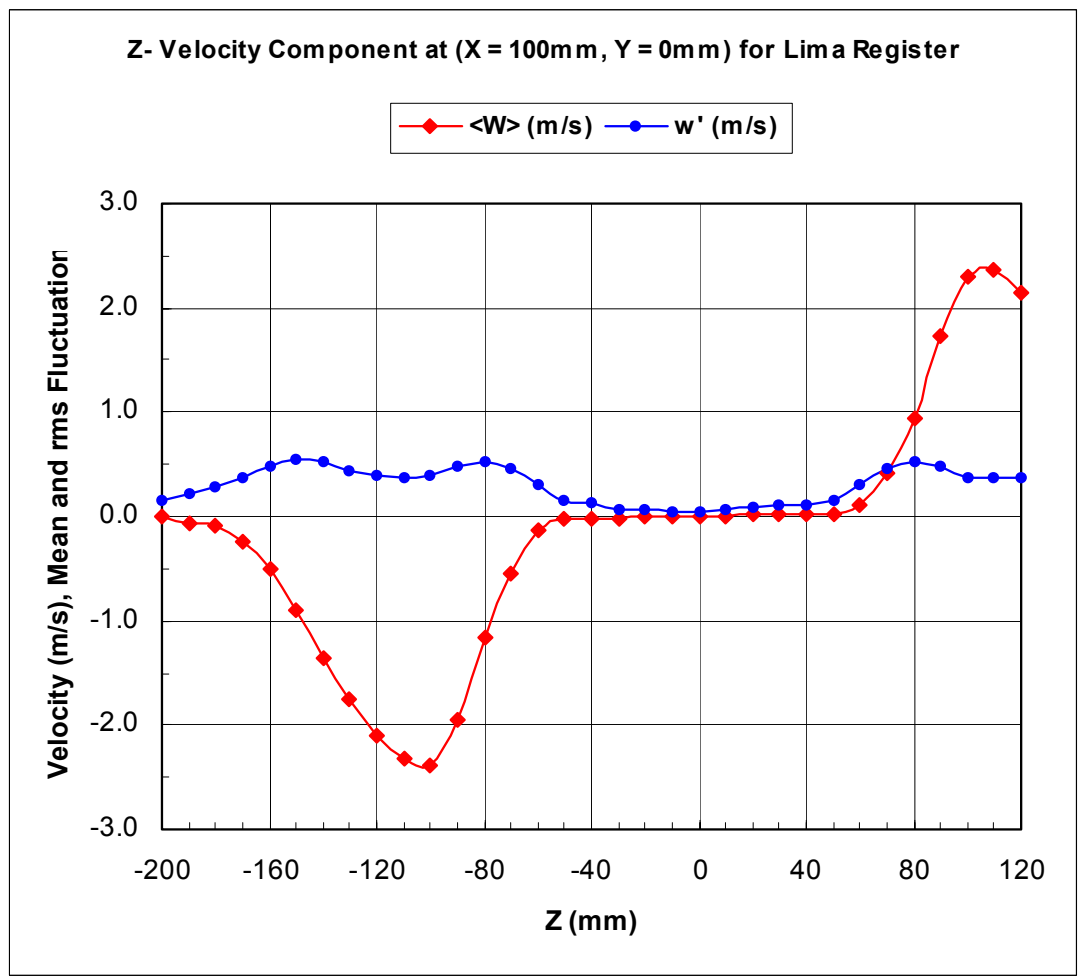

Figure 20. Measured mean and rms fluctuation of the vertical velocity component at the exit of the Lima register. Measurements at $100 \mathrm{~mm}$ downstream of the register exit and $Y=0 \mathrm{~mm}$. Nominal flow rate: $66 \mathrm{cfm}$ 


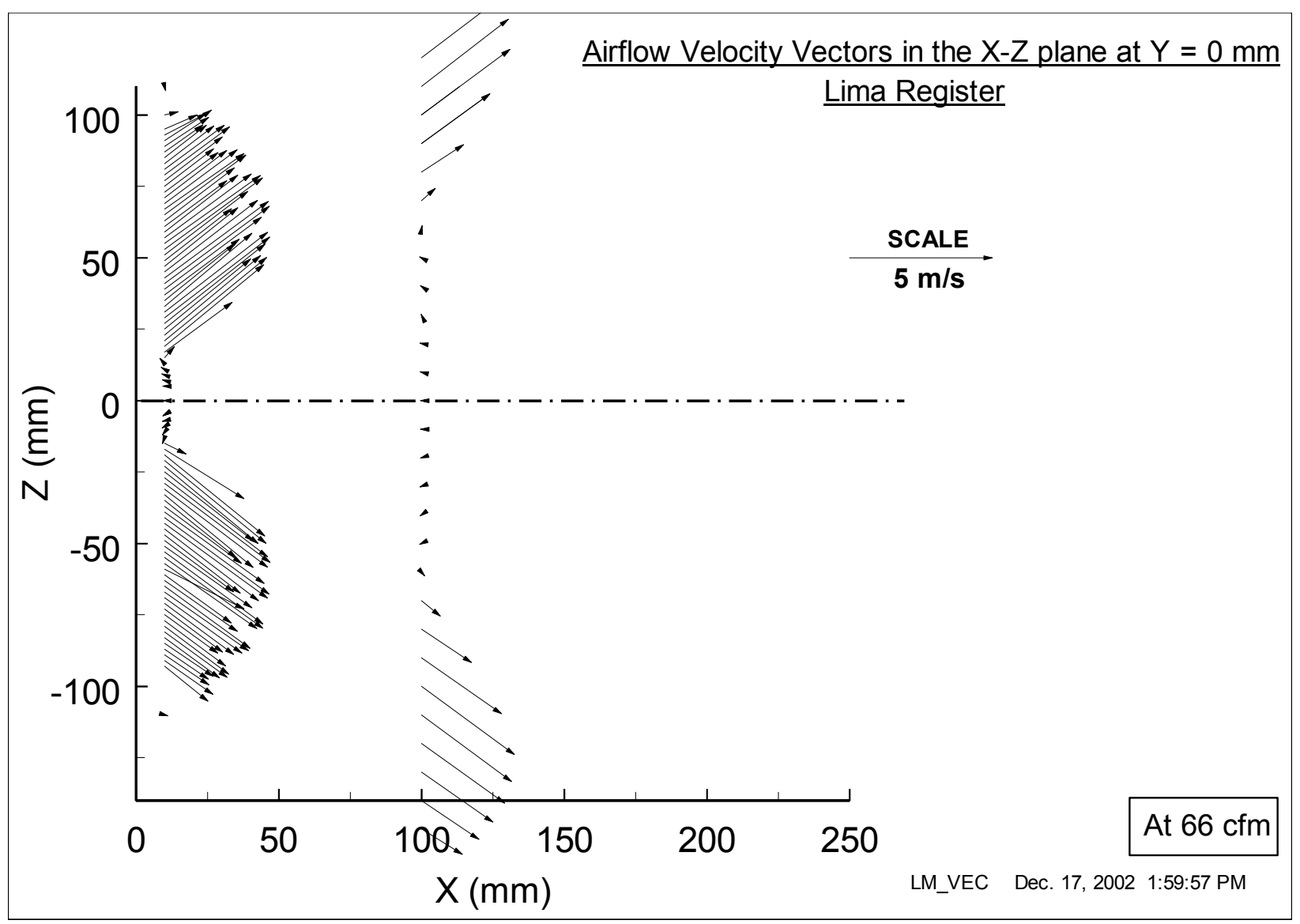

Figure 21. The measured mean velocity vectors in the $X-Z$ plane at $Y=0$ for two downstream locations $(X=10 \mathrm{~mm}$ and $X=100 \mathrm{~mm})$ for the Lima Register exit.

\subsection{Airflow Measurements for the High-Flow Case}

\subsubsection{The Axial and Vertical Velocity Components}

Because of the observed symmetry of the velocity profiles (about $\mathrm{Z}=0$ and $\mathrm{Y}=0$ ) under low flow rate conditions, velocity profile measurements for the high-flow case were performed across only one quadrant of the Lima register outlet. A summary of the mean axial velocity component profiles and associated rms fluctuations in it at $X=5 \mathrm{~mm}$ are presented in Figures 22 and 23 . The measurements of the vertical velocity component are shown in Figures 24 and 25. The velocity profiles appear similar to the ones observed for the low-flow case. This is further discussed in the next section.

\subsubsection{The Scaling of Velocity Components with Flow Rate for the Lima Register}

The purpose of making velocity measurements for the high-flow case was to see if there was a significant change in the near-field velocity distribution at the exit of the register with the volumetric flow rate through the register. Normally, one would expect that if there is no flow regime change with the flow rate, the velocity profiles should scale with the flow rate. That is, if the velocity components are normalized with the flow rate, the scaled (or dimensionless) velocity profiles will be very nearly identical at different flow rates. (One such example of a flow regime change would be the onset of flow separation at a deflecting blade (straight or curved) at high flow rates and no separation at low flow rates.) 


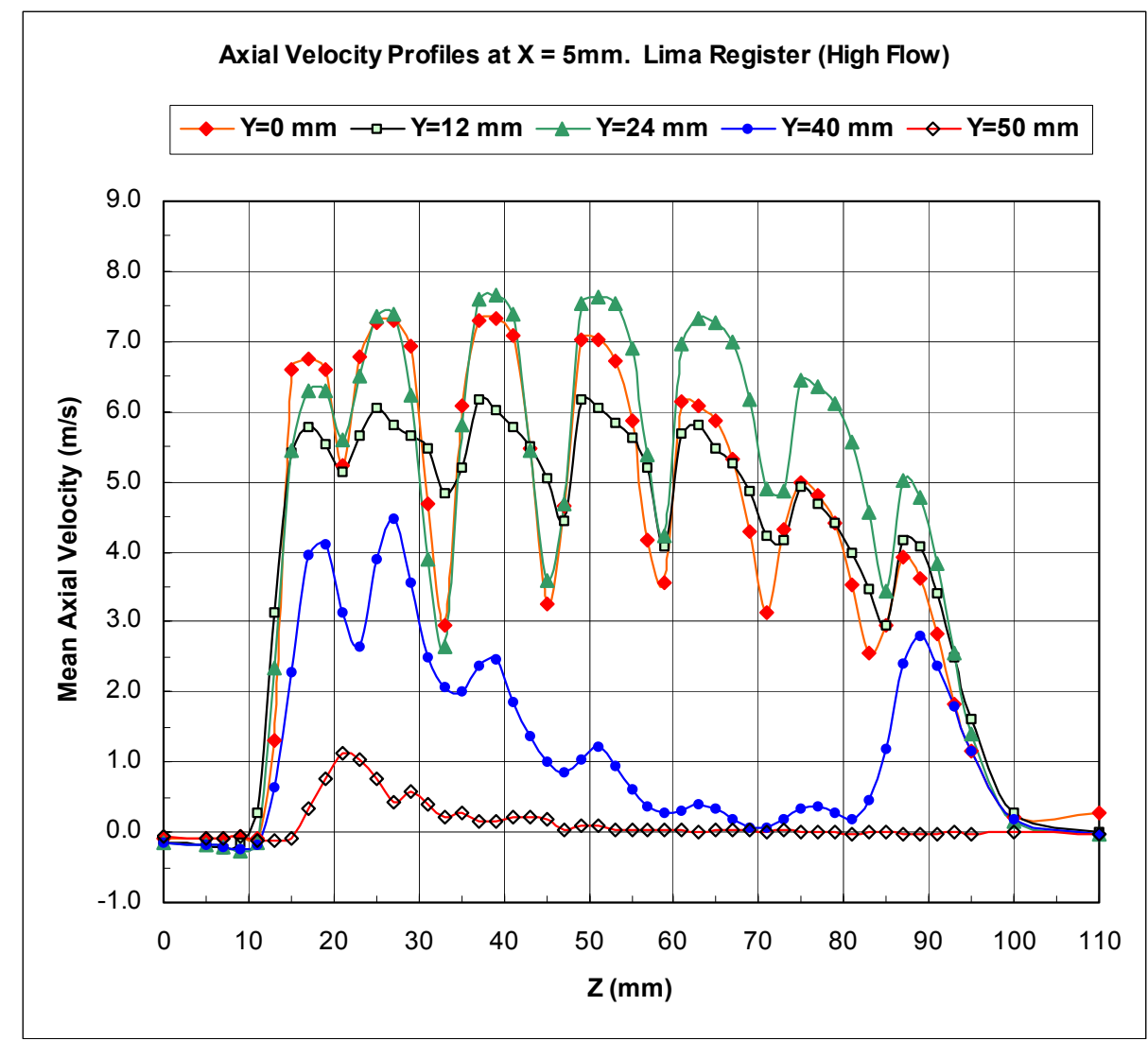

Figure 22. Measured mean axial velocity component $(\langle U\rangle)$ profiles at the exit of the Lima register. Measurements from $Y=0$ to $Y=50 \mathrm{~mm}$ at $5 \mathrm{~mm}$ downstream of the register exit. Nominal flow rate: $126 \mathrm{cfm}$

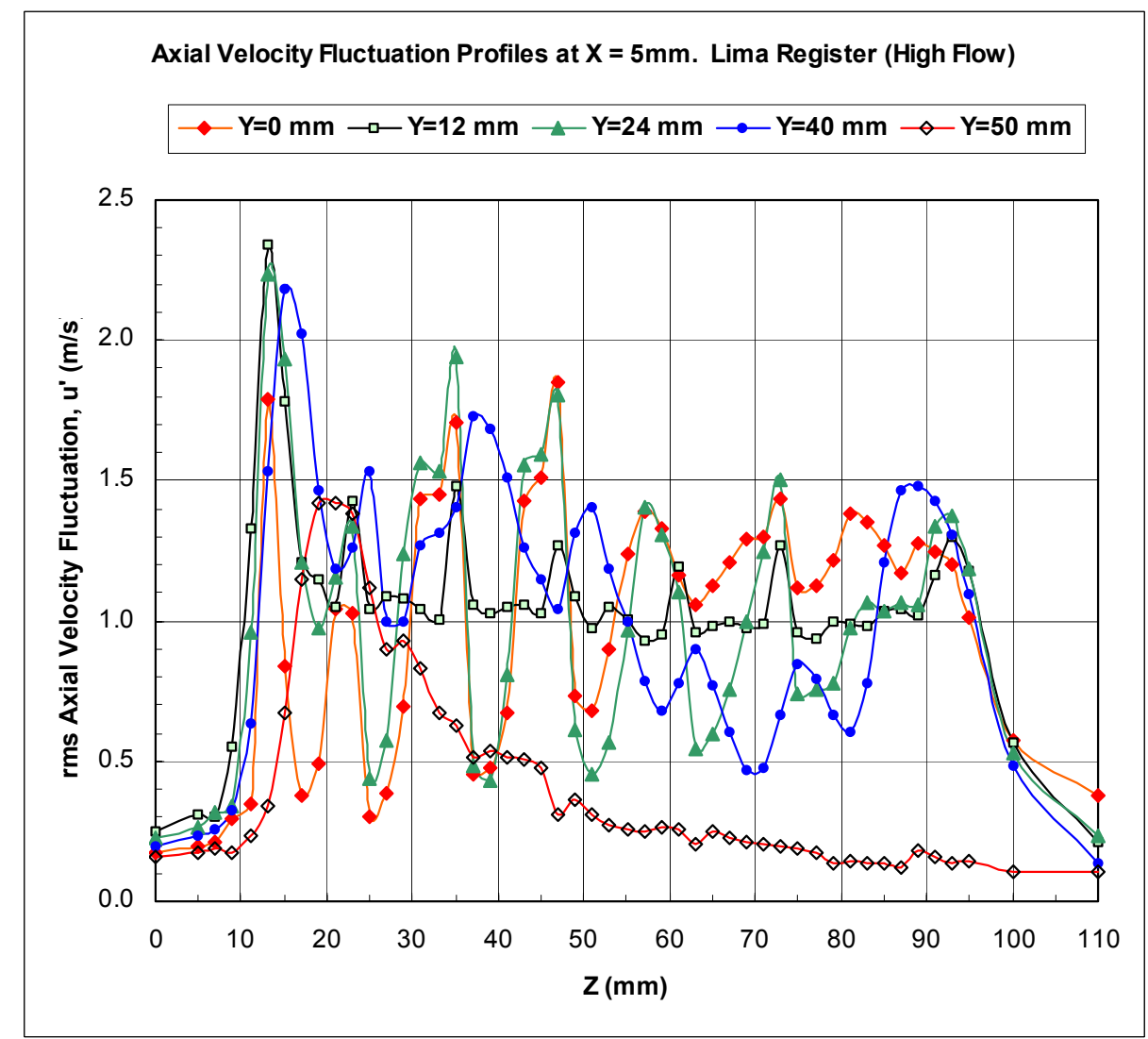

Figure 23. Measured turbulence level in the axial velocity component at the exit of the Lima register. Measurements from $Y=0$ to $Y=50 \mathrm{~mm}$ at $5 \mathrm{~mm}$ downstream of the register exit. Nominal flow rate: $126 \mathrm{cfm}$. 


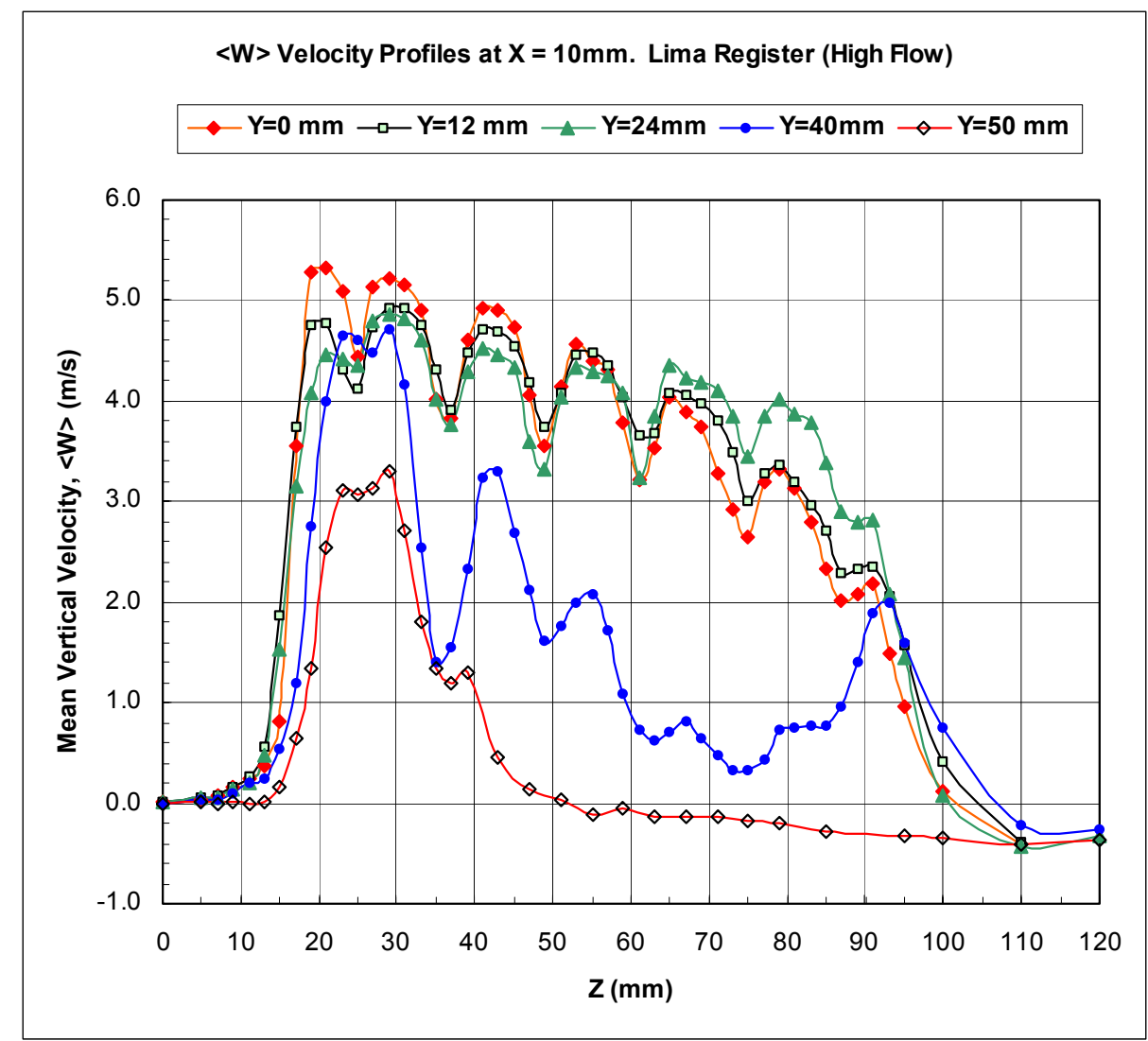

Figure 24. Measured mean vertical velocity component profiles at the exit of the Lima register. Measurements from $Y=0$ to $Y=50 \mathrm{~mm}$ at $10 \mathrm{~mm}$ downstream of the register exit. Nominal flow rate: $126 \mathrm{cfm}$.

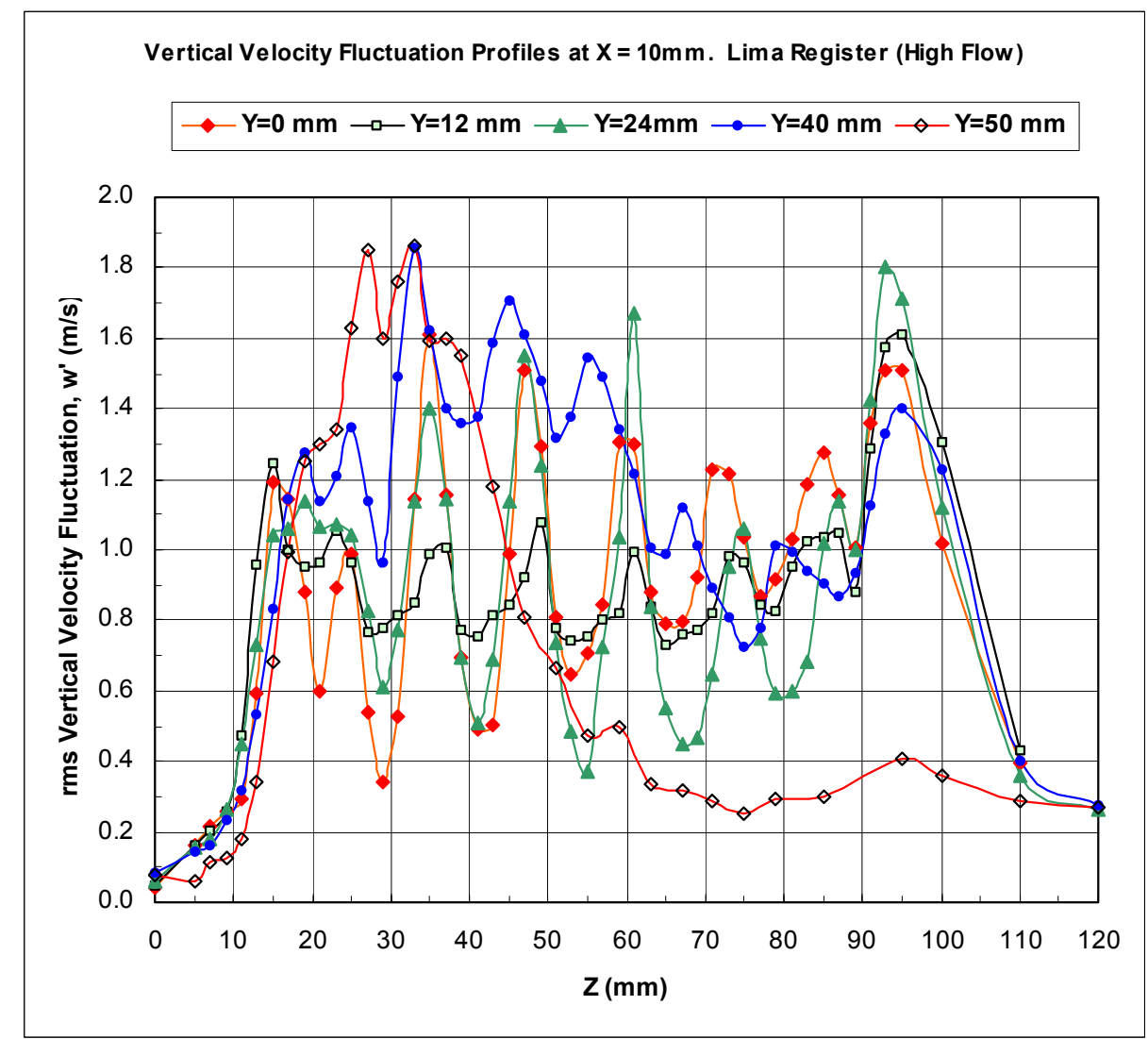

Figure 25. Measured turbulence level in the vertical velocity component at the exit of the Lima register. Measurements from $Y=0$ to $Y=50 \mathrm{~mm}$ at $10 \mathrm{~mm}$ downstream of the register exit. Nominal flow rate: $126 \mathrm{cfm}$. 


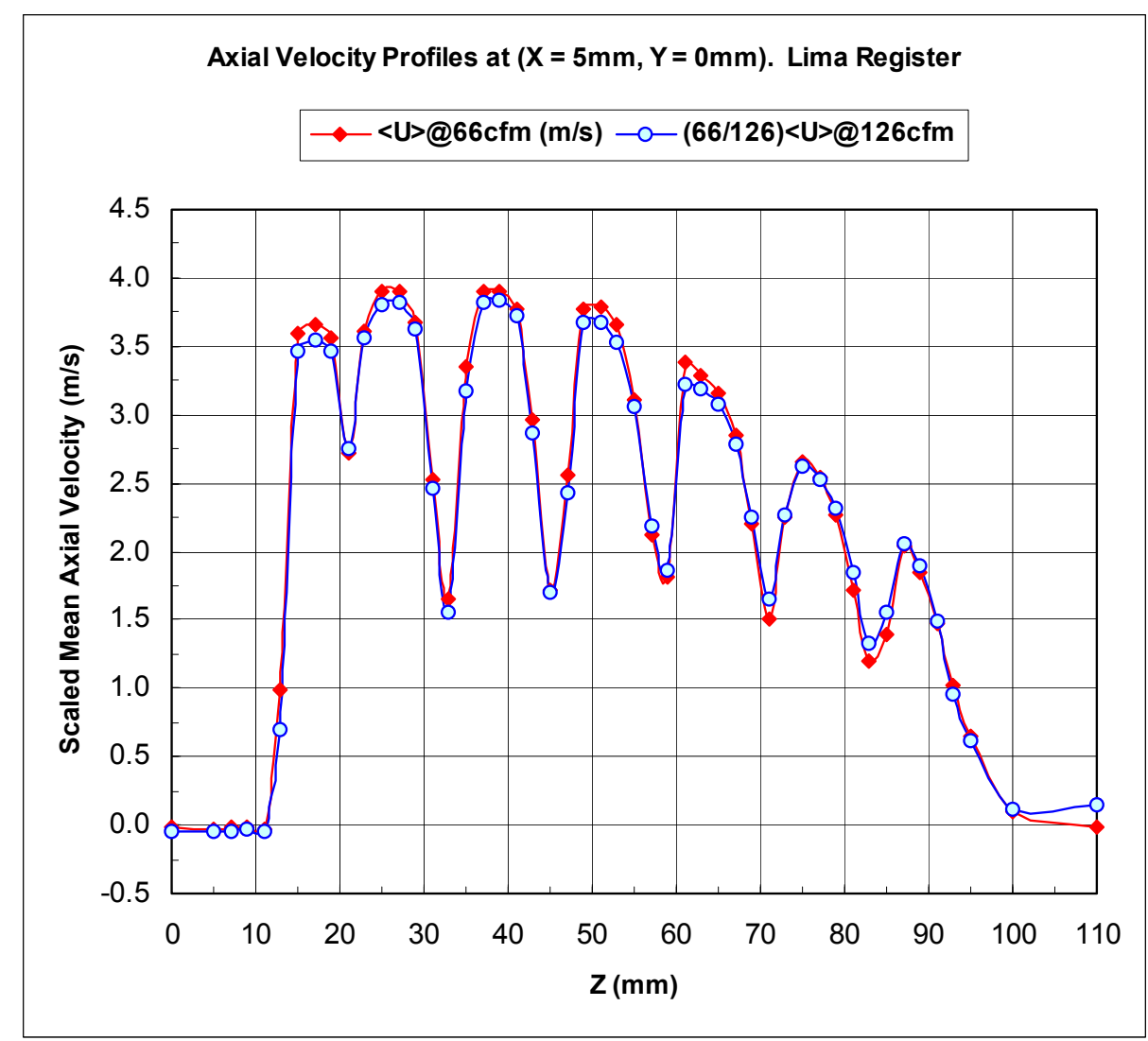

Figure 26. Comparison of mean axial velocity profiles at $X=5 \mathrm{~mm}$ and $Y=$ $0 \mathrm{~mm}$ for the Lima Register at two flow rates. The measured mean velocity at $126 \mathrm{cfm}$ has been multiplied by the flow rate ratio of $(66 / 126)$.

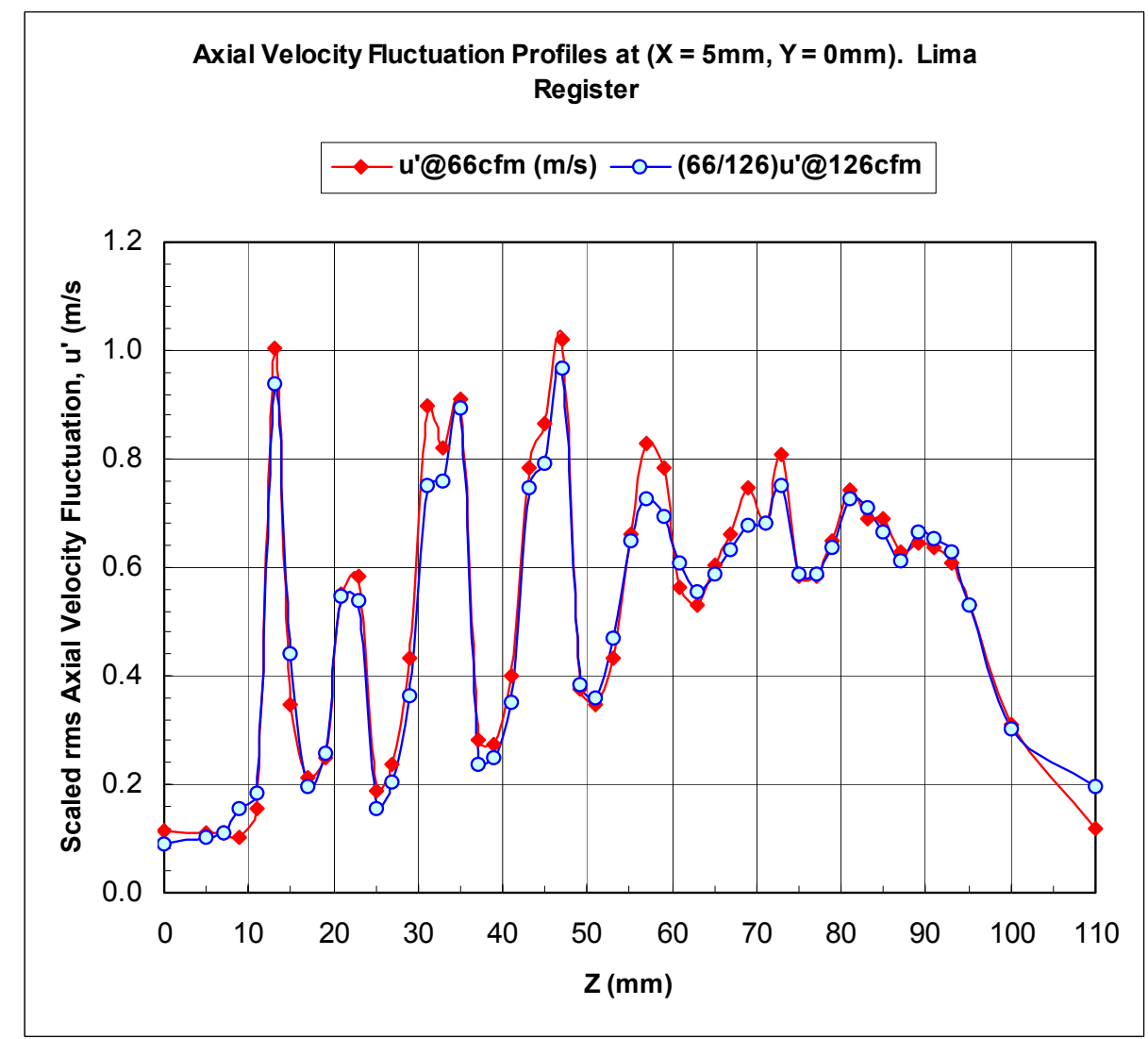

Figure 27. Comparison of turbulence level in the axial velocity component at $X=5 \mathrm{~mm}$ and $Y=0 \mathrm{~mm}$ for the Lima Register at two flow rates. The measured u' at $126 \mathrm{cfm}$ has been multiplied by the flow rate ratio of $(66 / 126)$ 


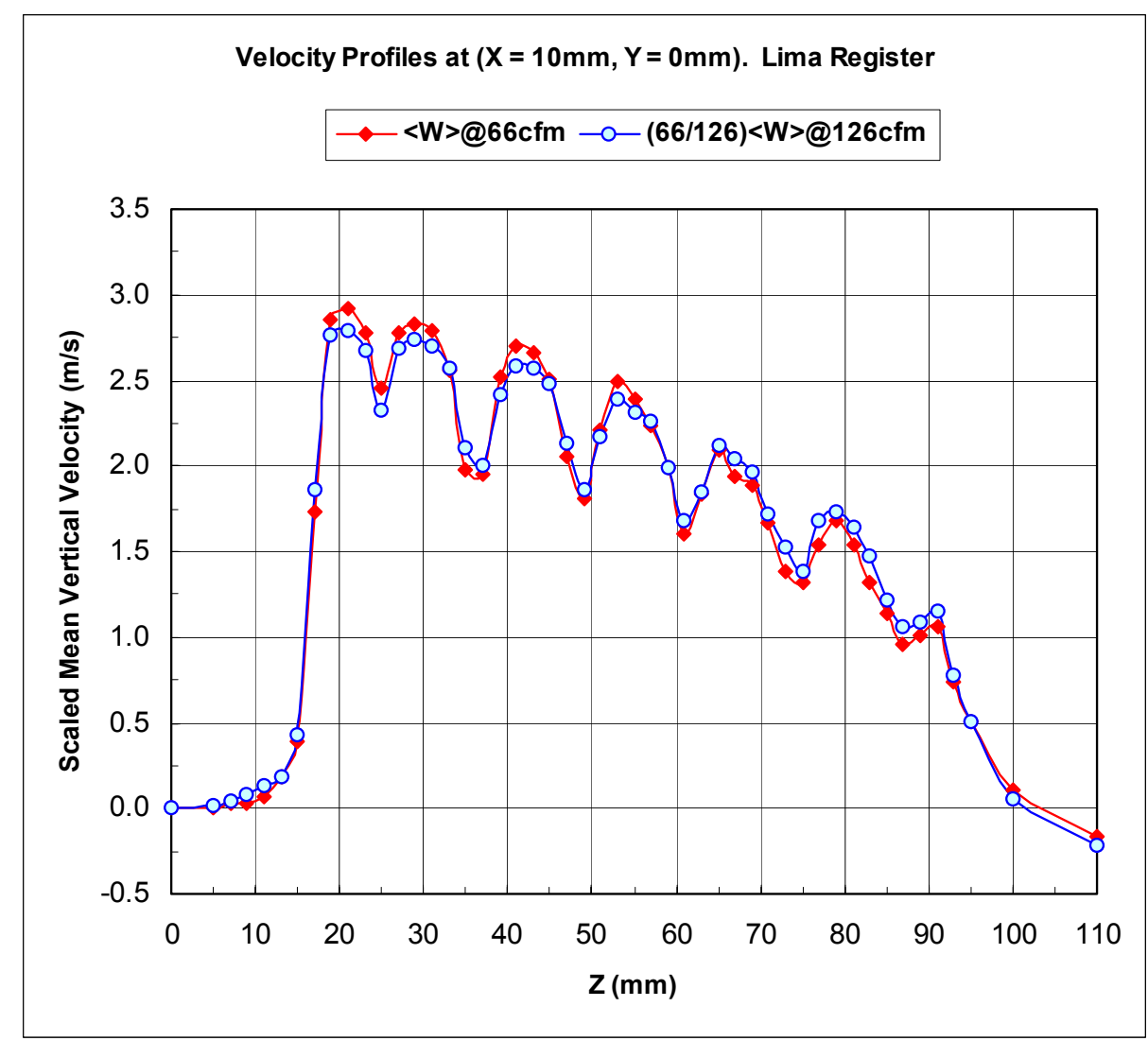

Figure 28. Comparison of mean vertical velocity profiles at $X=10 \mathrm{~mm}$ and $Y=0 \mathrm{~mm}$ for the Lima Register at two flow rates. The measured mean velocity at $126 \mathrm{cfm}$ has been multiplied by the flow rate ratio of $(66 / 126)$.

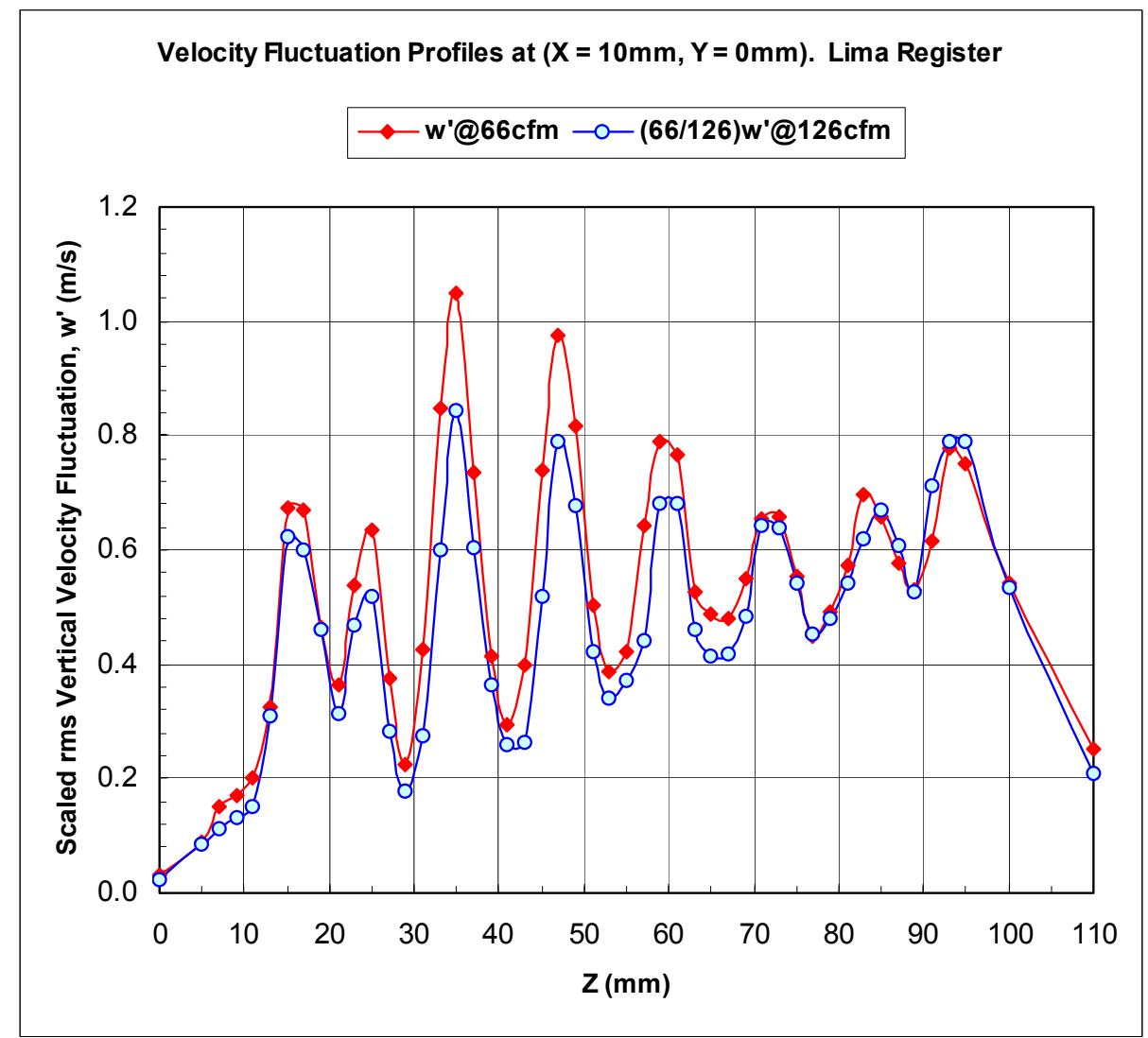

Figure 29. Comparison of turbulence level in the vertical velocity component at $X=10 \mathrm{~mm}$ and $Y=0 \mathrm{~mm}$ for the Lima Register at two flow rates. The measured $w^{\prime}$ at $126 \mathrm{cfm}$ has been multiplied by the flow rate ratio of $(66 / 126)$. 


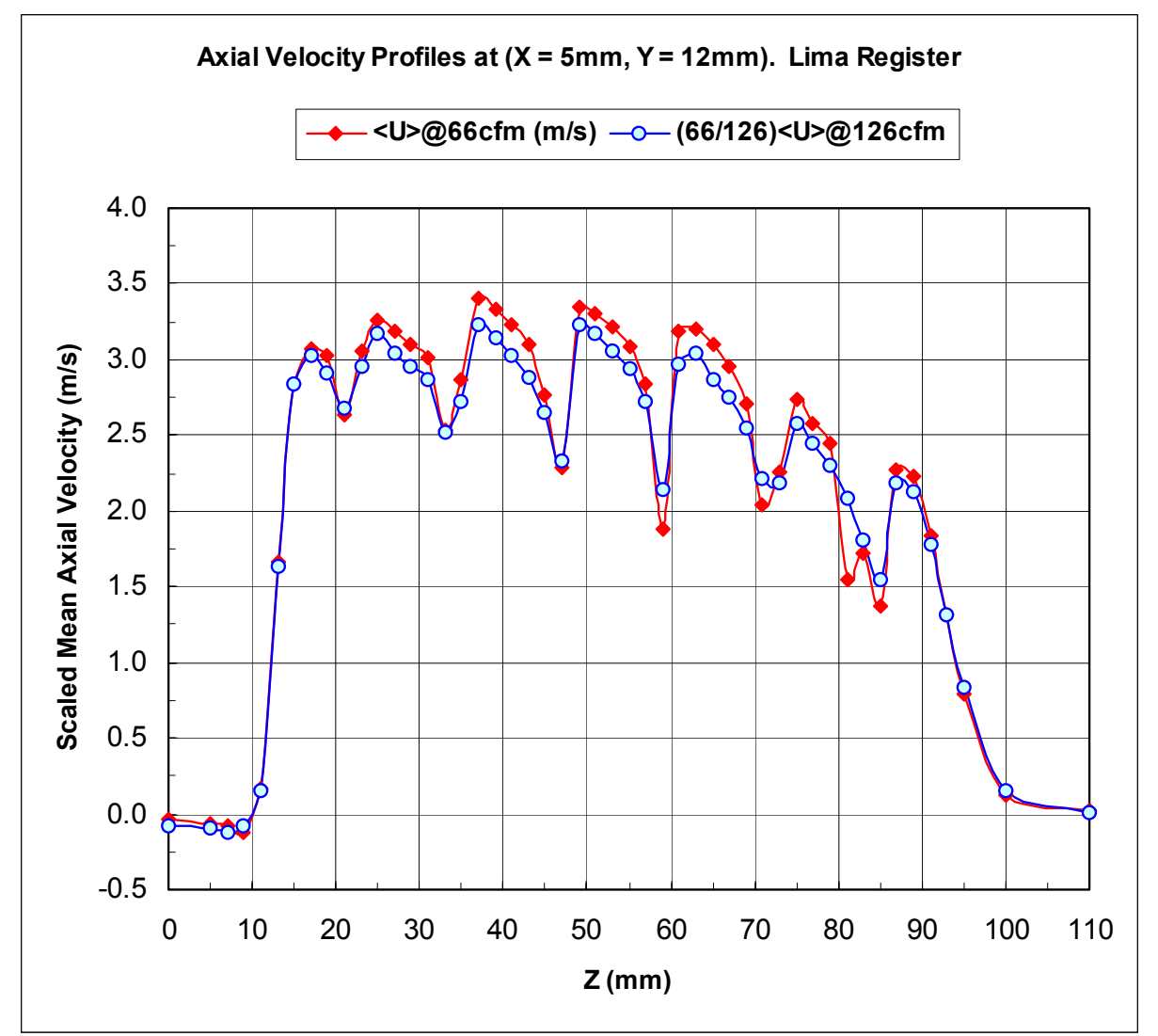

Figure 30. Comparison of mean axial velocity profiles at $X=5 \mathrm{~mm}$ and $Y=$ $12 \mathrm{~mm}$ for the Lima Register at two flow rates. The measured mean velocity at $126 \mathrm{cfm}$ has been multiplied by the flow rate ratio of $(66 / 126)$.

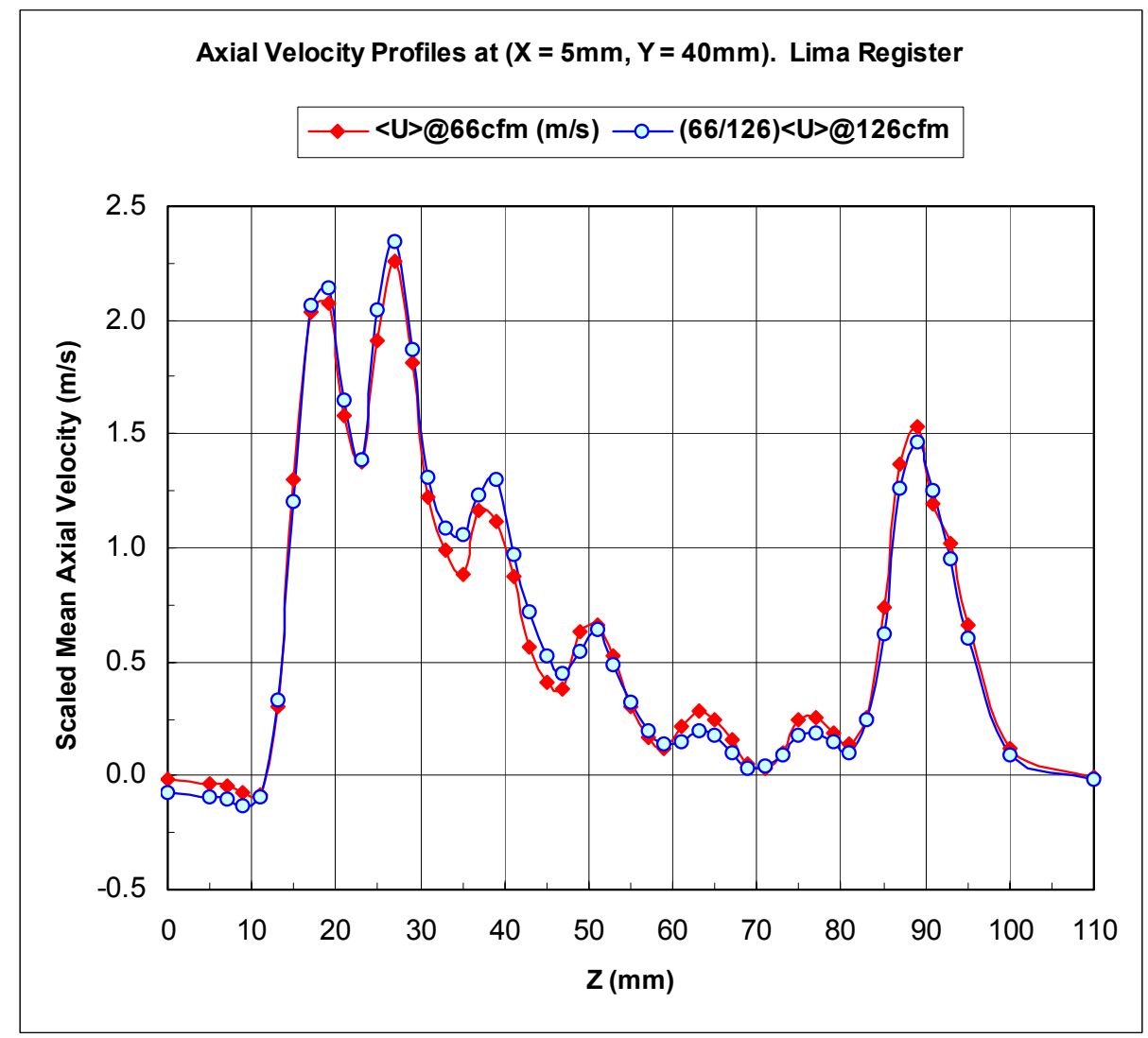

Figure 31. Comparison of mean axial velocity profiles at $X=5 \mathrm{~mm}$ and $Y=$ $40 \mathrm{~mm}$ for the Lima Register at two flow rates. The measured mean velocity at $126 \mathrm{cfm}$ has been multiplied by the flow rate ratio of $(66 / 126)$. 


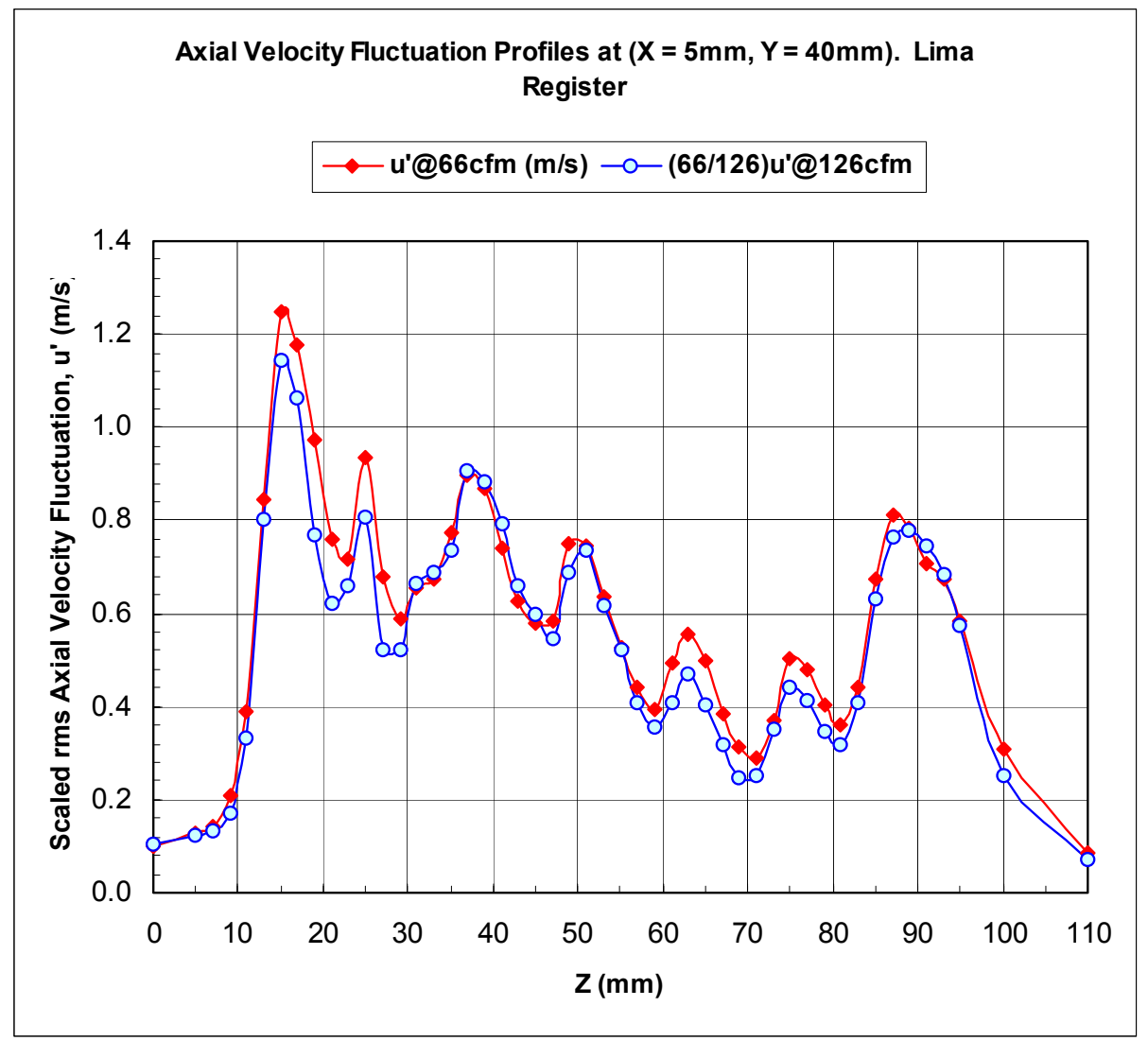

Figure 32. Comparison of turbulence level in the axial velocity component at $X=5 \mathrm{~mm}$ and $Y=40 \mathrm{~mm}$ for the Lima Register at two flow rates. The measured $u^{\prime}$ at $126 \mathrm{cfm}$ has been multiplied by the flow rate ratio of $(66 / 126)$.

Figures 26 through 32 show a comparison of various velocity profiles at identical locations for the two flow rates of $66 \mathrm{cfm}$ and $126 \mathrm{cfm}$. For comparison purposes the measured velocity at the higher flow rate has been normalized by the flow rate ratio of (66/126). These figures show that for this Lima register the near-field velocity profiles scale with the flow rate.

\section{VELOCITY MEASUREMENTS AT THE EXIT OF THE HART \& COOLEY REGISTER}

\subsection{Introduction}

Following the velocity measurements discussed above, the Lima register was removed and the boot was rotated by 90 degrees. As shown in Figure 33, the Hart \& Cooley register was then installed at the end of the boot. This register was installed with the longer cross-sectional dimension in the horizontal (Y) direction. As before, the velocity measurements were performed for the same two nominal volumetric flow rates of $66 \mathrm{cfm}$ and $126 \mathrm{cfm}$. As shown in Figure 33, the axial coordinate $\mathrm{X}$ is measured from the flat face of the register and not from the trailing edge of the curved deflecting blades. Prior to installation of the Hart \& Cooley register, the flow control dampers at the inlet of this register were removed. This was done in consultation with IBACOS since they had performed experiments with the same register without the dampers. 
Velocity measurements were performed at two axial locations: $X=22 \mathrm{~mm}$ and $X=120 \mathrm{~mm}$. The $Z$ coordinate was traversed across the face of the register for many $Y$ coordinate locations. Since the register has a natural symmetry about $Y=0$, the measurements were not made across the entire right half of the register face. Instead, the Y coordinate was only varied in the range of $-120 \mathrm{~mm}$ to $+30 \mathrm{~mm}$.
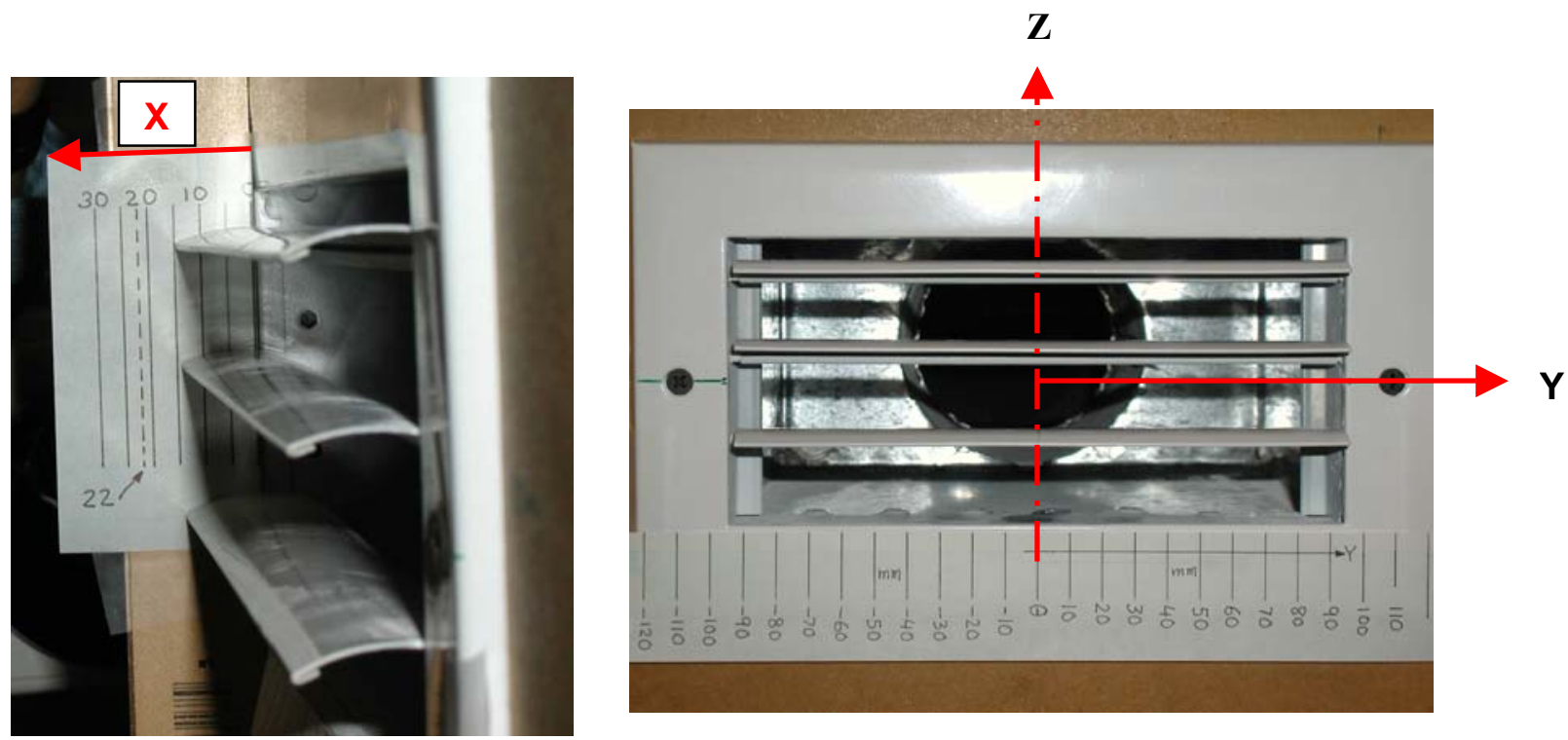

Figure 33. Photographs of the installed Hart \& Cooley register together with the labeled coordinate axes. The flow control dampers have been removed from the register and all the three deflecting blades are in the horizontal position. The photograph on the left shows the zero of the X-axis and the measurement location of $X=22 \mathrm{~mm}$ (dotted line).

\subsection{Airflow Measurements for the Low Flow Case}

\subsubsection{The Axial Velocity Component}

The axial velocity measurements at $\mathrm{X}=22 \mathrm{~mm}$ and $\mathrm{Y}=0$ as a function of the $\mathrm{Z}$ coordinate are presented in Figure 34. This axial location is about $7 \mathrm{~mm}$ downstream of the trailing edge of the blades. A photograph of a portion of the register is superimposed on these velocity measurements to show the correlation between the variations in the velocity profile and the location of the flow deflecting blades. While the maximum mean axial velocity component is about $4.5 \mathrm{~m} / \mathrm{s}$, the maximum rms fluctuation in it is about $1.1 \mathrm{~m} / \mathrm{s}$. As one would expect, the peaks in the rms fluctuation u' occur near the locations of maximum in the mean velocity gradient (region of maximum shear).

A summary of the mean axial velocity profiles (as a function of $\mathrm{Z}$ ) for various $\mathrm{Y}$ locations at the downstream distance of $X=22 \mathrm{~mm}$ is presented in Figures 35 and 36. The latter figure shows that the measurements at $\mathrm{Y}=30 \mathrm{~mm}$ are close to measurements at $\mathrm{Y}=-30 \mathrm{~mm}$, and the measurements at $\mathrm{Y}=$ $15 \mathrm{~mm}$ are close to measurements at $\mathrm{Y}=-15 \mathrm{~mm}$, thus indicating reasonable symmetry of velocity profiles in the central region around $\mathrm{Y}=0$. These mean axial velocity profiles (for $\mathrm{Y} \leq 0$ ) are further presented as a three-dimensional line plot in Figure 37. The observed sharp drop in the measured mean axial velocity component with the $\mathrm{Y}$ coordinate for $|\mathrm{Y}| \geq 40 \mathrm{~mm}$ is seen more clearly in Figure 38. By observing the front face of the register in Figure 33 above, one would expect a fairly uniform velocity profile as a function of $Y$ for at least $|Y| \leq 75 \mathrm{~mm}$. This rather sharp variation of the velocity with the $Y$ coordinate is clearly a result of the simple boot design, which is a sudden transition from a 4" diameter duct to a 4"x8" rectangular cross-section.

Measurements of the rms fluctuations in the axial velocity component, u', are summarized in Figure 39. 


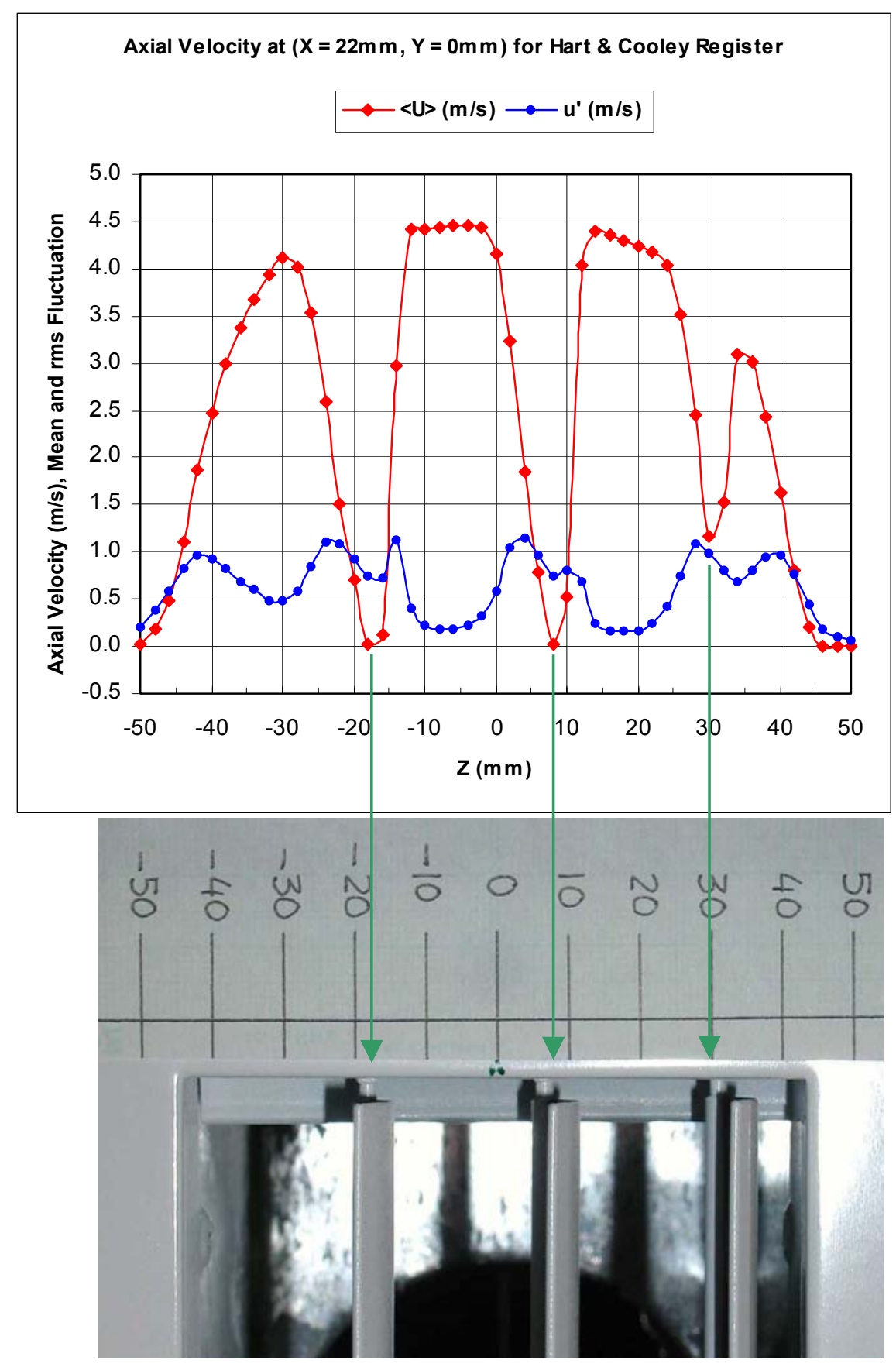

Figure 34. Measured mean and rms fluctuation of the axial velocity component at the exit of the Hart \& Cooley register. Nominal flow rate: $66 \mathrm{cfm}$. A superimposed photograph of the register shows the correlation between the velocity variations and the deflecting vanes of the register. Measurements at $22 \mathrm{~mm}$ downstream of the register exit and $Y=0 \mathrm{~mm}$. 


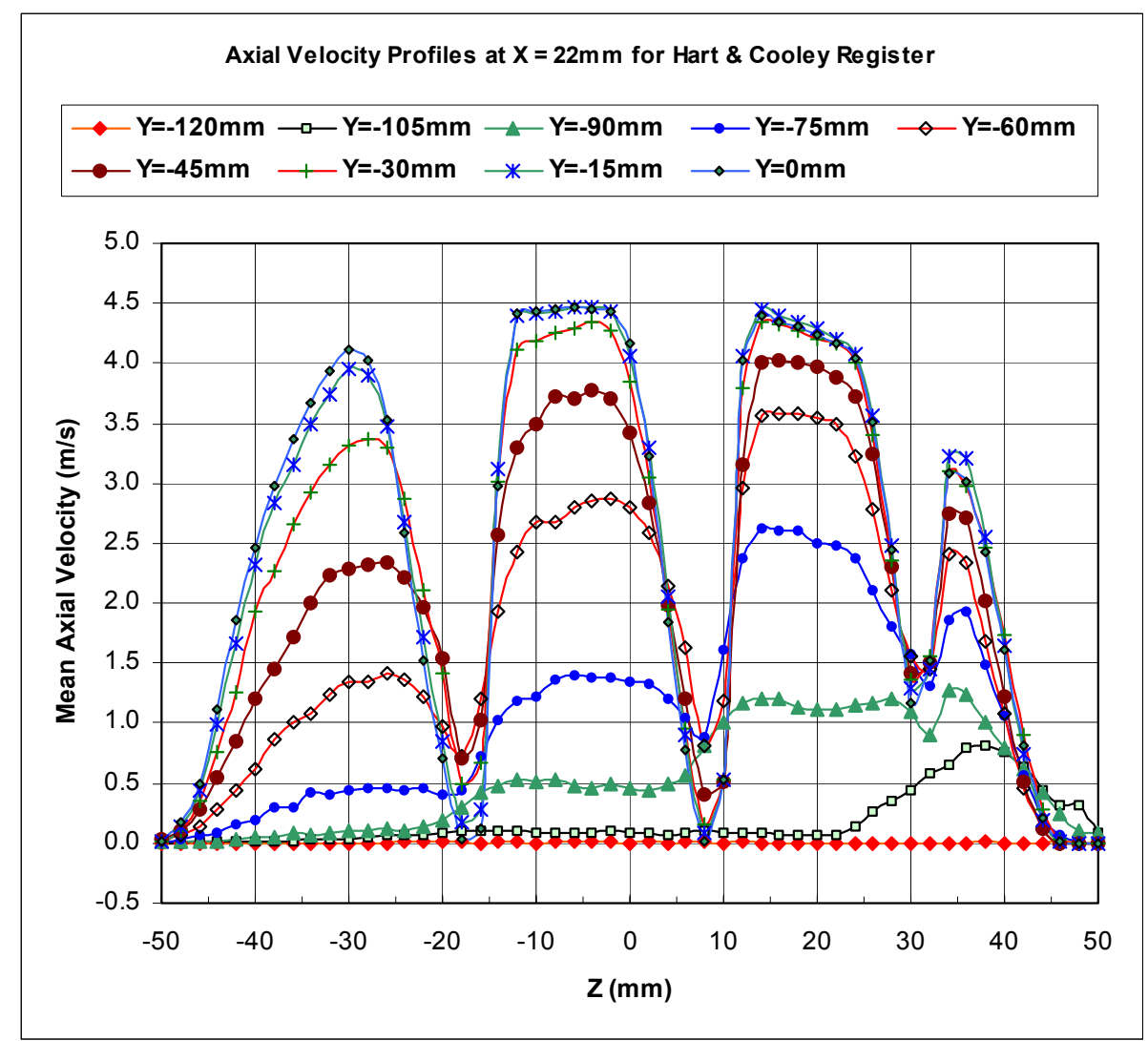

Figure 35. Measured mean axial velocity component $(\langle U\rangle)$ profiles at the exit of the Hart \& Cooley register. Measurements from $Y=0$ to $Y=-120 \mathrm{~mm}$ at $22 \mathrm{~mm}$ downstream of the register exit. Nominal flow rate: $66 \mathrm{cfm}$.

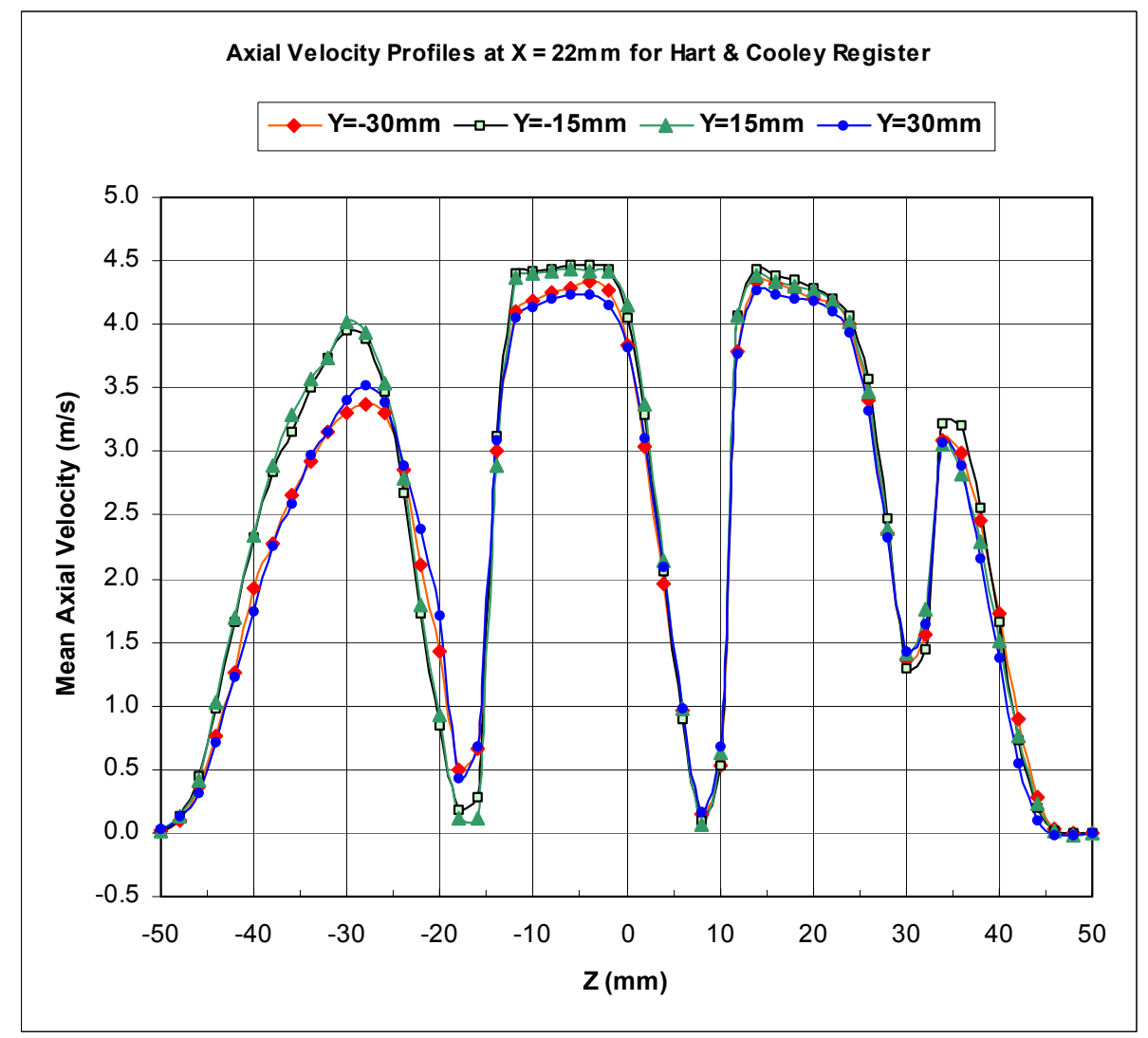

Figure 36. Measured mean axial velocity component $(\langle U\rangle)$ profiles at the exit of the Hart \& Cooley register. Measurements from $Y=-30 \mathrm{~mm}$ to $Y=$ $30 \mathrm{~mm}$ at $22 \mathrm{~mm}$ downstream of the register exit. Nominal flow rate: $66 \mathrm{cfm}$. 


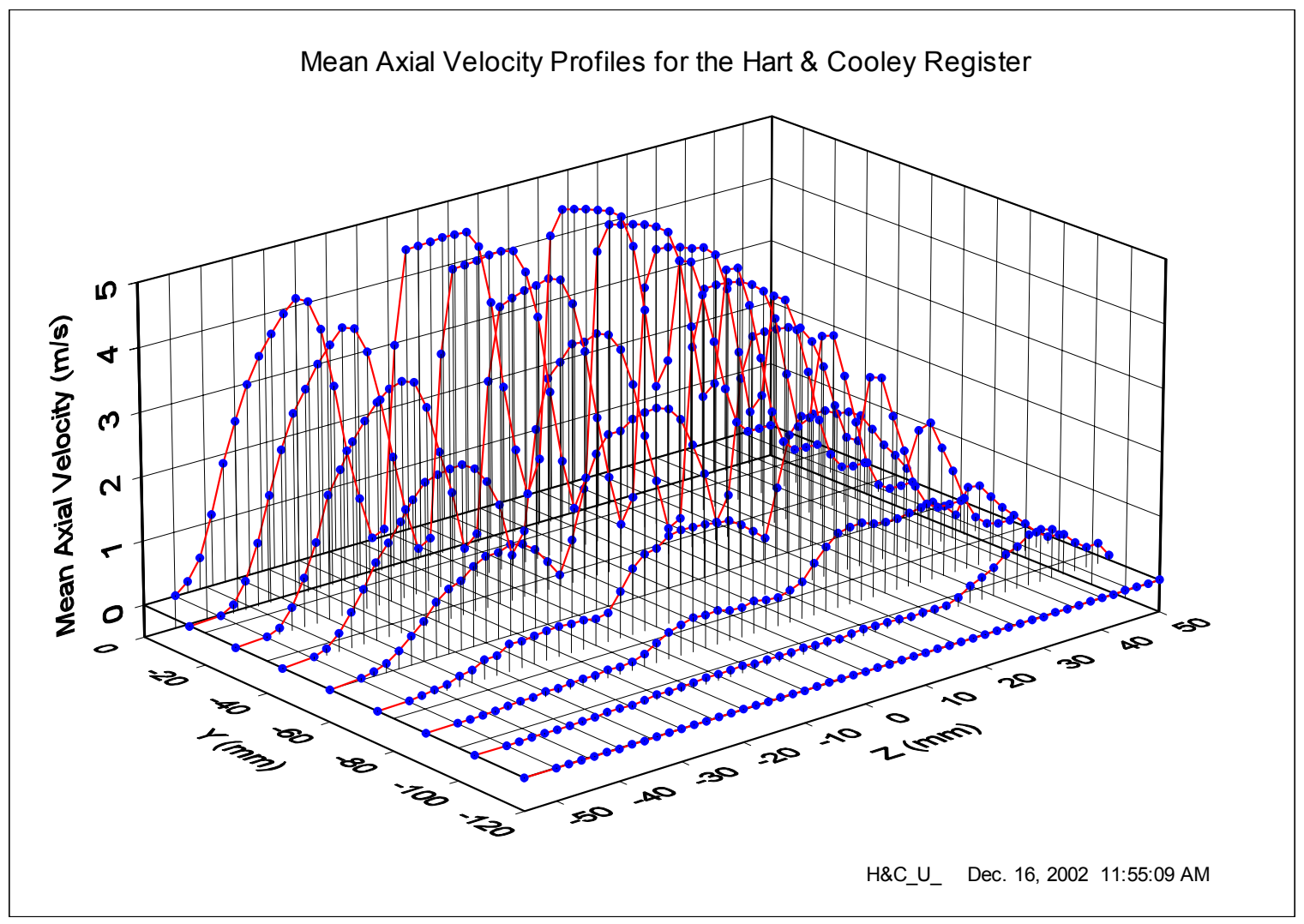

Figure 37. A three-dimensional line plot of the mean axial velocity component $(<U>)$ at the exit of the Hart \& Cooley register. Measurements at $22 \mathrm{~mm}$ downstream of the register exit. Nominal flow rate: $66 \mathrm{cfm}$. Note that $Z$ is the vertical coordinate.

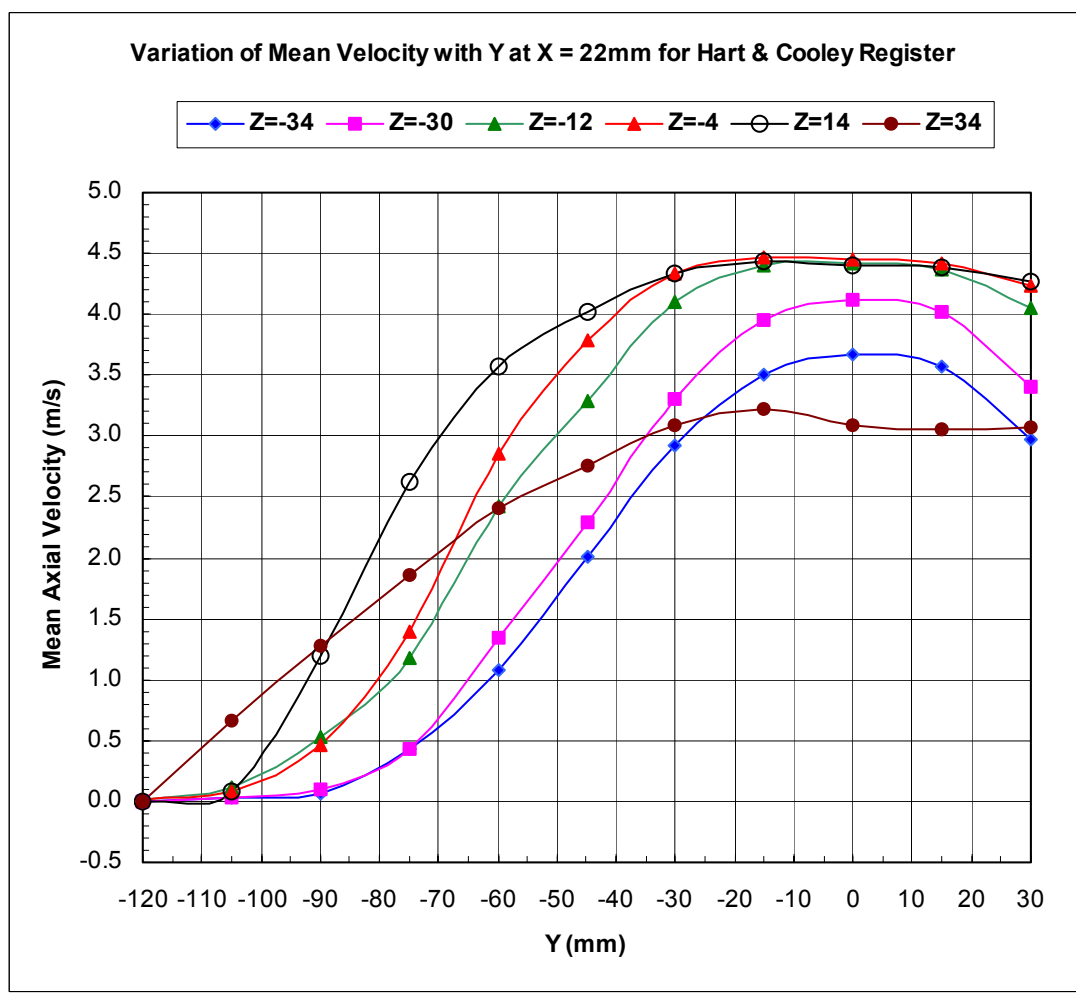

Figure 38. Variation of the mean axial velocity component $(<U>)$ with the lateral coordinate $Y$ showing the effect of the boot design on exit velocity profile. Nominal flow rate: $66 \mathrm{cfm}$. 


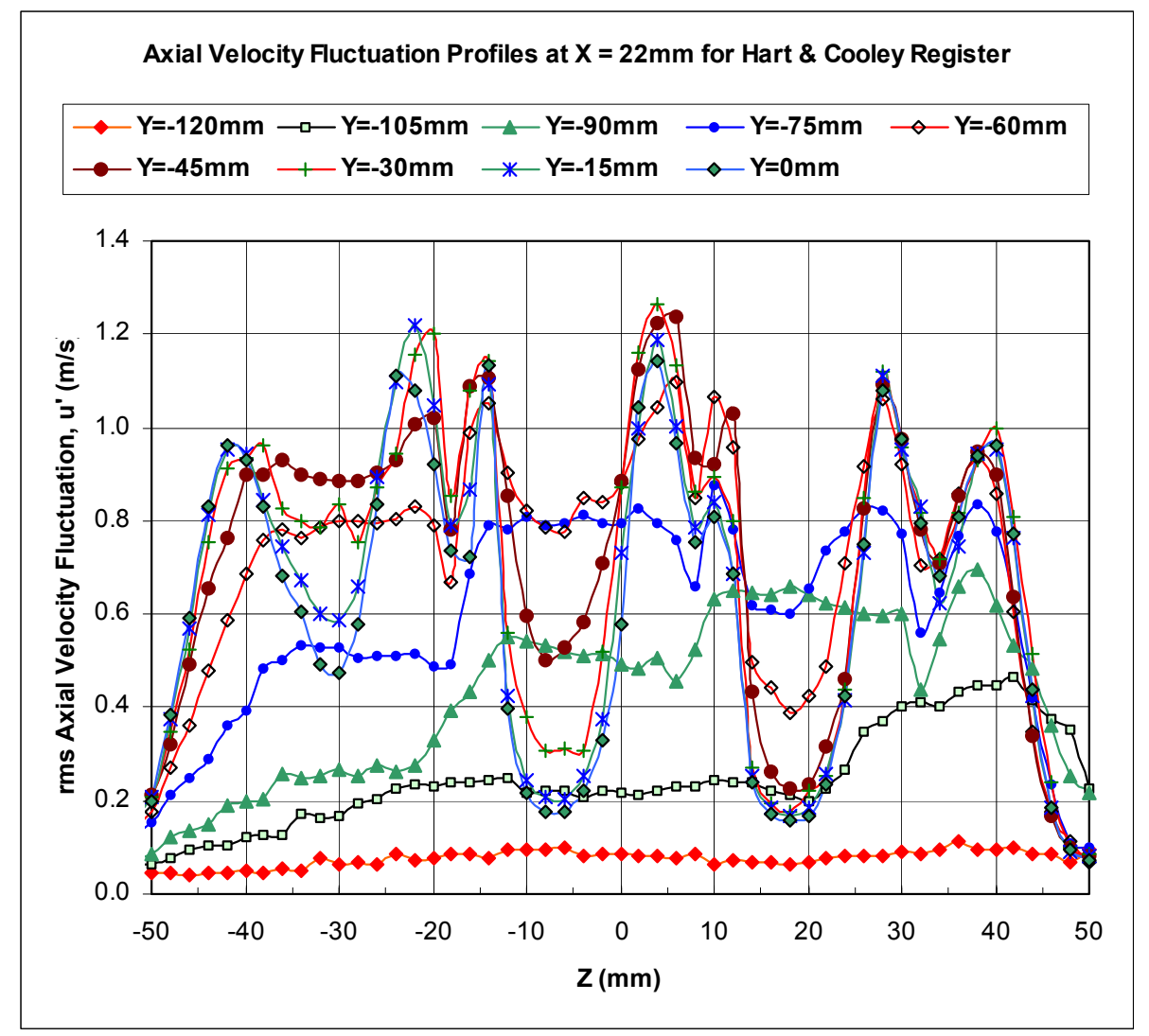

Figure 39. Measured turbulence level in the axial velocity component at the exit of the Hart \& Cooley register. Measurements from $Y=0$ to $Y=-120 \mathrm{~mm}$ at $22 \mathrm{~mm}$ downstream of the register exit. Nominal flow rate: $66 \mathrm{cfm}$.

\subsubsection{The Vertical Velocity Component}

The measurements of the mean vertical velocity component are summarized in Figures 40 and 41 . The velocity profiles show periodic variations that are clearly a result of the deflecting blades. The magnitude of the vertical velocity component is much smaller than that of the axial velocity component. This is to be expected since the deflecting blades were set in the horizontal position. However, the direction of the velocity component shows a definite trend from top to bottom. Near the bottom, the flow is moving upwards, and near the top, the airflow is downwards. The measurements of the rms fluctuations in the vertical velocity component, w', are summarized in Figure 42. It is noted that the peak rms fluctuation in the vertical velocity component is larger than the peak value of the mean vertical velocity component. However, the peak values of u' and w' are of similar magnitudes. 


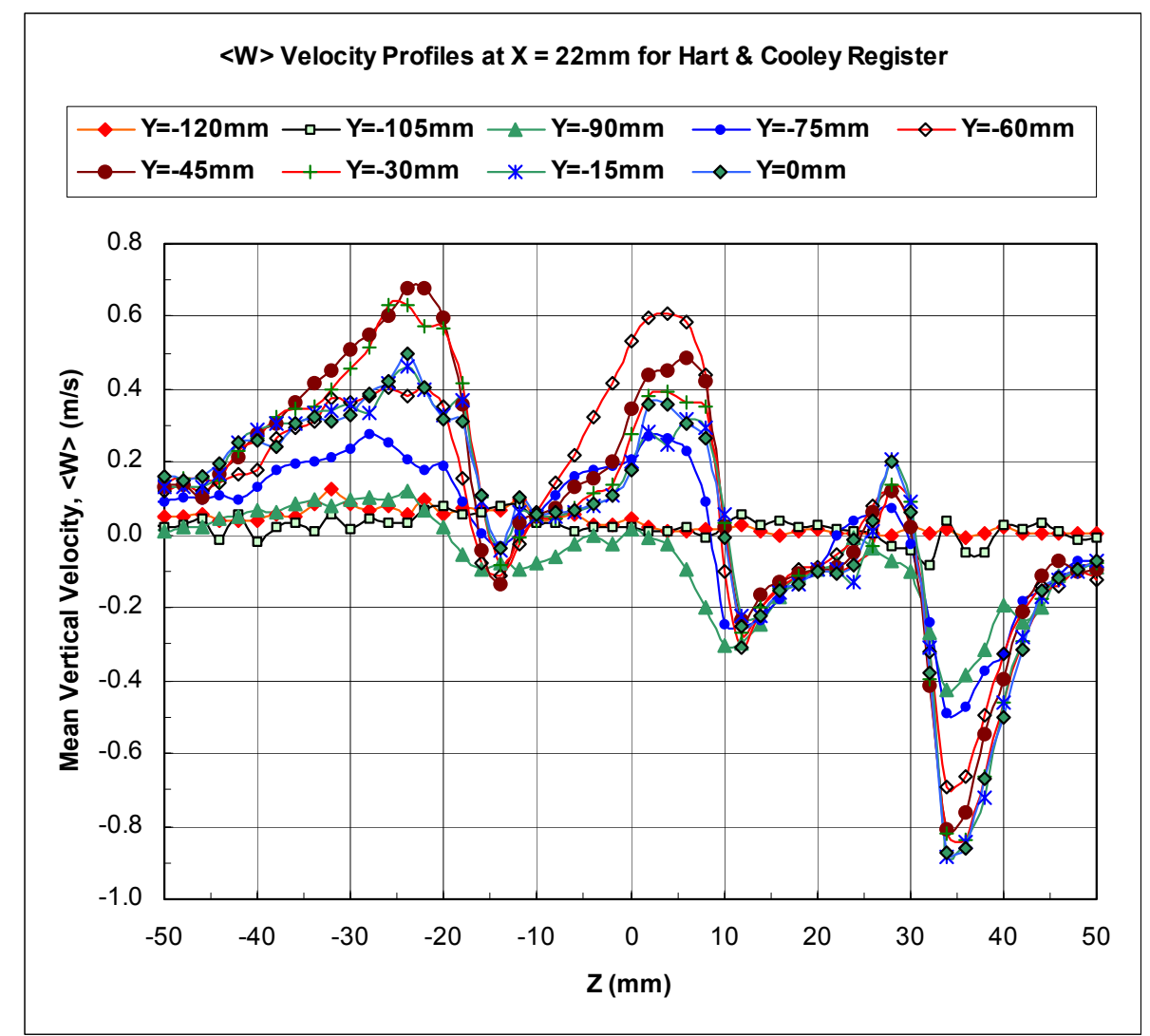

Figure 40. Measured mean vertical velocity component profiles at the exit of the Hart \& Cooley register. Measurements from $Y=0$ to $Y=-120 \mathrm{~mm}$ at $22 \mathrm{~mm}$ downstream of the register exit. Nominal flow rate: $66 \mathrm{cfm}$.

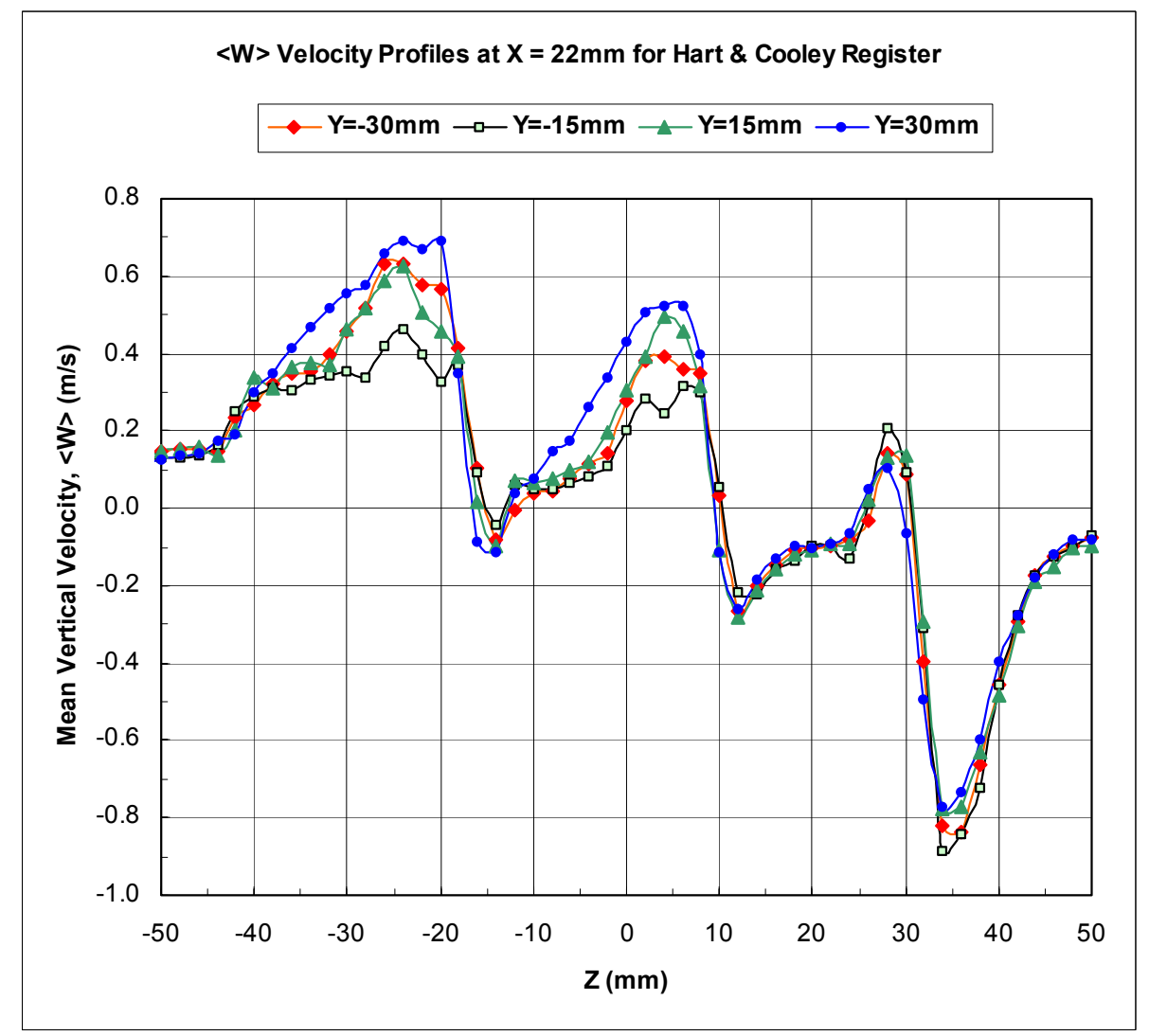

Figure 41. Measured mean vertical velocity component profiles at the exit of the Hart \& Cooley register. Measurements from $Y=-30 \mathrm{~mm}$ to $Y=30 \mathrm{~mm}$ at $22 \mathrm{~mm}$ downstream of the register exit. Nominal flow rate: $66 \mathrm{cfm}$. 


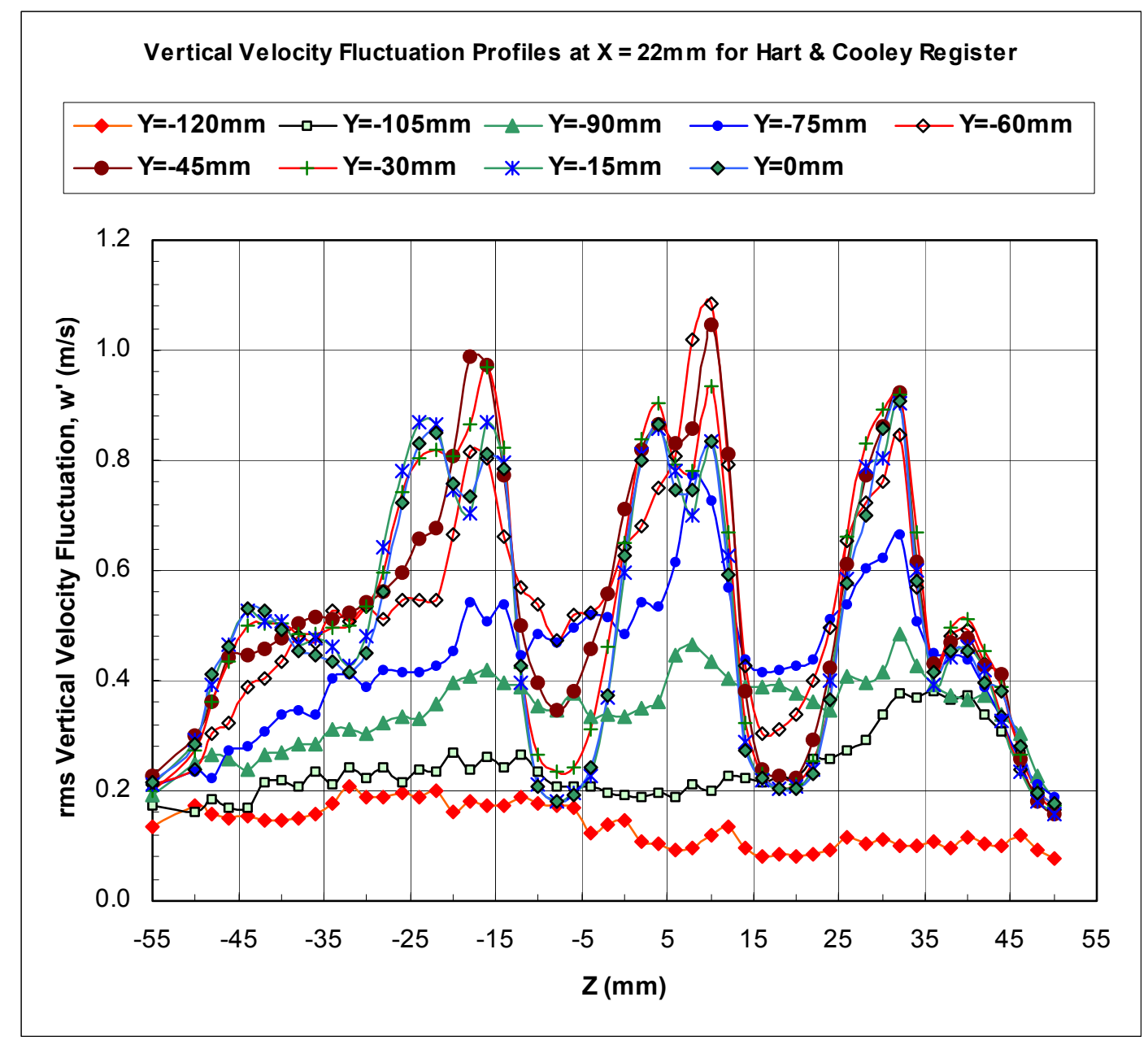

Figure 42. Measured turbulence level in the vertical velocity component at the exit of the Hart \& Cooley register. Measurements from $Y=0$ to $Y=-120 \mathrm{~mm}$ at $22 \mathrm{~mm}$ downstream of the register exit. Nominal flow rate: $66 \mathrm{cfm}$.

\subsubsection{The Axial Evolution of the Velocity Components for the Hart \& Cooley Register}

The axial and vertical velocity components were also measured at the downstream location of $\mathrm{X}=$ $120 \mathrm{~mm}$. These measurements, together with the corresponding measurements at $X=22 \mathrm{~mm}$, are plotted in Figures 43 and 44. As can be seen from these figures, the turbulent mixing has completely diffused the periodic variations in the velocity components due to the deflecting blades in this short distance. We also note that that there is only minimal growth in the width of the airflow in the Z-direction while the flow moves from $X=22 \mathrm{~mm}$ to $X=120 \mathrm{~mm}$. These measurements were used to generate a plot of airflow velocity vectors in the $\mathrm{X}-\mathrm{Z}$ plane at $\mathrm{Y}=0$, and are shown in Figure 45. The influence of the three curved blades of the register on the velocity vectors near the exit (at $X=22 \mathrm{~mm}$ ) is clearly seen. In addition, the motion of entraining ambient air near the edges of the jet is also evident from this figure. 


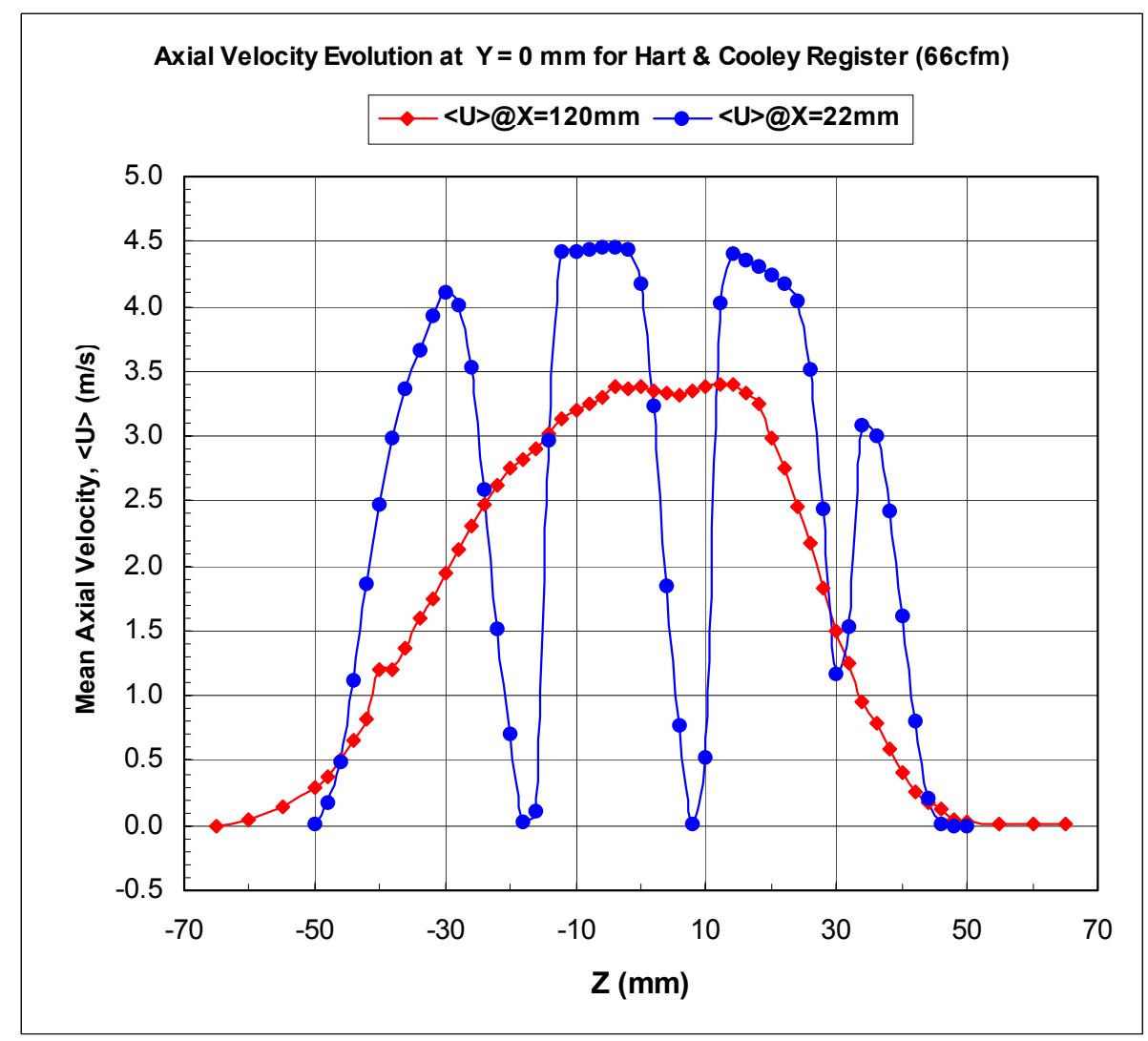

Figure 43. The evolution of the mean axial velocity component profiles with the downstream distance, $\mathrm{X}$ for the Hart \& Cooley register. Measurements at $Y=0$. Nominal flow rate: $66 \mathrm{cfm}$.

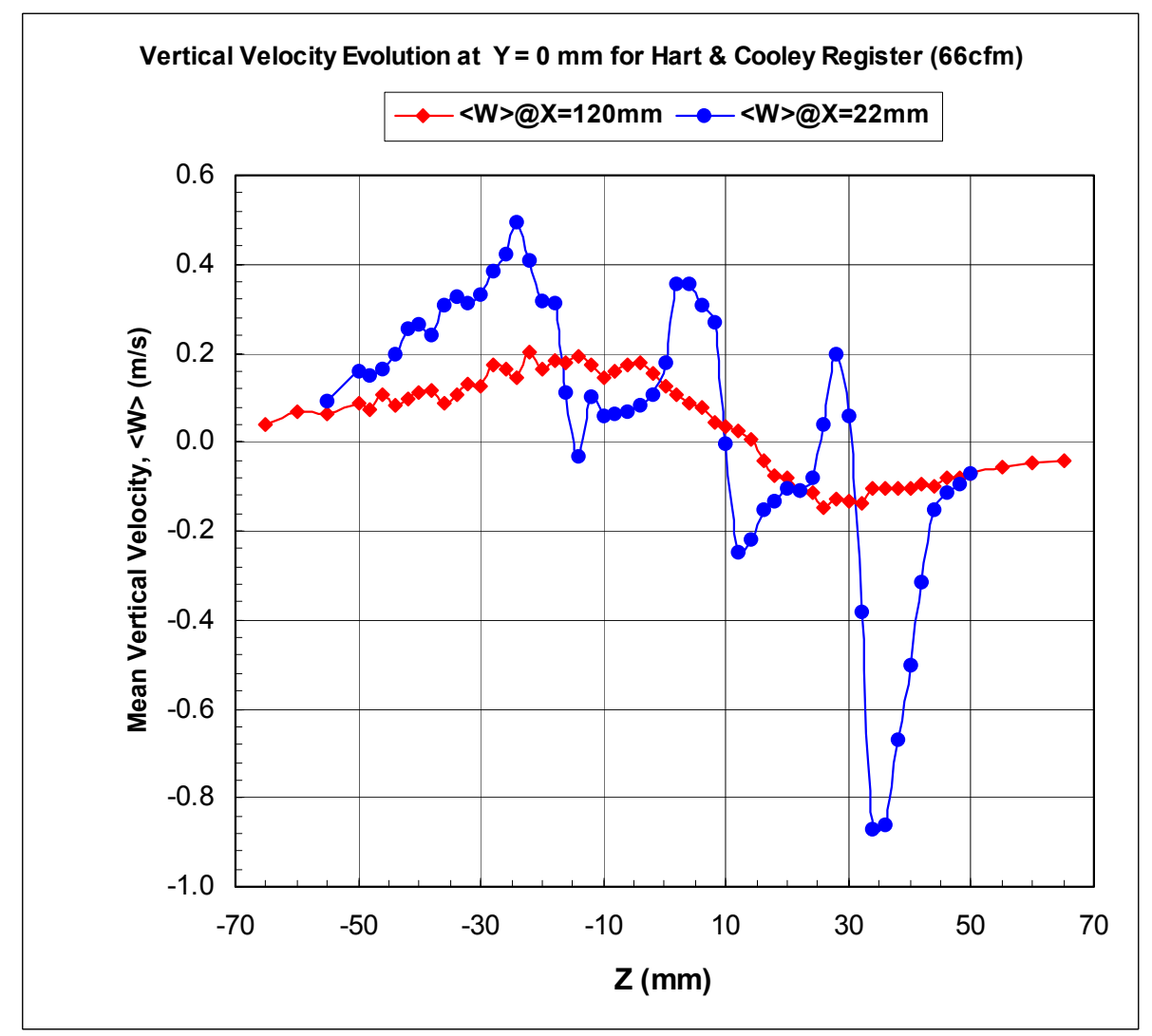

Figure 44. The evolution of the mean vertical velocity component profile with the downstream distance, $\mathrm{X}$ for the Hart \& Cooley register. Measurements at $Y=0$. Nominal flow rate: $66 \mathrm{cfm}$. 


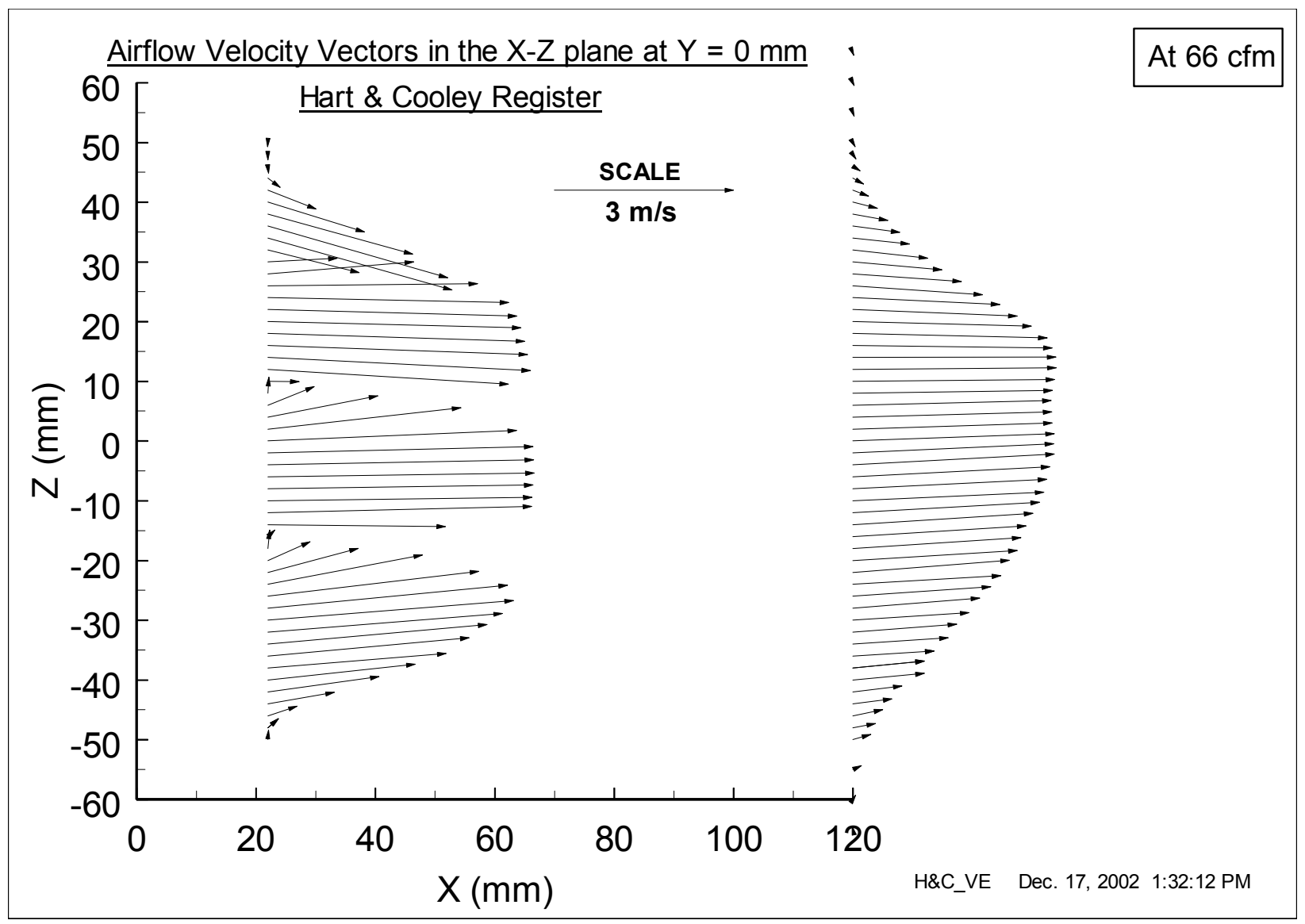

Figure 45. The measured mean velocity vectors in the $X-Z$ plane at $Y=0$ for two downstream locations $(X=22 \mathrm{~mm}$ and $X=120 \mathrm{~mm})$ for the Hart \& Cooley Register exit. Nominal flow rate: $66 \mathrm{cfm}$.

\subsection{Airflow Measurements for the High-Flow Case}

A limited number of velocity profiles measurements were also made at the high-flow rate setting of $126 \mathrm{cfm}$ for the Hart \& Cooley register. Two profiles (as a function of the vertical coordinate, $\mathrm{Z}$ ) along the central plane $(\mathrm{Y}=0)$ at the two axial locations of $22 \mathrm{~mm}$ and $120 \mathrm{~mm}$ were measured for each of the axial and vertical velocity components. These measurements, together with the corresponding measurements at $66 \mathrm{cfm}$, are presented in Figures 46 through 53. For comparison purposes, the measured velocities at $126 \mathrm{cfm}$ have been multiplied by the scaling factor of $(66 / 126)$. These measurements show that if all the three blades of the register are set in the horizontal position, then, the velocity field near the exit of the register may be expected to roughly scale with the total airflow rate through the register (in the range of $65 \mathrm{cfm}$ to $126 \mathrm{cfm})$. However, the vertical velocity component shows some minor departures from similarity at $X=22 \mathrm{~mm}$ (see Figure 48). A plot of the airflow vectors for the high-flow case is shown in Figure 54. When compared to the corresponding plot for the low flow case in Figure 45, only minor deviations at $\mathrm{X}=22 \mathrm{~mm}$ are noticed. 


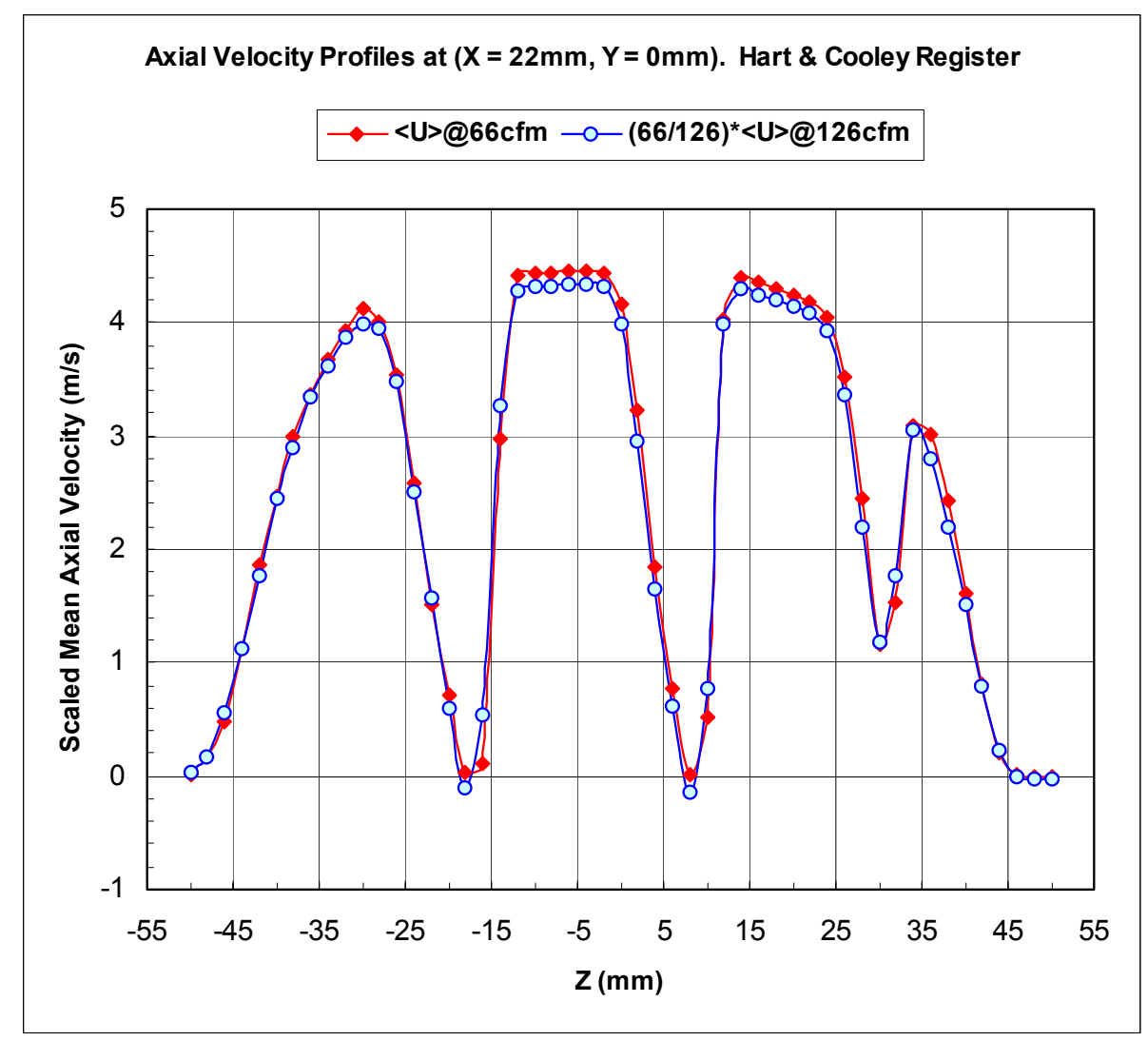

Figure 46. Comparison of mean axial velocity profiles at $X=22 \mathrm{~mm}$ and $Y=$ $0 \mathrm{~mm}$ for the Hart \& Cooley register at two flow rates. The measured mean velocity at $126 \mathrm{cfm}$ has been multiplied by the flow rate ratio of $(66 / 126)$.

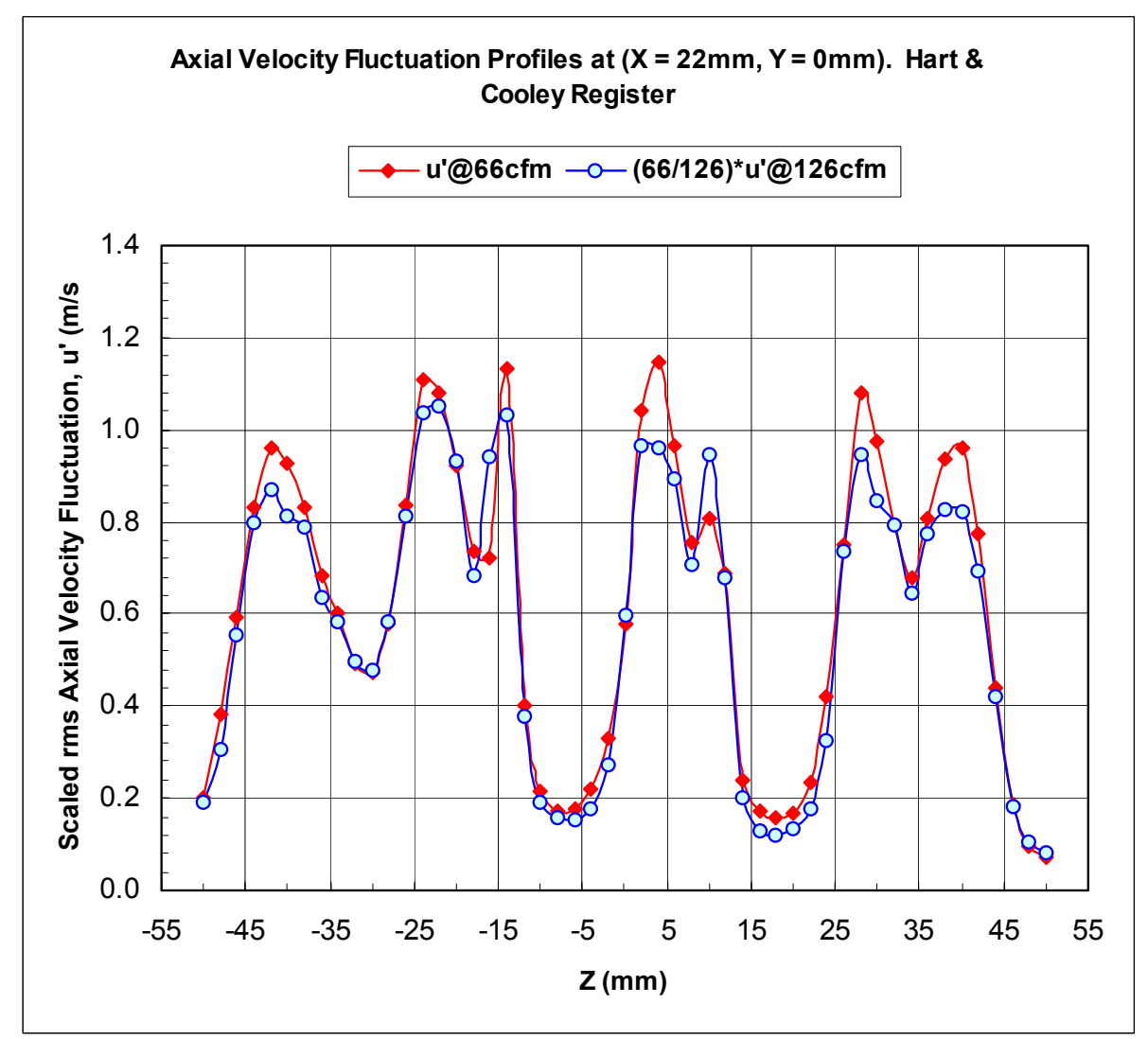

Figure 47. Comparison of turbulence level in the axial velocity component at $X=22 \mathrm{~mm}$ and $Y=0 \mathrm{~mm}$ for the Hart \& Cooley register at two flow rates. The measured u' at $126 \mathrm{cfm}$ has been multiplied by the flow rate ratio of $(66 / 126)$. 


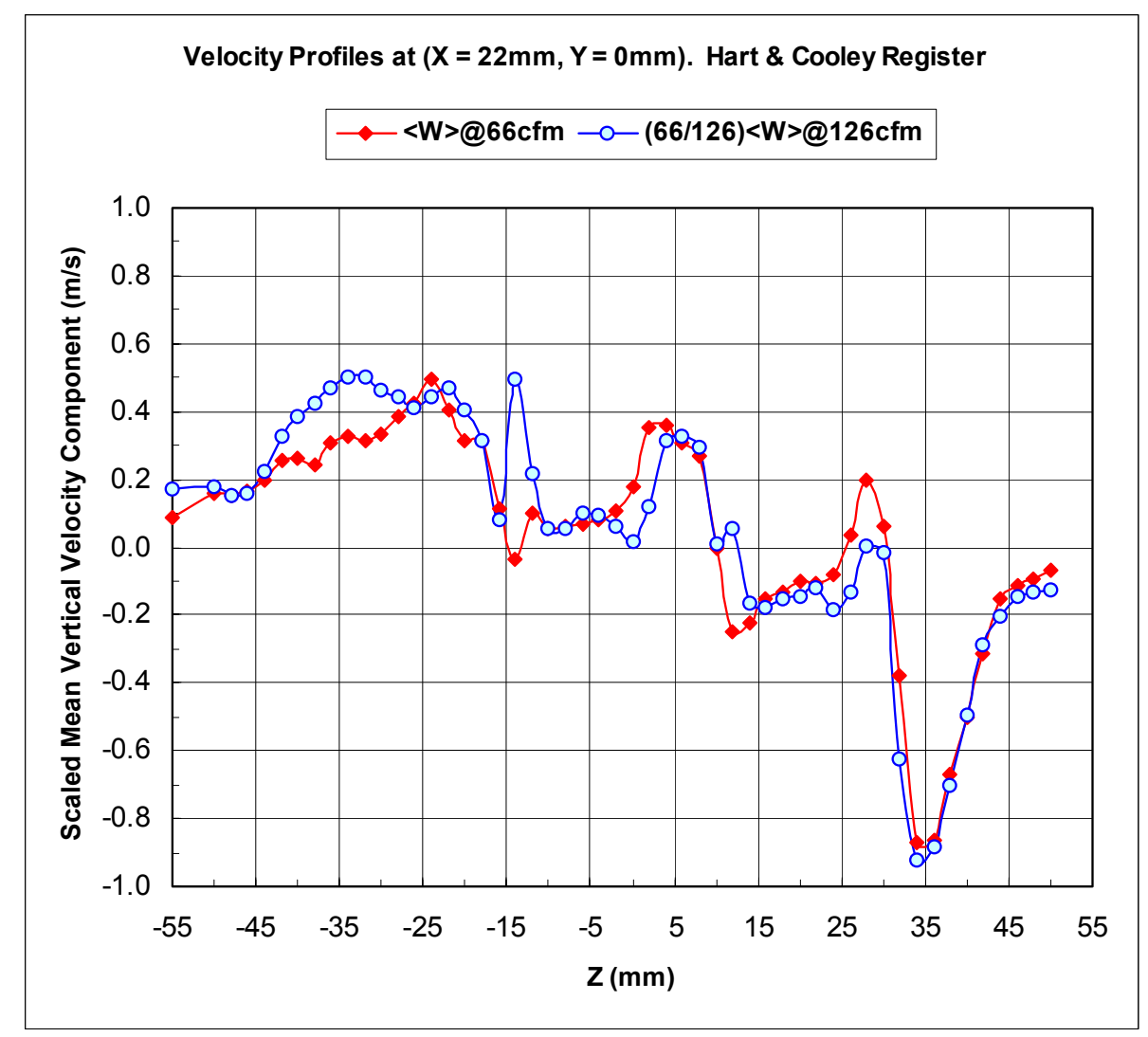

Figure 48. Comparison of mean vertical velocity profiles at $X=22 \mathrm{~mm}$ and $Y$ $=0 \mathrm{~mm}$ for the Hart \& Cooley register at two flow rates. The measured mean velocity at $126 \mathrm{cfm}$ has been multiplied by the flow rate ratio of $(66 / 126)$.

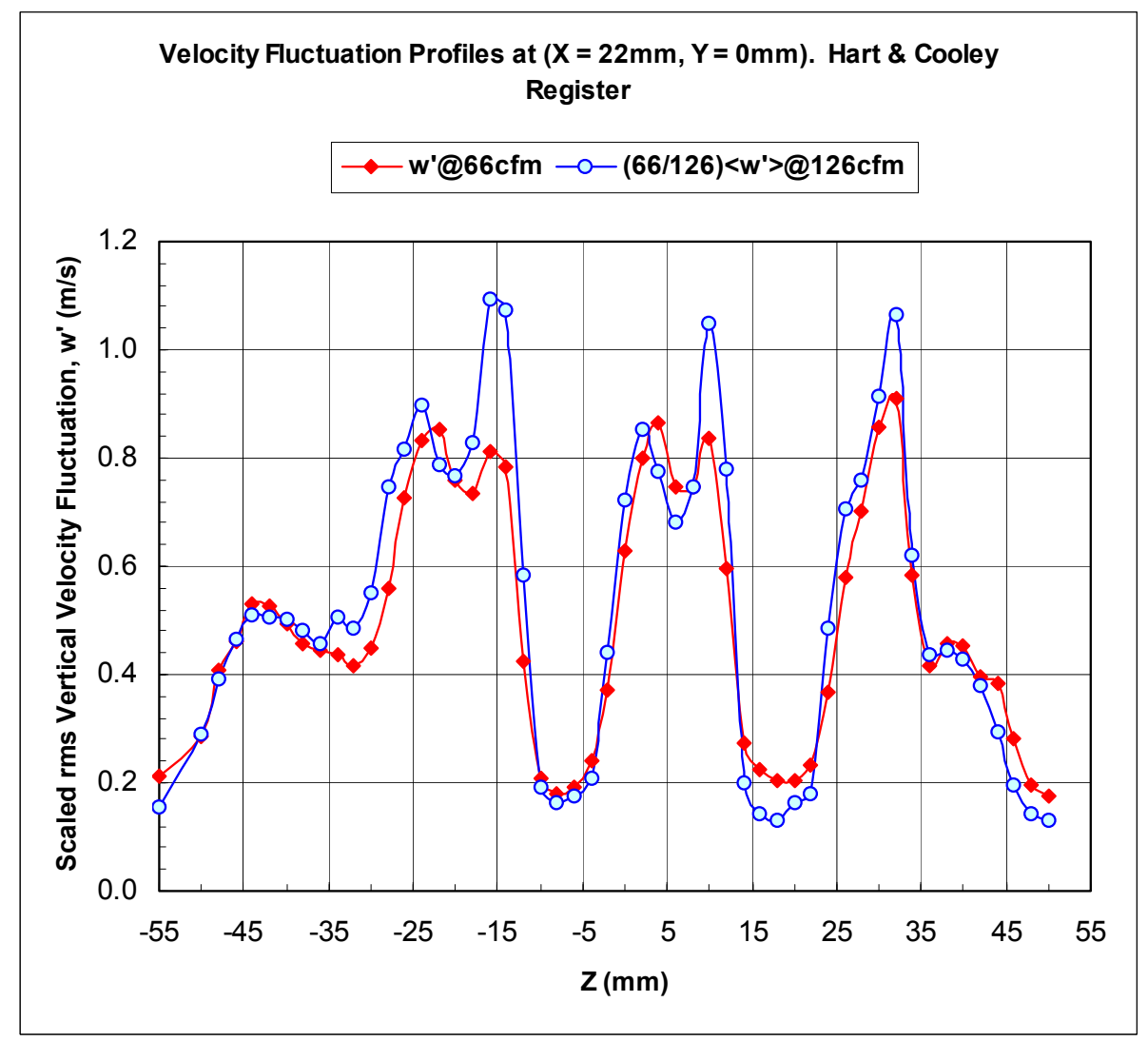

Figure 49. Comparison of turbulence level in the vertical velocity component at $X=22 \mathrm{~mm}$ and $Y=0 \mathrm{~mm}$ for the Hart \& Cooley register at two flow rates. The measured $w^{\prime}$ at $126 \mathrm{cfm}$ has been multiplied by the flow rate ratio of $(66 / 126)$. 


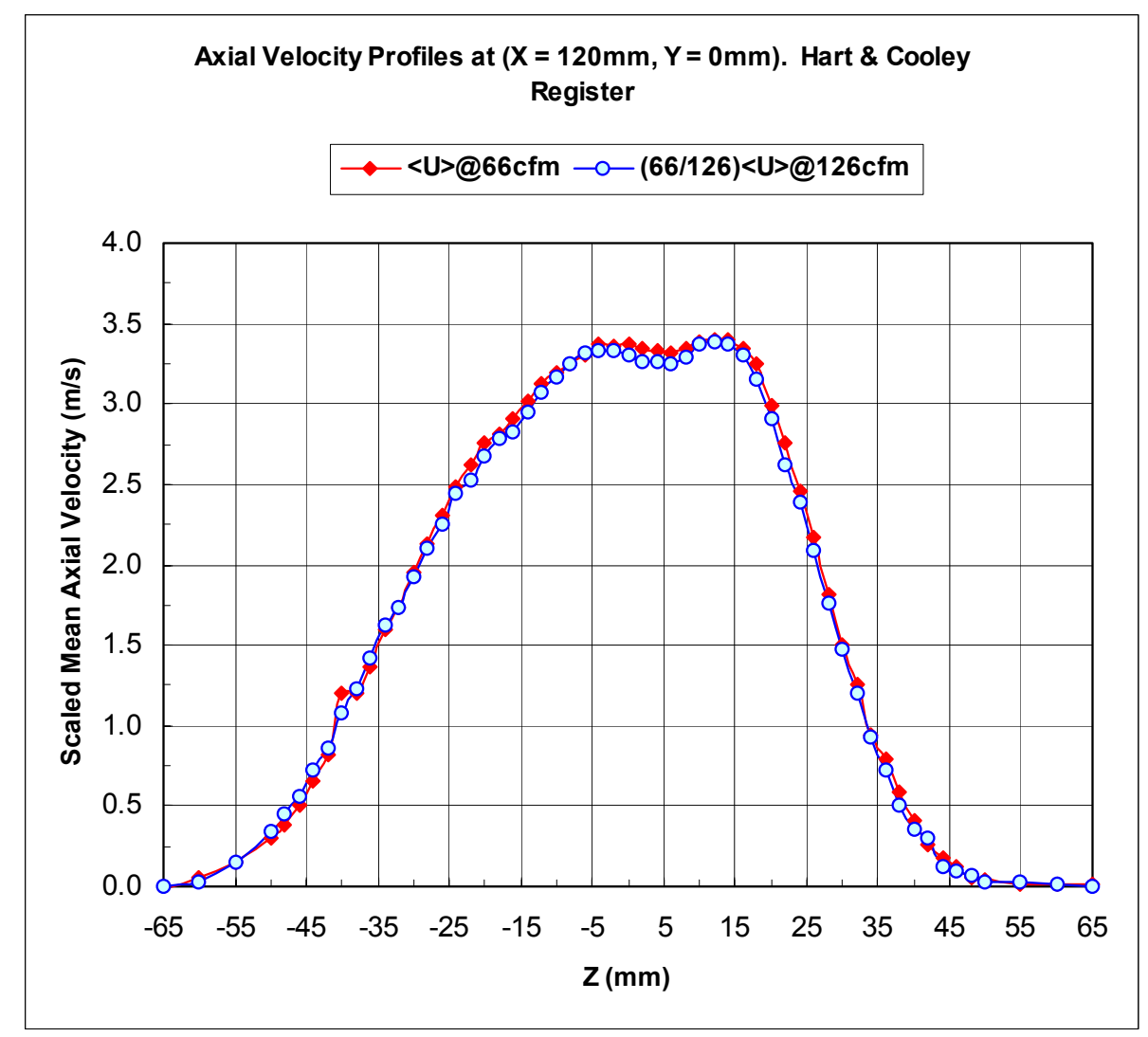

Figure 50. Comparison of mean axial velocity profiles at $X=120 \mathrm{~mm}$ and $Y=$ $0 \mathrm{~mm}$ for the Hart \& Cooley register at two flow rates. The measured mean velocity at $126 \mathrm{cfm}$ has been multiplied by the flow rate ratio of $(66 / 126)$.

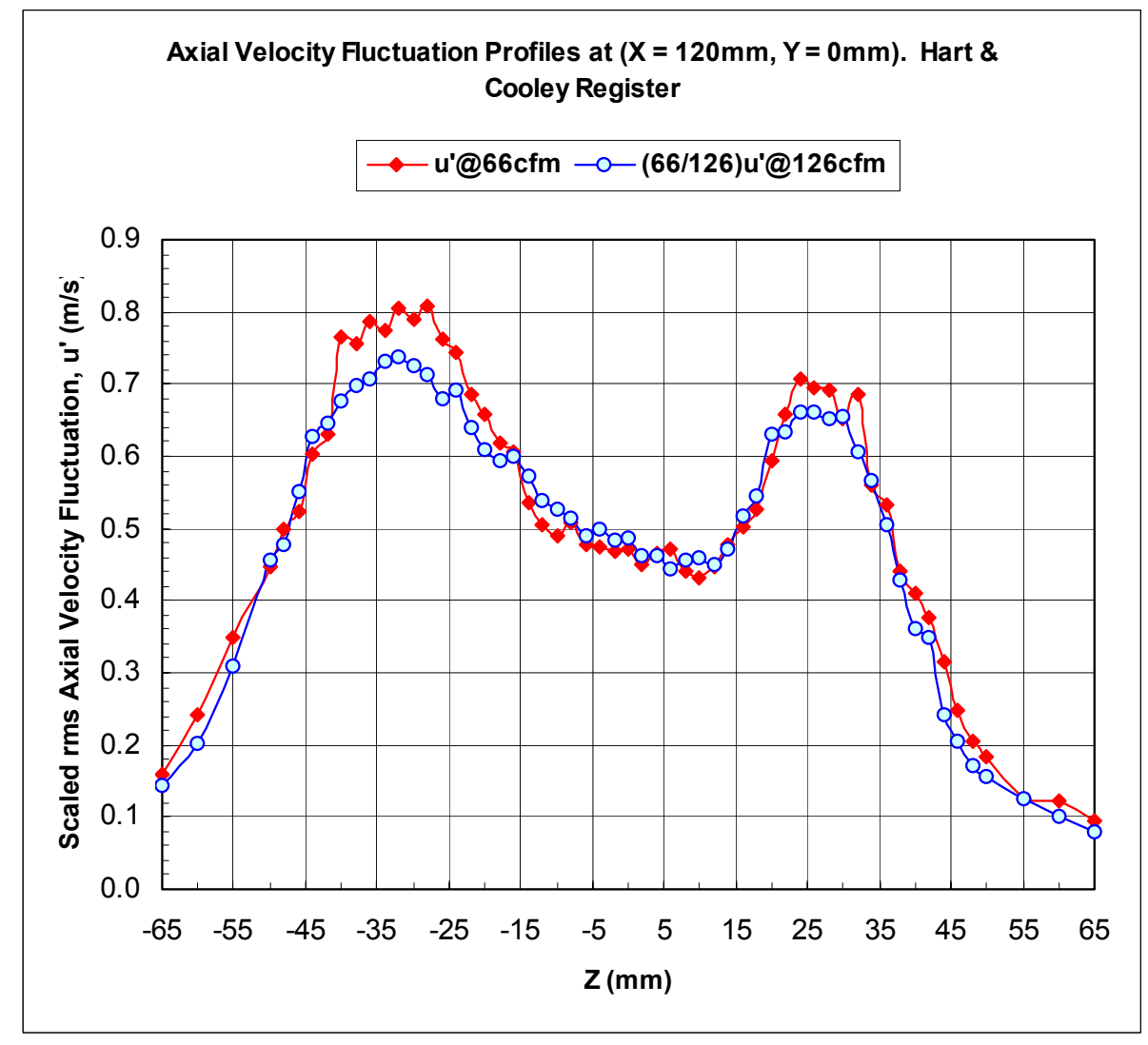

Figure 51. Comparison of turbulence level in the axial velocity component at $X=120 \mathrm{~mm}$ and $Y=0 \mathrm{~mm}$ for the Hart \& Cooley register at two flow rates. The measured $\mathrm{u}^{\prime}$ at $126 \mathrm{cfm}$ has been multiplied by the flow rate ratio of (66/126). 


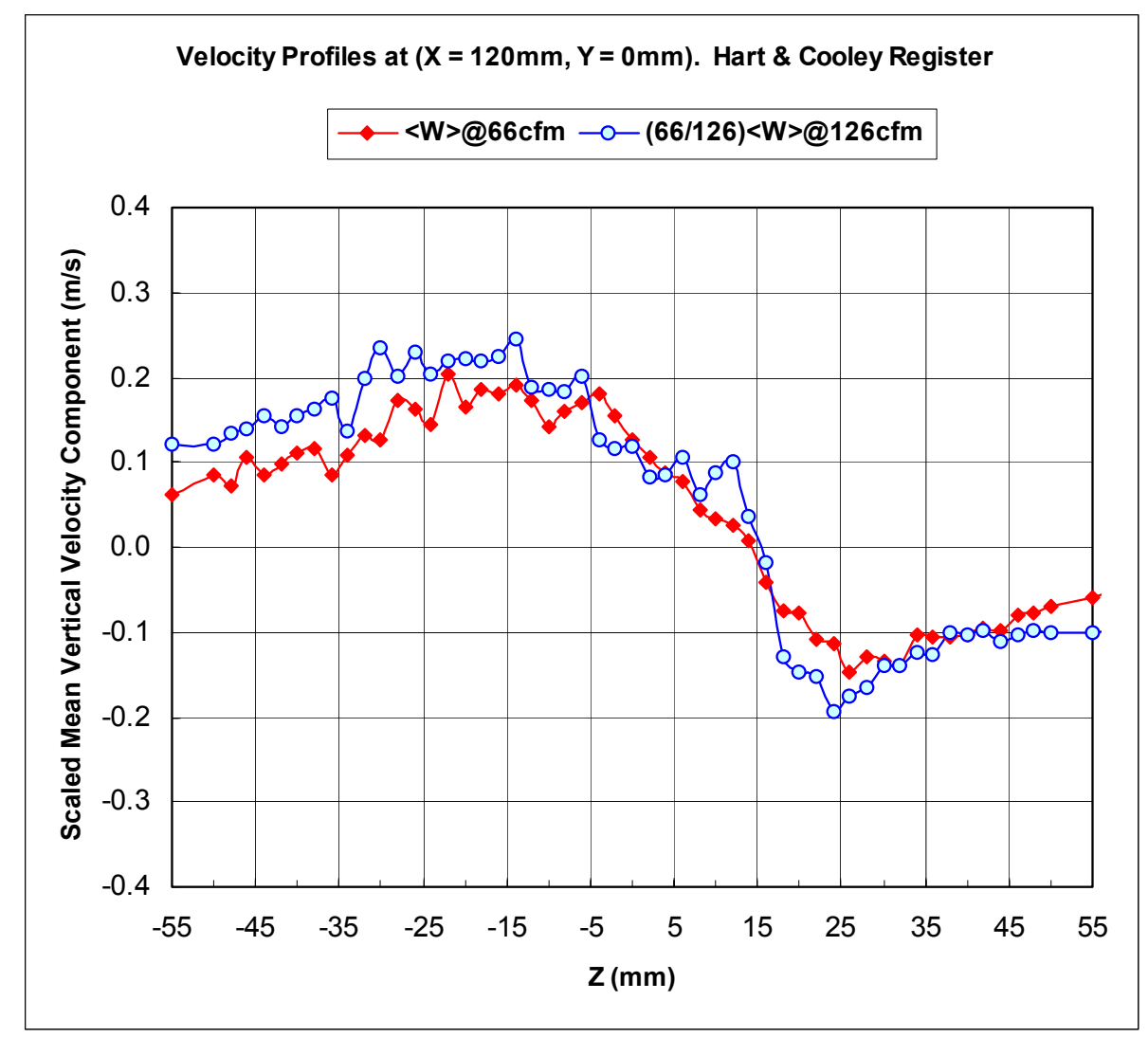

Figure 52. Comparison of mean vertical velocity profiles at $X=120 \mathrm{~mm}$ and $Y$ $=0 \mathrm{~mm}$ for the Hart \& Cooley register at two flow rates. The measured mean velocity at $126 \mathrm{cfm}$ has been multiplied by the flow rate ratio of $(66 / 126)$.

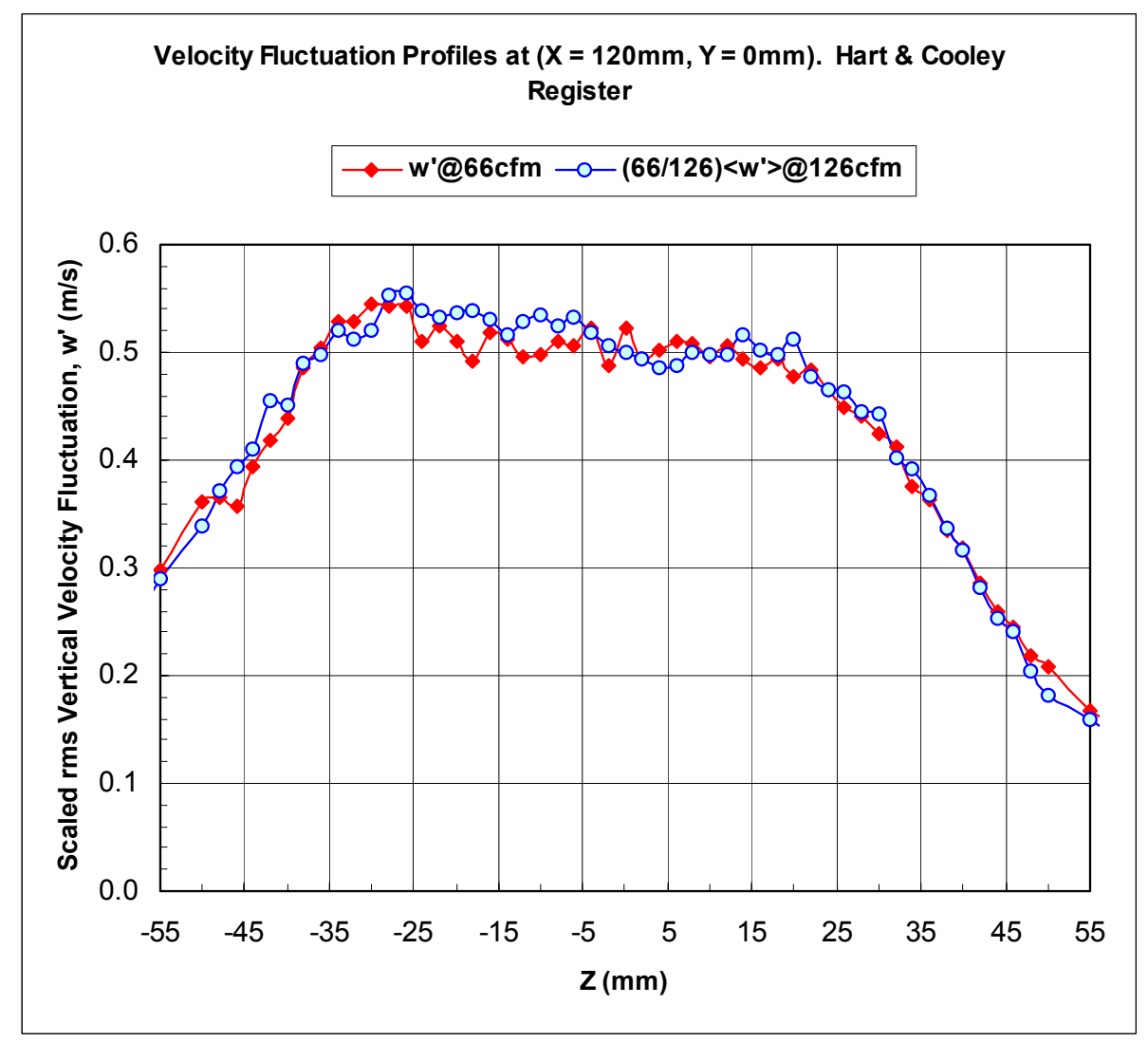

Figure 53. Comparison of turbulence level in the vertical velocity component at $X=120 \mathrm{~mm}$ and $Y=0 \mathrm{~mm}$ for the Hart \& Cooley register at two flow rates. The measured w' at $126 \mathrm{cfm}$ has been multiplied by the flow rate ratio of (66/126). 


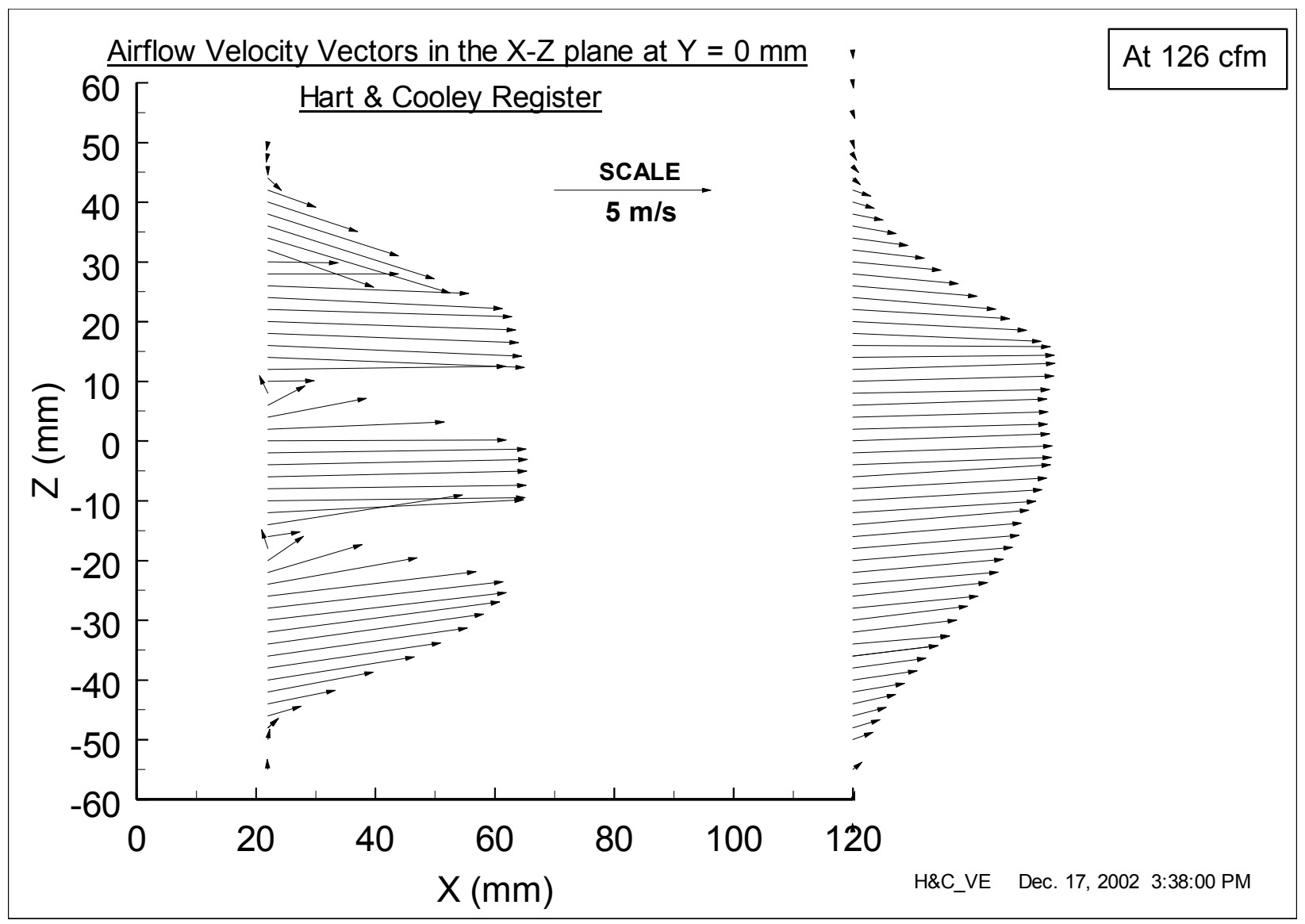

Figure 54. The measured mean velocity vectors in the $X-Z$ plane at $Y=0$ for two downstream locations $(X=22 \mathrm{~mm}$ and $X=120 \mathrm{~mm})$ for the Hart \& Cooley Register exit. Nominal flow rate: $126 \mathrm{cfm}$.

\section{CONCLUDING REMARKS}

A facility to test and measure the airflow distribution at the exit of HVAC registers was designed and fabricated. The objective of this facility is to provide velocity data at the exit of registers that can then be used as an input boundary condition in a modern Computational Fluid Dynamics (CFD) code to predict the velocity and temperature distribution in an enclosure (whose atmosphere is to be conditioned by the airflow from the register). Thus register performance parameters (for example, "throw") can be predicted as a function of variables like the flow rate from the register. Towards this end, during the course of this work, two commonly used registers were tested. Both registers were 8"x4" sidewall registers. Laser Doppler Velocimetry was used to measure the axial and vertical components of the velocity vector at various locations across the face of the registers. The measurements are presented in this report. For the two cases (Lima register and the Hart \& Cooley register with blades in the horizontal position) studied here, the results suggest that the velocity field at the very exit of each of these registers scales with the flow rate through the registers. However, this was observed only for the case when the duct blaster varies the flow rate through the register directly. This would correspond to the mode of operation in which the supply fan (of an HVAC system) has a "High" and "Low" setting. This conclusion may not be true when the built-in register dampers are used to adjust the flow rate. During the second phase of this work, these results will be used to make CFD predictions of the register performance in an enclosure. 